Illinois State University

ISU ReD: Research and eData

Theses and Dissertations

7-6-2018

\title{
"The Testing Served Its Purpose": High-Stakes Testing as a Method of Categorization and Control in Young Adult Dystopian Novels
}

Rebecca Lorenzo

Illinois State University, rboite.lorenzo6@gmail.com

Follow this and additional works at: https://ir.library.illinoisstate.edu/etd

Part of the English Language and Literature Commons

\section{Recommended Citation}

Lorenzo, Rebecca, "'The Testing Served Its Purpose": High-Stakes Testing as a Method of Categorization and Control in Young Adult Dystopian Novels" (2018). Theses and Dissertations. 910.

https://ir.library.illinoisstate.edu/etd/910

This Thesis is brought to you for free and open access by ISU ReD: Research and eData. It has been accepted for inclusion in Theses and Dissertations by an authorized administrator of ISU ReD: Research and eData. For more information, please contact ISUReD@ilstu.edu. 
“THE TESTING SERVED ITS PURPOSE”: HIGH-STAKES TESTING AS A METHOD OF CATEGORIZATION AND CONTROL IN YOUNG ADULT DYSTOPIAN NOVELS

\section{REBECCA LORENZO}

\section{Pages}

In “"The Testing Served its Purpose': High-Stakes Testing as a Method of Categorization and Control in Young Adult Dystopian Novels," I examine representations of high-stakes testing in the Divergent, Legend, and Testing trilogies using educational, cultural studies, and dystopia/utopia scholarship. In chapters one and two, I examine each society's system of highstakes testing and the ideological indoctrination and physical repression used by those in power to maintain control of the citizenry, respectively. In the third chapter, I analyze the ways in which the state's indoctrination, coupled with an exaggerated focus on the success or failure of specific individuals, creates competition among peers and deflects blame from the State. Ultimately, I conclude that these trilogies support the need for overlapping subject positions through the narrative pattern examined in chapter four. I argue that this narrative pattern implies that subjectivity should be established in dialogic interaction with other people in varied subject positions and the regime in order to produce gradual, realistic change. However, the continued emphasis on the individual as a catalyst for change undermines the necessity of productive interactions between the regime, the masses, and the privileged individual savior. KEYWORDS: Categorization, control, dystopia, high-stakes testing, ideology 
“THE TESTING SERVED ITS PURPOSE”: HIGH-STAKES TESTING AS A METHOD OF CATEGORIZATION AND CONTROL IN YOUNG ADULT DYSTOPIAN NOVELS

REBECCA LORENZO

A Thesis Submitted in Partial Fulfillment of the Requirements for the Degree of

MASTER OF ARTS

Department of English

ILLINOIS STATE UNIVERSITY

2018 
Copyright 2018 Rebecca Lorenzo 
“THE TESTING SERVED ITS PURPOSE”: HIGH-STAKES TESTING AS A METHOD OF CATEGORIZATION AND CONTROL IN YOUNG ADULT DYSTOPIAN NOVELS

REBECCA LORENZO

COMMITTEE MEMBERS:

Roberta Trites, Chair

Karen Coats 


\section{ACKNOWLEDGMENTS}

At this point, I'd like to thank all the incredible humans who helped me throughout this project. First, I have to thank my wonderful adviser, Dr. Roberta Trites, for fielding an obnoxious amount of questions and for her unending patience as she helped me grow as a writer, a scholar, and an overall person. Without her, this project would not have been possible. I'd also like to thank Dr. Karen Coats, my brilliant second reader whose insights were invaluable and played a huge role in tightening up my writing and strengthening my arguments. Dr. Coats’ generosity and patience throughout this project played an enormous role in its completion.

Beyond my committee, I'd like to thank the various faculty members who invested time in this process and fielded miscellaneous questions and concerns. I'd like to thank my cohort and fellow graduate students for their unwavering support and the community they provided as I

went through this process. Moving across the country for the opportunity to complete my MA at Illinois State University was difficult at times but having an incredibly warm group of people to share my woes and triumphs with was an integral part of this project. Specifically, I'd like to thank my officemate, Brie Litwiller, for her willingness to set-up and attend "writing days" with me, for her compassion when my anxieties seemed poised to overwhelm me, and for her encouragement, without which I could never have gotten through graduate school. I'd also like to thank my incredible partner, Ethan Kelly, for his continuous and ongoing support. I could not have picked a better man to share my triumphs with, and his constant celebration of each achievement, no matter how small, is a large part of how I completed this project.

I'd like to thank my loving family who supported me in various ways throughout this project, consistently reassuring me that everything would work out so long as I kept working toward my goal. Knowing that my family always had my back helped me shut down my inner 
critic when she got too boisterous, and I couldn't have made it through this process without them. I'd also like to thank Katy Lewis who somehow managed to play the roles of close friend and mentor simultaneously. She was the voice of reason that helped me achieve my goals while always making sure I took care of myself throughout this process. I'd like to thank Courtney Cox who was both a copyeditor and friend through this process. I'd also like to acknowledge the crucial role that my cat, Toothless, played in this process. Every tear was met with a loving forehead nudge from Toothless and every success was memorialized with snuggles, dancing, and squishes. He may not know it, but he's always a big part of my successes.

Finally, I'd like to thank two of my best friends Alexis Plater, my roommate, and Liz Cachey. To say that these two women were instrumental in my success would be an understatement. Both these women were always ready and willing to listen to my concerns and anxieties regarding this project, and they both acted as sounding boards as I developed the arguments in this thesis. Beyond that, the two of them were always in my corner. They provided snacks, celebrations, advice, and just about anything else I needed. Their support meant and means the world to me. Without these people and many others, I could not have completed this project, but with them I was able to create something I was proud of. I will forever be thankful for their support. 


\section{CONTENTS}

Page

ACKNOWLEDGMENTS $\quad$ i

INTRODUCTION: THE COMFORT OF CATEGORIZATION 1

Review of the Literature $\quad 1$

The Scope of this Thesis $\quad 10$

CHAPTER I: THE COMPLACENCY IN CATEGORIZATION: HOW HIGH-STAKES

TESTING AIDS IN THE CYCLICAL REPRODUCTION OF THE RULING IDEOLOGY 16

The Role of High-Stakes Testing in the Educational Ideological State Apparatus:

$\begin{array}{ll}\text { An Introduction } & 16\end{array}$

The Dominance of the Educational Ideological State Apparatus and What

That Implies

Policy-Makers as Puppet Masters and How Dystopian Conditions

Make this Clear

“Is Your Child’s Trial Coming Up?”: Propaganda as Reinforcement of Testing

Mania

"Because They Don't Know What The Testing Entails": The Role of Data

Manipulation in Propagating the Ruling Ideology 30

How Information is Re-Conceptualized in Favor of High-Stakes Testing

How the Slippery-Slope Argument Creates a Cultural Myth of Testing as

Necessity

"Heroes Get More Options for Their Future": How High-Stakes Testing Provides the

Illusion of Agency 
Why Test-Takers Fear Failure

"Dejection. Heartbreak. Failure": How Psychological Turmoil from

High-Stakes Testing Leaves Students Vulnerable to Manipulation 43

Discipline, Gratification, and the Lack of Choice in High-Stakes Testing 46

The Semblance of Agency 48

That's What the Government is Doing, "Conditioning People to Be Happy Under its

Thumb": High-Stakes Testing as a Method of Control Through Ideological

Indoctrination $\quad 51$

Conclusion: The Implications of Ideological Control 53

CHAPTER II: “WRONG ANSWERS WILL BE PENALIZED”: HOW THE REPRESSIVE

STATE APPARATUSES FURTHER PROMOTE CATEGORIZATION THROUGH HIGH-

$\begin{array}{lc}\text { STAKES TESTING } & 56\end{array}$

$\begin{array}{ll}\text { Introduction } & 56\end{array}$

The Interplay of the Educational ISA and Repressive State

$\begin{array}{lr}\text { Apparatuses (RSA) } & 58\end{array}$

Potential Gratification Versus Discipline: The Logic of Using Punishment

as Motivation in Systems of High-stakes Testing 60

$\begin{array}{ll}\text { Utilitarianism in the Dystopian Context } & 61\end{array}$

"Unless They Saw Something Dangerous in Him": Policing Those Who Threaten to

Challenge the Ruling Ideology $\quad 65$

“Because You Did Too Well”: The Danger of Being Special 65 
"They Will Make an Example of Me": The Role of the Public Execution in Homogenization

The Effect of Discipline: Self-Policing, Defeatist Mentalities, and Unsuccessful

Rebellion

$\begin{array}{ll}\text { How Surveillance Fosters Self-Policing } & 72\end{array}$

How Test-Based Class Divisions Foster Defeatist Mentalities 77

"From One Tyrant to Another": Failed Rebellion by Those Marginalized

Conclusion

CHAPTER III: “THE ODDS FAVOR MY FAILURE”: HOW COMPETITION, MANIPULATED STRUCTURES, AND CONFIRMATION BIAS ENSURE THE

REPRODUCTION OF A RULING CLASS IN SUPPORT OF HIGH-STAKES TESTING 88

Normative Scores and the Competitive Atmosphere They Foster: An Introduction

The Promotion of Competition

"One Bad Thing Goes Away and Another Replaces It": How Manipulated Testing

Structures Foster Extremes of Desired Characteristics

"People do Strange Things Under Pressure": The Role of Isolation

"Failure Recommended by Staff": The Arbitrary Nature of the High-Stakes

Test-Based Categorization

Cia's Paradoxical Test

Factors and Confirmation Bias

Conclusion: "Know Your Enemy"

CHAPTER IV: FROM BYSTANDER TO ACTOR: SUBJECTIVE AGENCY IN YOUNG 
$\begin{array}{ll}\text { Introduction } & 109\end{array}$

“I Can’t Even Fathom it”: Estrangement, Awareness, and Subjectivity 111

Marginalization, Privilege, Empathy, and the Move from Bystander to Actor 121

Rebel from Inside the System: The Role of Overlapping Positionalities 126

$\begin{array}{ll}\text { Conclusion } & 132\end{array}$

$\begin{array}{ll}\text { WORKS CITED } & 135\end{array}$ 


\section{INTRODUCTION: THE COMFORT OF CATEGORIZATION}

In my thesis, “"The Testing Served its Purpose': High-Stakes Testing as a Method of Categorization and Control in Young Adult Dystopian Novels," I examine the systems of highstakes testing in the following young adult (YA) dystopian trilogies: Veronica Roth's Divergent trilogy, Marie Lu's Legend trilogy, and Joelle Charbonneau's The Testing trilogy. The quotation in my title is from Charbonneau's The Testing, and the scene from which it comes speaks to the exigency of this project. The main character, Cia, walks in to her dorm room during The Testing to find that her roommate has committed suicide. Dr. Barnes, the head of The Testing, addresses Cia after the fact and "reassures" her that though "this event is unfortunate, the Testing served its purpose" (94). While the dystopian nature of Charbonneau's trilogy may go beyond the consequences of high-stakes testing in the United States, The Testing trilogy and the other primary texts I examine in this thesis criticize testing to call attention to the way high-stakes testing in the U.S. is already dystopian. Moreover, these trilogies offer their own, sometimes misguided, solutions for how to change this corrupt system.

\section{Review of the Literature}

Jonathan Alexander and Rebecca Black's 2015 article, “The Darker Side of the Sorting Hat: Representations of Educational Testing in Dystopian Young Adult Fiction," starts some of the work that this thesis aims to continue. In their article, Alexander and Black examine highstakes educational testing. They address more traditional question-and-answer type tests as well as tests of physical exertion, and they begin to do so by noting the cultural-historical moment that provides the exigency for this work:

In recent decades, there has been a great deal of controversy surrounding the viability, effectiveness, and fairness of such tests. Proponents argue that they hold schools and 
teachers accountable for student learning, supply data on student performance that can be used to improve instruction, provide a standard, equitable means of assessing student achievement, and motivate students to improve their academic skills. Opponents contend that such tests can have a negative impact on the quality of instruction (e.g., faculty adopting a "teach to the test" approach) as well as teacher and student morale, and that a standardized test is an ineffective means of capturing the nuances and complexities of students' knowledge and abilities. (208)

Alexander and Black note that as a result of this climate around high-stakes testing, many representations of such testing can now be found in young adult dystopian literature where "the dire circumstances presented in the dystopian worlds have not yet come to pass but remain latent warnings of impending catastrophe" (210). Alexander and Black ultimately argue that these representations, which "explore how our current cultures of educational testing might be structuring our imagination of both the present and future," illustrate how the testing systems in these novels are used to control adolescents through categorization, identity regulation, and, ultimately, the maintenance of the status quo (211). Alexander and Black conclude their article with a discussion on the costliness of rebellion in these novels and note that, despite this, a thread of hope remains even in the extreme conditions of these dystopias. In their words, they "hope that the marking of such trends will lead to productive discussion, greater critical selfconsciousness, and renewed interest in working toward an equitable world before the hyperbolic dystopias depicted in these books become fully realized" (233).

I also analyze in more depth the trends Alexander and Black have raised in "The Darker Side of the Sorting Hat." While Alexander and Black do significant work in identifying highstakes testing as a method of categorization and control, their article, with the exception of the 
introduction, does not situate this discussion in reference to existing education scholarship on high-stakes testing. As such, their argument can be expanded, so I will utilize high-stakes testing scholarship in my reading of these books to show the nuanced ways in which these representations have hyperbolized certain testing structures (such as one size fits all tests, slippery slope arguments, etc.) to the point that these structures become almost unrecognizable. By excavating these moments and relating them to existing testing structures in the United States, I hope to expand Alexander and Black's argument to account for the ways in which the testing systems of the world we are living in are already dystopian and to analyze further the consequences of these structures.

Within my thesis, I will expand upon Alexander and Black's discussion of testing as a method of social control with integration from cultural studies scholarship. Cultural studies scholarship provides the basis through which I analyze individual testing structures and the systems of high-stakes testing in these texts for how they manipulate an unaware citizenry to be complicit in their own oppression. I examine these manipulations using concepts from cultural studies, including ideas such as Althusser's concept of Ideological State Apparatuses and Repressive State Apparatuses, Foucault's Panopticon, and Freire's banking model of education, in order to call attention to the more specific ways these texts achieve the trends first examined by Alexander and Black. Doing so provides a concrete grounding through which discussions of these dystopian representations of high-stakes testing can be used to promote the sort of "greater critical self-consciousness, and renewed interest in working toward an equitable world" that Alexander and Black seek in beginning this work (233).

I position myself as a children's literature scholar operating at the intersection of dystopian, cultural, and education theory. The first of these positions helps to provide me with 
insight into the functions and tropes of dystopian literature, and, specifically, the critical dystopia. The second enables me to frame these dystopian young adult novels through discussions of ideology, surveillance, and discipline. The third allows me to examine how the characteristics of high-stakes testing have been transcribed into the aptitude test in the Divergent Trilogy, the Trial in Legend Trilogy, and The Testing in The Testing Trilogy.

Initially, this thesis requires the incorporation of scholarship on dystopias, and, more specifically, critical dystopias. First introduced in first introduced in Lyman Tower Sargent's "The Three Faces of Utopianism Revisited," a critical dystopia is a self-reflexive dystopia that is "a non-existent society described in considerable detail and normally located in time and space that the author intended a contemporaneous reader to view as worse than contemporary society," (9). Narratives of critical dystopias begin in medias res and usually illustrate a sort of awakening in which a character previously unaware of the dystopic tendencies of his/her society slowly becomes aware of these tendencies. Critical dystopias thus create a space for resistance because they follow this character as he or she "move[s] from apparent contentment to an experience of alienation and resistance" (Baccolini and Moylan 5).

At the beginning of a critical dystopia, the focal characters are often supportive of their societies through coercion or ignorance. Thus, readers may not immediately notice the dystopian aspects of the story world even as they recognize some similarities between that story world and their own reality. However, as the more dystopian tendencies of each society come to light, the reader undergoes what is described by Moylan and Clare Bradford, Kerry Mallan, John Stephens, and Robyn McCallum, as estrangement or defamiliarization. By positioning readers through the protagonists in these works in a "familiar society now seen freshly and critically... [the authors of these texts] negotiate an 'anthropological strangeness"” that generates "a 
distanced space that can draw willing readers away from the society that produces and envelops them," allowing such readers to look upon their lived experience critically (Moylan 4). While Moylan, Bradford et al. and other scholars such as Maria Varsam and Lyman Tower Sargent focus on the reader when describing this process, I will shift the focus to the estrangement protagonists go through as they move from being bystanders to becoming actors. This process of moving from inaction to action against the dystopian regime is observed by Elizabeth Bullen and Elizabeth Parsons in other young adult dystopian novels, but I expand upon their arguments and analyze the narrative pattern that this process appears to take.

Pertinent to the dystopian scholarship employed in this thesis are discussions of agency and subjectivity in young adult literature. My primary reference for this topic is Robyn McCallum's Ideologies of Identity in Adolescent Fiction: The Dialogic Contradiction of Subjectivity, which is referenced and expanded upon in New World Orders in Contemporary Children's Literature: Utopian Transformations by Bradford et al. and, more significantly in Fiona Hartley-Kroeger’s “Silent Speech: Narration, Gender, and Intersubjectivity in Two Young Adult Novels." Relying on McCallum, I will examine the role of dialogic interaction in the formation of subjective agency. In dystopian novels, questions of agency (whether there can be agency in societies with such high levels of surveillance and social constraints) are often foregrounded. In young adult dystopian novels, these questions are raised in conversation with the subject of society itself. As noted by Bradford et al., dystopias examine "the political systems, the networks of power and resistance, and the discoursal regimes, which constrain and enable identity formation" (8). McCallum argues that subjective agency is developed in dialogic interactions with others while Hartley-Kroeger uses McCallum's argument with the caveat that, in dystopian novels, the protagonists are "subject to, or capable of being acted on or influenced 
by forces other than oneself, such as situations, environment, and other characters" and thus cannot be described as having agency (277). I, however, will use McCallum's work with dialogic interaction and posit that this type of interaction is crucial to the process of estrangement necessary for protagonists to realize and act against the dystopian tendencies of their societies. I agree with Hartley-Kroeger, but to a different end. Yes, these adolescent protagonists are acted upon by other forces, especially the dominant ideologies of their respective societies, but to imply that subjective agency can only be achieved when an individual exists separately from these forces is impossible. Instead, these trilogies seem to indicate that subjective agency is not a matter of establishing an essential self against totalitarian dystopian regimes, but a matter of establishing overlapping positionalities that result from dialogic interactions with others and with the regime in order to produce gradual, realistic change.

Beyond dystopian and corresponding subjectivity scholarship, I will also be working with cultural studies scholarship to frame my arguments. Inherent in my earlier disagreement with Hartley-Kroeger is the Althusserian belief that one cannot ever be outside of ideology, as well as a wariness regarding the neoliberal focus on the individual. According to Althusser, an essential self-uninfluenced by others or society is an impossible ideal. My understanding of neoliberalism, however, comes from David Harvey's argument in "Freedom is Just Another Word.” In historicizing neoliberalism, Harvey illustrates that the focus on the individual defines neoliberalism, a concept whose beginnings can be interpreted as a political movement used to tempt those unhappy with their socioeconomic situation to promote legislation lessening governmental regulations that ultimately benefit primarily those already privileged. Within this context, these novels often undermine their own criticism of the dystopian conditions of their 
societies because they imply that systemic corruption may only be lessened through the actions or sacrifices of a comparatively privileged individual savior.

Althusser is also important to this project because "Ideology and Ideological State Apparatuses" provides the framework for Chapters One and Two. Althusser argues that any given society has two methods that help keep its citizens embedded in their preferred social formation: ideological control through institutions that cyclically produce and promote the ideology of those in power through propaganda and other manipulations, and a repression of those who fail to adhere to the dominant ideology. In dystopian narratives where the regime's power is typically absolute, both ideological and repressive methods are used to maintain control over citizens. Althusser's ideological and repressive control informs concepts of discipline and gratification in Foucault's Discipline and Punish, and together these theories help account for the in medias res quality of critical dystopias, characterized by the protagonists' initial lack of awareness of the dystopian tendencies in their societies.

Drawing on both these cultural theorists, I examine the various ideological and repressive tools that enforce the dominant ideology. I will argue that high-stakes testing and the categorization resulting from it is a method of control that keeps test-takers submissive within their societies through ideological manipulation and fear tactics resulting from repressive acts. The protagonists in young adult dystopian novels often require a major separation or estrangement from their society in order to begin to question it, eventually acting against it as is typical of a critical dystopia.

Given my focus on high-stakes testing as a method of categorization and control, it is crucial to this project that I incorporate education scholarship into my arguments. Straddling education and cultural studies is Paolo Freire's Pedagogy of the Oppressed. Of particular interest 
to the work of this thesis is Freire's denouncement of the banking model of education as a method of control, and his argument that the oppressed often internalize the oppressor's prejudices. Building on the same concepts that Althusser and Foucault apply while also clearly discussing education, Freire provides a clear link between these disciplines.

To further illuminate Freire's first position, I will introduce the scholarship on highstakes testing. First, however, I must note that scholarship on this subject is significant and sometimes overwhelming. However, as noted by Ann Filer in her "Introduction" to Assessment: Social Practice and Social Product, this scholarship can typically be divided into two subsets: a technical discourse and a sociological discourse. Though Filer discusses assessment more generally, these subsets apply to high-stakes testing scholarship as well.

The first subset is an examination of the technical aspects of high-stakes testing that parallel Freire's banking model of education. In both cases, test-takers become empty receptacles for information. As a result, both systems “minimize or annul the students' creative power and ... stimulate their credulity," ultimately serving the interest of the oppressors (Freire 73). In education scholarship, this could be equated with the fact that teachers end up teaching to the test, constraining what students learn in the classroom. While many scholars comment on this tendency, they often do so in terms of the accountability of teachers. I have chosen not to emphasize this in my work because the dystopian novels I work with often forego the teacher, making the link between the test-taker and policy-makers more tangible. Instead, I focus on the technical aspects of high-stakes tests that call into question their validity and thus undermine the categories formed by these tests. As noted by Madaus et al., R. Murray Thomas, and many others, one example is the use of cut-scores. Cut-scores are a "predetermined test score that separates one performance level from another" (Madaus et al. 54). This arbitrary score may 
determine the difference between success and failure, but it does not account for human or interpretive error very often. Cut-scores are one example of the technical aspects that can potentially undermine the validity of high-stakes testing.

More important to my work is the sociological aspect of high-stakes testing scholarship because the testing systems in my primary texts do not relate back to those in education scholarship in a one-to-one correspondence. In fact, the dystopian texts I am working with address success and failure as polarized ends that share very little middle ground because success is equated with and individual's continued existence in this system and maybe some reward, such as riches, while failure is equated with ostracism, poverty, and sometimes even death. While one cannot say the same about the high-stakes testing systems in the United States, many of the consequences to students' lives feel dire to them. As mentioned by Horace Lucido in Educational Genocide, high-stakes testing promotes a culture of fear as test-takers realize that their futures, to some degree, hang in the balance. Paired with Althusserian repression and taken to dystopian extremes, an almost paralyzing culture can develop as students fear failure. In other words, test-takers are often ideologically inclined to support testing (due to the testing mania noted by Madaus et al.), and those not inclined may be scared into it.

Beyond fear, education scholars often discuss the highly competitive atmosphere promoted by high-stakes testing systems. Students feel constantly tested, constantly watched, and constantly measured against one another, which promotes a focus on the individual that can create animosity among peers. Dystopian young adult novels make extreme this animosity to the point of betrayal, but this is the point: if we view high-stakes testing as a method of control, then it becomes clear that the first to benefit from this hostility are those in control of the systempolicy-makers and those who profit from delivering the tests. Policy-makers then further 
manipulate information and testing conditions to ensure that they can promote their own interests.

\section{The Scope of this Thesis}

Due to the in medias res quality of dystopias and critical dystopias, readers enter the fictional worlds of Roth's Divergent, Lu's Legend, and Charbonneau's The Testing trilogies through the first-person perspectives of characters who have been navigating dystopian systems of high-stakes testing their entire lives. In each trilogy, readers follow first-person narrators as they go through a process of awakening in which the protagonists become progressively more aware of the dystopian tendencies of their societies before ultimately acting to change or revolutionize said society. In each trilogy, however, the protagonists essentially begin their narratives entirely unaware of theses tendencies because of years of indoctrination they have undergone. Day, as a fugitive from the Republic, is the exception.

In order to examine this process of awakening, I find it best to scaffold my chapters so that they address the initial indoctrination, both ideological (chapter one) and physical (chapter two), and the consequences of this indoctrination on peer-to-peer relationships and society in general (chapter three). After doing so, I will identify and analyze the estrangement that these protagonists must go through to develop empathy for those marginalized and, in a position of privilege, work toward change (chapter four).

The first two chapters depend on Althusser's “Ideology and Ideological State Apparatuses," which I will use as a framework to examine each society's system of high-stakes testing and the ideological indoctrination and physical repression used by those in power to maintain control of the citizenry. In the third chapter, I will analyze the ways in which the indoctrination fostered by the methods examined in the first two chapters, coupled with an 
exaggerated focus on the success or failure of specific individuals, creates toxic competition among peers and a system of control that cyclically reproduces itself

Ultimately, I will conclude that the promotion of overlapping subject positions through the narrative pattern examined in chapter four offers a solution to the tension between the individual and the repressive dystopian regime. I will argue that the solution offered is that the self should be established in dialogic interaction with others and the regime in order to produce gradual, realistic change. However, the continued emphasis on the individual as a catalyst for change undermines the necessity of productive interactions between the regime, the masses, and the privileged individual savior.

The protagonists of these young adult trilogies find it difficult to move from being bystanders who are unaware or willfully ignorant of the dystopian features of their societies to becoming politically engaged actors. In fact, these protagonists are so embedded in the dominant ideology promoted and maintained by the categorization of their respective systems of highstakes testing that they find comfort in it. They require what utopian/dystopian scholars refer to as defamiliarization or estrangement to begin to acknowledge the dystopian tendencies in their societies. Defamiliarization and estrangement are terms that arise from translations of unheimlich, or the uncanny, and are used interchangeably by many scholars. I, however, will use estrangement for consistency and to align myself with the utopia/dystopia scholars on whose theories I rely.

It should be noted that, due to space and time constraints, I have chosen to focus on primary texts that represent high-stakes testing in a more traditional sense. That is to say, Roth, Lu, and Charbonneau all depict testing not just as a matter of physical trials that pre-teen or adolescent test-takers may go through, but also as intellectually challenging examinations that 
take place in my traditional classroom settings. In Lu's Legend trilogy, 10-year-old citizens of The Republic go through the Trial, a grueling assessment that includes a physical trial, an interview, and a traditional question-and-answer examination. In Charbonneau's The Testing trilogy, 16-year-old high school graduates must undergo The Testing in order to gain admission to the University and secure the opportunities the institution provides. As a process, The Testing begins with a set of question-answer subject exams and then introduces physical trials for the test-takers who pass all the preceding exams. Should they be accepted to the University, testtakers experience more physical and intellectual examinations. As opposed to the Trial and The Testing, the aptitude test in Roth's Divergent is not a traditional test, as 16-year-old test-takers of dystopian Chicago must ingest a serum that puts them under and into a mental simulation. However, the aptitude test is taken in a school setting and follows a sort of question-answer pattern: adolescent test-takers are presented with scenarios and told to choose (a question of sorts) what course of action to follow (their choice being the answer).

Despite the differences between the specific types of testing represented in the Divergent, Legend, and Testing trilogies, the tests in the primary texts examined in this work have one thing in common: they are high stakes-tests. As explained by Barbara Plake in "Current State of HighStakes Testing in Education":

What makes a test high-stakes really has little to do with the test itself and much more to do with the consequences of how the test scores are used. When a test is used to make important decisions, whether those decisions are about the student who took the test of about others involved in the education process, then the test is deemed high-stakes. (Emphasis in original 11-12) 
In each of these young adult dystopian novels, the testing undergone by adolescent and preadolescent test-takers can be classified as high-stakes. In fact, due to the life-or-death extremes typically employed by dystopian narratives, the testing in these texts is even more high-stakes than those in the United States, as decisions not only impact the trajectory of each student's future, but also whether s/he will have any future at all.

As indicated by the title of this work, Roth's Divergent trilogy, Lu's Legend trilogy, and Charbonneau's The Testing trilogy are all examples of young adult dystopian novels. However, it may be more fitting to use another term to describe these narratives: critical dystopia. Critical dystopias are known for exploring "new forms of oppositional agency" and going on to "explore the ways to change the present system so that...marginalized peoples do not only survive but also try to move toward creating a social reality that is shaped by an impulse to human selfdetermination" (Moylan 189). In other words, critical dystopias reflexively question the dystopian regime through the depiction of the experiences of those marginalized by said regime, typically ending with a hopeful turn in favor of those marginalized.

Additionally, my focus on critical dystopias has another implication. As noted in the chapter outline section of this introduction, the fourth chapter of this thesis will examine a narrative pattern common in young adult dystopian novels using the concept of estrangement. While this concept could certainly be used in the examination of a more realistic representation of high-stakes testing, I believe it is especially suited to my focus on dystopian novels because dystopian novels distance the reader through a similar process of estrangement. By tracing the protagonists' processes of awakening from politically disengaged citizens to actors for sociopolitical change in a world from which the reader is estranged, readers can engage with the potential critiques these dystopias offer. In dystopias and critical dystopias, the purpose of such 
hyperbolic representations is to provide distance while calling attention to the similarities between the reader's world and the dystopian one. I wish to capitalize on this characteristic in my discussion of estrangement. By excavating the narrative pattern through which protagonists in these novels become aware of the dystopian tendencies of their world, I will examine the model provided for the reader by these texts for their own political awakening — a model they may, given the estrangement enabled by critical dystopias, internalize.

Finally, given the reflexive nature of critical dystopias and the fact that all three trilogies used in this thesis are dystopian representations of the US, I have chosen to narrow the scope of this thesis solely to discussions of high-stakes testing in the United States. Because Roth's, Lu's, and Charbonneau's trilogies all depict dystopian extremes of the testing system in the United States, analyzing the trilogies alongside education scholarship focused on high-stakes testing in the US will provide insights that might otherwise go unnoticed. As Bradford et al. note in their conclusion, young adult critical dystopias are particularly interesting because they are "packaged according to the ideological and political orientations of their adult creators" and presented to readers who may be "vulnerable to prevailing ideologies and politics" (185). This has two implications. First, coming from a contemporary author's imagination, critical dystopias are inherently tied to the author's cultural-historical moment, which means that readings that take the context in which the text was written - part of which is influenced by place—into account may prove more useful. Second, critical dystopias seem to call politically passive young people to action in the contemporary societies on which these dystopias are based. As such, given the time and space constraints of this project, I have chosen to narrow my focus to critical dystopias and education scholarship that examine high-stakes testing in the United States. This is not to say that 
this work will not be applicable to other situations in other countries, but my reading and analysis are best served with these parameters in mind. 


\section{CHAPTER I: THE COMPLACENCY IN CATEGORIZATION: HOW HIGH-STAKES}

\section{TESTING AIDS IN THE CYCLICAL REPRODUCTION OF}

THE RULING IDEOLOGY

\section{The Role of High-Stakes Testing in the Educational Ideological State Apparatus: An Introduction}

Towards the end of Joelle Charbonneau's Graduation Day, the protagonist and focalizer, Cia, encounters a person she believes to be in charge of The Testing in The United Commonwealth, Dr. Barnes. ${ }^{1}$ During this encounter, Dr. Barnes reiterates the role that The Testing plays and has played in their society: "The Testing has helped our country get through the darkest time in our history. People have come to trust the system and the leaders it produces. They believe in it" (267). This and other such moments in Charbonneau's The Testing trilogy, Veronica Roth's Divergent trilogy, and Marie Lu's Legend trilogy speak to the prominence of high-stakes testing in these dystopian narratives and how citizens generally view such testing to be essential for each society to function. Similarly, in the United States high-stakes testing has become a dominant method through which students are analyzed and categorized. As noted by children's literature scholars Jonathan Alexander and Rebecca Black, "with standardized testing occupying such a prominent place in contemporary educational contexts, it is not surprising that various manifestations of high stakes testing have made their way into popular fiction for young adults" (208). This is certainly true of the aforementioned trilogies.

${ }^{1}$ In Charbonneau's trilogy, the author consistently capitalizes The Testing. I intend to maintain this capitalization throughout this work so as to be consistent with my primary texts. Similarly, I intend to adhere to the capitalization of other words describing the testing systems used in Roth's, Lu's, and Charbonneau's worlds for the same reason. 
In Contemporary Dystopian Fiction for Young Adults: Brave New Teenagers, Balaka Basu, Katherine R. Broad, and Carrie Hintz point out that YA dystopian texts describe nonexistent societies "intended to be read as 'considerably worse' than the reader's own" (3). As such, dystopias provide a level of distance — a sort of temporary safety — from the issues they engage with that allows the reader to enter into the culture's discourse about these issues. At the same time, Susan Louise Stewart explains that dystopian novels are "set in a future with recognizable features," and, as a result, they call attention to the ways in which the societiesdepicted as extreme in these texts - are not presenting the future to be as distant as one might expect or hope (159). Moreover, while dystopian novels generally present "dire futuristic scenarios.... these fantastical scenarios are clearly grounded in 'pressing global concerns' from contemporary society" (Alexander and Black 210). As also noted by Clare Bradford, Kerry Mallan, John Stephens, and Robyn McCallum, it is "this rootedness in the present that marks utopian/dystopian literature's ability to engage with concepts of contemporary society through a hypothetical unfolding of some possibilities (both preemptive and apocalyptic) inherent in the present condition" (144). Thus, by creating what Tom Moylan describes as "a distanced space that can draw willing readers away from the society that produces them and envelops them" (Scraps 30), YA dystopias can, as Rocío G. Davis observes, "function as critiques precisely by inviting parallels with certain aspects of contemporary culture, encouraging teens to be more thoughtful about politics and society and their place in it" (51). Alexander and Black conclude that YA dystopias enable "young readers to see the inequalities in their own communities" and encourages them to think through "systems of inequality" (232). In other words, the distance between reality and dystopian fiction allows readers to enter into conversations they might not have entered into otherwise, while the uncanny similarities that come to light between their 
realities and these dystopian worlds encourage readers to question and criticize existing institutions in their realities.

One such system popularly depicted in YA dystopian novels is the high-stakes testing system prevalent in the United States. However, it is important to recognize that not all tests are high-stakes tests. As discussed in the introduction to this thesis, high-stakes tests are those that are used to make decisions about a student's future. As George Madaus, Michael Russell, and Jennifer Higgins write in The Paradoxes of High-Stakes Testing, "it is the gravity of decisions like these that cause a state-mandated test to become a high-stakes test" (2). With these parameters in mind, we can consider the aptitude test in Veronica Roth's Divergent trilogy as a high-stakes test since that test significantly influences (more-or-less dictating) the faction (a personality-based category) each sixteen-year-old test-taker will join for the rest of their lives. Roth's protagonist, Tris Prior, attempts to navigate through this test-based society as a Divergent who does not fit into any one of the factions so that she can avoid becoming one of the factionless who live in poverty and are ostracized for their failure to fit in any faction. The Trial in Lu's Legend trilogy is also a form of high-stakes testing because preadolescent test-takers are made to endure both a written and physical exam that determines their future in the Republic, a military state in which those who test well are given military positions and considerable salaries, while those who do not are given jobs that pay very little and often endanger the workers. Finally, with this definition in mind, we can also view The Testing in Charbonneau's Testing trilogy as a high-stakes test since those in charge of The Testing select high-school-age students (based on their past education) for grueling weeks of written and physical exams that culminate in a survival-style trek through unrevitalized parts of the United Commonwealth. In Charbonneau's trilogy, those who pass The Testing can attend the University in the hopes of 
developing skills that could help them to revitalize the Earth, while those who were not chosen for The Testing must remain in the districts and make do with the limited opportunities offered there.

Alexander and Black note that the current public education climate in the U.S. is “dominated by preparing for, administering, and implementing the results of high stakes educational testing" (208). The same can be said of the societies represented in the Divergent, Legend, and Testing trilogies. Each of these dystopian societies depends on high-stakes testing scores as a way of categorizing their citizens into specific, often class-based, groupings. However, because these are dystopian texts, the societies take existing structures within highstakes testing systems to extremes and often equate a failure to adhere to test-based categorization, whether by performing poorly on tests or by resistance to the system in general, as rebellion, punishing adolescents who test poorly with marginalization or worse. Moreover, in each society high-stakes testing has become so ingrained in the culture's collective psyche that it is viewed by many in the same way that Tris perceives the test in Divergent: "It has been this way since the beginning of the great peace when the factions were formed. I think the system persists because we're afraid of what might happen if it didn't' (33). In other words, it is as Naomi Jacobs explains when speaking of Octavia Butler's Xenogenesis: “citizens of dystopia are gripped in a social formation so powerful, a web of control so densely woven, that at worst they do not even know they are not free" (92). As Tris states and Jacobs explains, high-stakes testing and the categorization it promotes persist, among other reasons, because too many people believe categorization is necessary and do not realize the cost of such a system.

As a result, the protagonists of these novels and the citizenry in general have become complacent with regard to high-stakes testing. Moreover, though differences arise between the 
testing systems in these trilogies and the many nuanced high-stakes testing systems prevalent in the United States, the response of those living within these systems is much the same. As Horace Lucido observes of many Americans in Educational Genocide, the protagonists and citizens of these dystopian novels "have become addicted to high-stakes test scores. This addiction is supported and encouraged by our business culture and our local, state, and national governments" (38). Thus, the aim of this chapter is to analyze why the citizens of the dystopian societies in these trilogies predominantly support high-stakes testing by bringing to the forefront the actions that those in power take to ensure such endorsement by the citizenry. At the same time, I intend to demonstrate that these actions, which often seem extreme and divorced from America's high-stakes testing systems, are, at their core, strategies used repeatedly by proponents of high-stakes testing in the United States. However, before I can complete this work, in the following subsection I will touch upon high-stakes testing as a part of the educational Ideological State Apparatus, as defined by Louis Althusser.

The Dominance of the Educational Ideological State Apparatus and What That Implies In "Ideology and Ideological State Apparatuses," Althusser notes that within the State Apparatus there are two parts, "the body of institutions which represent the Repressive State Apparatus on the one hand, and the body of institutions which represent the body of Ideological State Apparatuses on the other" (14). Generally, the State Apparatus defines the state as a "force of repressive execution and intervention" in favor of the ruling class, and so it operates through the Repressive State Apparatus (the police, the government, the army, the courts, etc.) and the Ideological State Apparatuses (the religious ISA, the family ISA, the cultural ISA, etc.). In Althusser's essay, ideology "is the system of the ideas and representations which dominate the mind of a man or social group" (20). Althusser further states that one of the functions of any 
given Ideological State Apparatus, including the educational ISA on which this chapter focuses, is to ensure "submission to the rules of the established order.... In other words, the school ... teaches know-how, but in forms which ensure subjection to the ruling ideology" ( 5 emphasis in the original).

Implicit in the above statement is the acknowledgement of the educational ISA as the dominant Ideological State Apparatus, a point to which Althusser returns later in the essay. However, many educators and education theorists have argued that within the educational ISA, high-stakes tests have become a prevalent method of categorization and, through the capacity of such testing to reproduce existing class divisions, control of the status quo. In fact, as Wayne Au notes in "Meritocracy 2.0": "while the use of standardized testing in education in the US has been relatively consistent since the early 1900s, it has only been in the more recent decades where their use has risen to dominance" (29). Furthermore, in "The Development and Impact of High-Stakes Testing," Gary Natriello and Aaron M. Pallas write that, "in the last quarter of the twentieth century, testing was developed as a major tool of policymakers for the governance and regulation of education" (19). These educational theorists seem to affirm Althusser's claim "that the Ideological State Apparatus which has been installed in the dominant position in mature capitalist social formations...is the educational Ideological Apparatus" (17). This dominant Ideological Apparatus now functions through high-stakes testing and the categories that arise from such testing. However, while this "one Ideological State Apparatus certainly has the dominant role... hardly anyone lends an ear to its music: it is so silent! This is the School" (18). In other words, while the education system may be the dominant ISA espousing the ruling ideology, it does so in a way that is unrecognized by the general populous. 
The significant role of the educational ISA in the reproduction of the ruling ideology is not surprising given that "no other Ideological State Apparatus has the obligatory (and not least, free) audience of the totality of the children in the capitalist social formation" (Althusser 18). Within the more concealed aims of the educational ISA, however, high-stakes testing takes on a gate-keeping quality. In its use of what many citizens consider "objective," number-based scores, high-stakes testing works to provide the conditions Althusser considers to be necessary for the reproduction of the ruling ideology: a space for the "reproduction of submission to the ruling ideology for the workers, and [the] reproduction of the ability to manipulate the ruling ideology correctly for the agents of exploitation and repression" (5). In other words, high-stakes testing provides a method by which the educational ISA can reproduce the ruling ideology, while also reproducing the players necessary to reproduce the ruling ideology and the players that will be subjected to it. Therefore, within the educational ISA, high-stakes testing is a technique that acts as a capillary of the larger institution of the school. In Foucauldian terms, then, high-stakes testing "reaches into the very grain of individuals, touches their bodies and inserts itself into their actions and attitudes, their discourses, learning processes and everyday life" (Foucault, Power/Knowledge 39). Using Althusser as a theoretical frame, I will argue that high-stakes testing, and the categorization resulting from it, cyclically reproduce the ideology of those in the power class through the indoctrination of citizens facilitated by other strategies such as propaganda, manipulation of information, and willful ignorance.

\section{$\underline{\text { Policy-Makers as Puppet Masters and How Dystopian Conditions Make this Clear }}$}

Educational theorists Steven Lewis and Ian Hardy note that in the United States "standardized testing has become an entrenched means to ensure teacher, school and system accountability, and 'answerability' to legislators and the public" (245). Moreover, as P.L. 
Thomas states in Numbers Games, "people who have political and ideological agendas see education as a means of promoting those agendas" (44). In the testing climate in the United States, then, policy-makers are becoming increasingly involved with and controlling of existing high-stakes testing systems. YA dystopias, such as those in my primary texts, make extreme the reach of policy-makers in that there is no intermediary between such policy-makers and the testing systems they promote, unlike in the US, with various testing companies such as ETS and Pearson. Even so, some education theorists have noticed that "systems of high-stakes accountability evacuate power and control from the classroom level, concentrating them in the upper echelons of the bureaucratic hierarchies of US schools, districts, and state educational agencies" (Au, "Teaching Under" 35). In dystopian texts that hyperbolize the tactics used to promote high-stakes testing, however, this manipulation is more easily noticeable because some policy-makers are directly involved in the deceptions necessary for this manipulation.

In the following chapter, I analyze Roth's Divergent trilogy, Lu's Legend trilogy, and Charbonneau's Testing trilogy in the hopes of showing that high-stakes testing functions as a method of categorization employed by the educational ISA to keep the citizens of each dystopian society embedded in the ideology of those in power. This ideology cyclically promotes the cultural myth that the categorizations derived from high-stakes testing are necessary for each society to function by means of using propaganda, data manipulation, slippery slope arguments, and other tactics. However, as I analyze these tactics in these dystopian contexts, I hope to make the exigency of this project clear. The fact that my analysis so easily utilizes existing education theory based on the high-stakes testing systems in the United States to understand the actions of policymakers in these dystopian societies is concerning because it indicates that the devices 
which promote high-stakes testing, and thus promote the categorization resulting from such testing, may already be eerily dystopian in their nature.

\section{“Is Your Child's Trial Coming Up?": Propaganda as Reinforcement of Testing Mania}

A certain mania or obsessive preoccupation surrounds systems of high-stakes testing because, as noted by Madaus et al., in the United States "testing is woven into the fabric of our nation's culture and psyche" with students of all ages taking multiple tests a year to determine their progress and their track in school (4). This preoccupation leads to a belief in testing's necessity that often goes unchallenged due to what George Hillocks, Jr., refers to as interpretive frameworks: "a set of examined or unexamined assumptions and explanations that we use to interpret situations we encounter in the world" (13). While critiques and concerns with highstakes testing may arise, many citizens see high-stakes testing as a normal part of schooling. As a result, when critiques emerge, testing proponents and policy-makers often dismiss them, thus ensuring that, overall, testing remains supported.

In other words, "the current public education climate in the United States is dominated by preparing for, administering, and implementing the results of high stakes educational testing” (Alexander and Black 208). However, as noted by Lucido, these systems are based on an unproven premise: that "a once-a-year set of multiple choice tests accurately reflect the truth of what an individual student knows and is able to do" (27). Despite this flawed premise that Lucido and other education scholars have noted, high-stakes testing continues to dominate schools. Moreover, while scholars such as these offer challenges to systems of high-stakes testing, noting the various problems that exist in these systems, they are often ignored by policymakers and others in privileged positions that could theoretically adjust or eradicate the system. These scholars are likely ignored because of the high profitability of high-stakes testing — and 
possible lobbying from testing firms exacerbates the unwillingness of legislators to consider factors. Furthermore, non-specialists on the subject of high-stakes testing may not notice these problems and may instead accept high-stakes testing as a normal part of the education process. In other words, these problems are complex and may be, at this time, irresolvable. This is, in part, because of the indoctrinating capacities of the educational ISA that promotes and enforces the prevalent technique of categorizing students through high-stakes testing.

Similarly, a manic aura surrounds the high-stakes testing systems present in the Divergent, Legend, and Testing trilogies, and the readers' attention is turned to this often in the first few pages of each text. ${ }^{2}$ In Charbonneau's The Testing, Cia prepares for her high-school graduation and, while looking at herself in the mirror, hopes "that today is not the end of [her] education, but [she has] no control over that. Only a dream that [her] name will be called for The Testing" (6). In Roth's Divergent, Tris similarly worries over the aptitude test in the first scene of the novel noting that "today is the day of the aptitude test that will show me which of the five factions I belong in. And tomorrow, at the Choosing Ceremony, I will decide on a faction; I will decide the rest of my life; I will decide to stay with my family or abandon them" (2). While not explicitly describing it, these quotations inherently touch upon the mania surrounding highstakes testing in these novels by making clear the importance that both Cia and Tris attribute to such testing. Moreover, the inclusion of such quotations so early in these primary texts speaks to the fact that high-stakes testing is at the foreground of each character's mind. While one could argue that this is only the case because both characters face the possibility of being tested in the immediate future, the confidence with which Cia and Tris discuss their testing and the possible

${ }^{2}$ The events in Legend occur years after both June and Day have undergone The Trial so the same cannot be said for Lu's trilogy. 
consequences of it implies that this is not the first time these thoughts have come to the forefront of their minds.

In the Divergent, Legend, and Testing trilogies, as well as in the contemporary US, many tactics employed by proponents of high-stakes testing and those who control the educational ISA (policy-makers) support this mania. One such tactic is propaganda, and this is nowhere clearer than in Lu's Legend trilogy. In Lu's Legend, for example, this propaganda is foregrounded in much the same way that the testing mania is in Divergent and The Testing in that it is mentioned within the first few pages of the text: "Most of the pictures on the screens are of happy things: smiling children standing under a bright blue sky, tourists posing before the Golden Gate Ruins, Republic Commercials in neon colors. There's also anti-colonies propaganda" (1). While Day, the second focalizer in the Legend trilogy's dual-voice narrative, only delineates the latter as a form of propaganda, the same could be said for the happy scenes presented as both work towards bestowing the Republic, which is stratified through testing, with praise while condemning its primary enemy. Moreover, only ten pages later Day enters a hospital and encounters more propaganda, observing that the "Elector's portrait [is] on the office's back wall, a thirty-inch screen [is] on the side wall, with the sound muted and a headline that reads: 'TRAITOROUS “PATRIOTS” GROUP BOMBS LOCAL MILITARY STATION, KILLS FIVE’ followed by 'REPUBLIC DEFEATS COLONIES IN BATTLE FOR HILLSBORO,'” indicating the ubiquity of this tactic in The Republic (Lu, Legend 11). In another scene in which June is the focalizer, the propaganda advertises ways to test better, touching, once again, on the mania surrounding high-stakes testing: "Thomas keeps his attention on the rotating commercials (our side currently shows a bright, gaudy Is your child's Trial coming up? Send him to Ace Trials for a free tutoring consultation!)” (277). 
There is no question, then, that this propaganda is pervasive. It is used both as a way of strengthening the Republic's claim to dominance and also as a way of maintaining the manic aura of high-stakes testing as a societal necessity. But propaganda is not always so apparent as it is in Lu's Legend trilogy with the Republic's “jumbotrons, always on, regardless of power shortages" espousing the aforementioned propaganda (39). Sometimes, as in Charbonneau's The Testing, propaganda is sneakier and found, not in the disembodied voice of a TV screen, but in the persuasive language used by those in charge of testing systems as they address test-takers: "You are here because you are the best and the brightest. On your shoulders rest the hopes of everyone in the United Commonwealth. Here among you are the future leaders of our country. All leaders must be tested, which is the process that you will begin here today" (75). By situating potential test-takers as future leaders, policy-makers in The Testing evoke the glory that may come from participation and success in The Testing to appeal to their audience, never mentioning the danger that such participation entails. The persuasive rhetoric coupled with the lack of accurate information marks this passage as a form of propaganda. That this propaganda is successful is clear both in Cia's immediate response, "People fidget in their seats. Nerves? Excitement? I admit I feel a combination of both," and, later, in her perplexed disbelief as she asks, "who would turn down the honor of being chosen for The Testing?" (22). More significant in this instance, however, is the tying of propaganda to the mania surrounding high-stakes testing in general and, further, the tying of this propaganda to the idea that high-stakes testing is necessary for the functioning of society.

Of young adult dystopian novels, Basu, Broad, and Hintz further note that, "access to information is often dangerous but is repeatedly presented as the only way to become free" (4). Likewise, when addressing high-stakes testing in the US, Lucido explains that "education has 
often been touted as a way out of poverty. By being educated, students should be increasing their options for what they would like to do in their lives" (83). However, while propaganda is pervasive, access to testing help, as advertised in Legend, is not. In fact, while these dystopian novels are based in fiction, the lack of acknowledgment of the money required to improve test scores is eerily similar to what Dale D. Johnson, Bonnie Johnson, Stephen J. Farenga, and Daniel Ness speak to in Stop High-Stakes Testing: "Bountiful amenities are available to the upper class and the ultra-rich and their children. Included are special schools that cater to children with some form of learning disabilities. Tuition costs are beyond the means of the working class, the lower class or the excluded" (67). Therefore, while propaganda may be ubiquitous in these societies in various forms and may, in fact, work towards promoting the idea that high-stakes testing is a necessity, the reality is that policy-makers and others in charge of high-stakes testing and the educational ISA often ignore class differences. Thus, propaganda becomes a form of manipulation utilized by these players to reinforce these ideas that support the testing mania that gave rise to the propaganda in the first place. Given this, it comes as no surprise that the citizens of the dystopian societies that Roth, Lu, and Charbonneau have created often overlook both the class differences inherent in propaganda and the effect of propaganda itself.

In Prodigy, Day touches upon the difficulty of recognizing propaganda and breaking with the ideology behind it: "You were trained to hate them. But they are a potential ally. I trust them more than I trust the Republic" (Lu 6, emphasis in the original). For Day, a fugitive rebel within the Republic who has been repeatedly attacked by those in power, the idea that the Republic may be manipulating citizens with the constant stream of pro-Republic and anti-Colonies propaganda is easy to swallow. For most citizens who are not persecuted, however, this is not the case. As George Madaus and Cathy Horn observe about testing in the US, "testing is so entrenched in our 
culture, and so taken for granted, most people fail to consider how it reshapes our social, educational, business, and moral life" (51). Thus, by bringing to light the inconspicuous nature of high-stakes testing as a technique in the US, the novel evokes the underhandedness that Althusser has noted resides within the educational ISA. Although the systems of high-stakes testing in the US and my dystopian texts differ, this can also be applied to high-stakes testing in the Divergent, Legend, and Testing trilogies. As a result, propaganda becomes a tactic that those in charge of high-stakes testing can use in order to manipulate the citizenry to believe that testing is necessary for society to function, thus feeding the same mania that gave rise to the propaganda in the first place.

In other words, propaganda is a tactic utilized to reinforce the belief that the categories of high-stakes testing are essential to each dystopian society. In reality, however, this belief, and the propaganda that helps promote it, work to retain testing as a method of reproducing the ruling ideology by reproducing those who would be subjected to that ideology and those who would enter the ruling class and continue this work. The danger here, then, is best explained by a sentiment shared throughout all my primary texts, but explicitly stated in Lu's Prodigy: "all it takes is one generation to brainwash a population and convince them that reality doesn't exist" (250). Constantly inundated with propaganda that shapes one's thinking, the characters in these YA dystopian novels become embedded in the existing social hierarchies of their societies without ever realizing that they have been manipulated into doing so. To make matters worse, citizens are also often entirely unaware of the degree to which they have been tricked, something that becomes clear when Roth's, Lu's, and Charbonneau's trilogies are read in tandem with education theory that highlights the different ways in which policy-makers actively strive to misinform the public. 


\section{"Because They Don't Know What The Testing Entails": The Role of Data Manipulation in Propagating the Ruling Ideology}

In Numbers Games, P.L. Thomas makes clear that part of high-stakes testing propaganda invokes over-valuing metrics:

Over the hundred-year span of American public education, numbers assumptions have negatively impacted the daily job of being a teacher and adversely impacted student learning.... In other words, the typical American believes wholeheartedly that a student's SAT score means something that it doesn't (or at least more than it does) and unflinchingly accepts that average SAT scores for a state clearly reflect the quality of all education in that state. ( 2 emphasis in the original)

This sentiment is not unique to Thomas' Numbers Games either. ${ }^{3}$ In fact, various other education scholars echo it. In fact, as Natriello and Pallas note, "another appeal of widespread testing to the policy community is the inherent efficiency of testing as a performance-monitoring process" (21). In other words, policy-makers recognize the usefulness of high-stakes testing while the American public often wholeheartedly adheres to this outlook. However, "there is, most shockingly, no corroborating evidence that these tests really do tell the truth about what a student knows and is able to do" (Lucido 94). Meanwhile, the high-stakes decisions made about testtakers with regards to their scores "are touted as scientifically objective" when, clearly, "they are not" (29). Moreover, education theorists such as Kurt F. Geisinger regularly argue that "using multiple valid measures is always more valid than using a single measure to make decisions"

${ }^{3}$ In Divergent, number-based scores are not used in the aptitude test, the preliminary high-stakes test. However, in the subsequent high-stakes testing Tris undergoes during her Dauntless initiation, Eric scores the initiates through a normative, number-based system. Therefore, I include Roth's trilogy in this claim. 
(246), echoing, once again, Lucido's assertion that “high-stakes test scores are not measures of any aspects of education. They do not tell the truth of what a student knows and is able to do" (159).

The three trilogies under consideration make clear that the faith placed on high-stakes testing results is widespread. In Roth's Divergent trilogy, for instance, test-takers regularly cite their belief in their test results. One minor character named Shauna even questions Tris' loyalty to Dauntless in Roth's Insurgent, arguing that she knows she belongs "in Dauntless because everything [she] did in that aptitude test told [her] so," and that she's "loyal to [her] faction for that reason - because there's nowhere else [she] could possibly be" (235). The same can be said of Lu's Legend trilogy. In fact, even when June discovers that those in charge of the Trial recorded Day's score incorrectly to make it appear as though he'd failed his trial when, in reality, he'd gotten a perfect score, she does not question the Trial itself: "Day didn't fail his Trial. Not even close. In fact, he got the same score I did: 1500/1500. I am no longer the Republic's only prodigy with a perfect score" (Lu, Legend 187). That June's opinion of Day shifts with her acknowledgement of his Trial score indicates that June, like Shauna in Insurgent, believes that people's high-stakes test scores are indicative of how much they know. Likewise, at the start of The Testing, Cia believes passionately that her academic achievement is measurable and hopes that her work will be enough to earn her a spot in The Testing. Cia's belief in the validity of high-stakes test scores remains intact as she takes the entrance exam for the university. In fact, when Cia is "assigned to the field of study [she] least wants to pursue," she does not question how the test was scored to produce this result, but rather the result itself (Charbonneau, Independent Study 19). In other words, she, like June and Shauna, rarely doubts high-stakes test scores, even while she may doubt the decisions made from such scoring. 
But where do these beliefs come from? One answer is the ruling ideology promoted by the educational ISA, but the reality of how these beliefs come to fruition is more complicated than this simple response. Indeed, such questioning is examined by R. Murray Thomas in HighStakes Testing: Coping with Collateral Damage: "In the public press, critics of achievement testing often claim that the entire testing process does more harm than good by (a) failing to provide a well-balanced evaluation of students' learning, (b) causing students anxiety, and (c) focusing teachers' efforts on preparing students for tests. Such publicity can weaken the public's faith in high-stakes plans" (113). As Thomas makes clear in this quotation, critiques of highstakes testing in the US can find a voice in the media, and, as a result, "parents and the general public can be confused and frustrated about the status of academic performance in their school," especially "when information regarding the condition of other schools is unavailable" (127). While challenges to high-stakes testing are less prominent in the Divergent, Legend, and Testing trilogies due to the dystopian extremes with which such challenges are handled and punished, they certainly exist. As a result, in both the high-stakes testing systems in the United States and in the dystopian trilogies I am studying, "The education debate is pregnant with political dishonestly, but often nested within political dishonestly is philosophical dishonestly, or at least philosophical bias crouched in objective rhetoric" (R. Thomas 56). In the next section, I will argue that, in addition to the propaganda used by policy-makers to promote high-stakes testing, policy-makers engage in various kinds of data manipulation to further indoctrinate citizens into the ruling ideology, which views testing as societal necessity and cyclically uses these tactics to reproduce itself. 


\section{How Information is Re-Conceptualized in Favor of High-Stakes Testing}

When discussing the state of education, policy-makers often "cite poor test results, declining international rankings, and decreasing enrollment in the hard sciences" (Lucido 73). What often goes unnoticed, however, is that in the "the discussion of what the test 'data' means ... [the] 'data' means nothing. It is the interpretation of this test 'data' that can be swung and twisted to support or deny a given position. Rational discussion is not possible when interpretation is prejudiced by a political or economic agenda" (94). To many education scholars, this comes as no surprise, since "dynamic was established in the early 1980s of manipulating scientific and statistical data to give political ideology a veneer of gravity" (P.L. Thomas 125).

The same can be said of policy-makers in the Divergent, Legend, and Testing trilogies with the difference that my primary texts focus more on distributing information that will stifle all critique of testing. For example, while testing proponents in the US will "gather a coterie of satisfied educators to openly support [high-stakes testing] legislation" in order to "counteract the negative publicity" (R. Thomas 113), policy-makers in these YA dystopian texts will disseminate footage of insurgents who challenge testing being executed, and "they'll play reruns of the footage for several days afterward" (Lu, Legend 282). What is important to note, however, is that even in the case above, manipulation of information is at work because, while the jumbotrons in the Republic seem to show that "Daniel Altan Wing [was] executed today by firing squad," Day is actually safe and, on the run, while his brother's death has become a method by which to further manipulate the people (296). Using the argument set forth by Madaus et al., we can see that storyline used by policy-makers in these primary texts is one that helps to indoctrinate citizens to favor the ruling ideology; ultimately, the goal of all this manipulation is to "convince 
the right people that the government is doing something to make all [their] lives better, even though it's not" (Roth, Allegiant 252).

What is clear in the above discussion, then, is that there is a "disjunction between rhetoric and reality" with regard to high-stakes testing (P.L. Thomas 68). By examining representations of high-stakes testing systems in tandem with education scholarship, we can gain insight into the ways in which the tactics employed to support high-stakes testing in the US have dystopian implications. Both the systems of high-stakes testing in the United States and those in these YA dystopian texts exemplify Althusser's claim that "what is represented in ideology is therefore not the system of the real relations which govern the existence of individuals, but the imaginary relation of those individuals to the real relations in which they live" (25). In other words, the tactics of manipulation employed by policy-makers in support of high-stakes testing indoctrinate citizens into the ruling ideology while simultaneously distorting the citizens' conceptions of reality so that the way they understand their societies matches up with the ideal conditions necessary to promote that ideology. In doing so, policy-makers ensure that challenges to highstakes testing go unheeded and unsupported, thus aiding the cyclical reproduction of the ruling ideology.

$\underline{\text { How the Slippery-Slope Argument Creates a Cultural Myth of Testing as Necessity }}$

In Roth's Divergent, Marcus Eaton, the leader of the Abnegation faction and of dystopian Chicago's government, argues that society needs the faction system resulting from the aptitude test in order to function. His speech at the Choosing Ceremony-the ceremony at which the freshly tested sixteen-year-olds must choose their faction-is an argument in support of highstakes testing, much like the 1983 report A Nation at Risk. Although over thirty years old, this report and its language has influenced laws like No Child Left Behind (NCLB) while also paving 
the way for high-stakes testing to become more widely used and standardized. The report called attention, through the citation of various test scores, to the ways in which international comparisons of student achievement to the United States were not favorable and asserted that America, if it remained idle in the realm of education, would fail to be globally competitive. Furthermore, in predominantly citing test scores as indicators of risk, A Nation at Risk opened itself up for use as an argument for establishing testing structures as a way of measuring global competitiveness because it "embraced testing as a policy tool to improve the quality of education" (Madaus et al. 20). If we read Eaton's speech, keeping in mind the rhetorical strategies used in texts like A Nation at Risk, we can gain insight into how Eaton's speech helps to indoctrinate citizens of dystopian Chicago into the ruling ideology through the construction of a cultural mythology that assumes testing is necessary for the operation of society.

The testing-for-factions in the Divergent trilogy depends on an indoctrinated belief that testing is necessary. That indoctrination permeates almost every aspect daily life for the residents of dystopian Chicago. Nevertheless, Eaton's speech in Divergent actively and significantly promotes the cultural mythology of testing-as-necessity for the first time in the novel through his employment of the slippery slope argument:

Our dependents are now sixteen. They stand on the precipice of adulthood, and it is now time for them to decide what kind of people they will be... Decades ago our ancestors realized it is not political ideology, religious, belief, race, or nationalism that is to blame for a warring world. Rather, they determined that it was the fault of human personalityof humankind's inclination toward evil, in whatever form that is. They divided into factions that sought to eradicate those qualities they believed responsible for the world's disarray. Working together, these five factions have lived in peace for many years, each 
contributing to a different sector of society.... but the reach of each faction is not limited to these areas.... In our factions, we find meaning, we find purpose, we find life.... Apart from them, we would not survive. (Roth, Divergent 42-43)

Eaton's statement advocates for the necessity of the aptitude test and the subsequent categorization through factions by operating through fear and nostalgia. The statement thus illustrates the slippery slope argument, a tactic often used to support testing structures in the United States that Madaus et al. identify in The Paradoxes of High-Stakes Testing. Proponents of testing, particularly policy-makers, use slippery slope arguments to press the need for high-stakes testing, implying that testing prevents society from sliding down into cataclysm. As such, these arguments create an aura of manic need around testing for society's success (24-25).

In A Nation at Risk for example, the report opens with the lines "our Nation is at risk. Our once unchallenged preeminence in commerce, industry, science, and technological innovation is being overtaken by competitors throughout the world" (Fraser 333). This sets the tone for the rest of the report because it fluctuates between language that invokes fear of an uncertain future and nostalgic idealizations of the US's superpower status, thus contrasting America's past success as a nation to the report's historical situation in which "the time [was] long past when America's destiny was assured simply by an abundance of natural resources and inexhaustible human enthusiasm" (333). Eaton's statement similarly implies that unless citizens adhere to the faction system resulting from the aptitude test, society will eventually fall into chaos. Like other slippery slope arguments, Eaton's statement draws upon past events—referencing the formation of the faction system as a method of salvation - in order to instill within his audience a sense of nostalgia. This nostalgia implicitly suggests that things were better then: when the faction system 
was first formed, the idealizations sharply contrasting with the potential chaos or personal peril that may come from any deviation from the testing system currently in place.

However, also present within Eaton's statement is the implied positive impact of the categorization of the faction system on individual citizens, which plays upon the nostalgic idealizations of the system. As shown in the latter half of the statement, the factions purportedly provide a purpose for each individual, making each person feel a sense of belonging even as they contribute to society in their factional roles. Because of the manic belief in the necessity of testing-based categories to prevent chaos and the nostalgia-driven idealization of the faction system, categorization becomes comforting. As long as the faction categories are intact and reinforced by the fresh categorization of the tested every year, society is as safe as it has always been. As Tris recalls while waiting for her test results: "even if we could [survive alone], we wouldn't want to. Without a faction we have no purpose and no reason to live" (Roth, Divergent 20). In this way, slippery slope arguments tether individual actualization to society's well-being, and a cultural myth "that children are apprenticed into at an early age" forms around categorization through testing as necessary for individual happiness (Alexander and Black 219). This belief passes from generation to generation and becomes so ingrained in the psyche of testtakers that citizens equate deviation from testing structures and their categories with both societal ruin and individual distress. Thus, Eaton's slippery slope argument helps to perpetuate the cultural mythology that testing, allowing for productive classification, supposedly ensures individual happiness while simultaneously benefiting society.

Choosing to support and navigate test-based categorizations for the good of society, adolescents integrate into standing organizational structures that ensure those structures remain intact. The cultural mythology of high-stakes testing thus cyclically ensures its own reproduction 
as the ideology of those in power continues to be taken-up, often unexamined. Analyzing Eaton's statement as a slippery slope argument, like the argument used in A Nation at Risk, places into relief how dystopian Chicago's leaders encourage the reinforcement of standing societal structures for the supposed good of all citizens. The difference between the severity of the stakes of the two arguments is indicative of the different contexts in which they operate. However, Eaton's justifications of testing take on a utopian gloss—grounded as they are in a reaffirmation of communal coherence and individual success. Despite this, Roth's heroine cannily surmises that they are ultimately predicated upon a logic of fear. Indeed, when Eaton intones the necessity of the faction system for survival, Tris realizes that inherent in his words is the threat of becoming factionless, a fear described as "greater even than the fear of death" (Roth Divergent 43-44). That is, Tris recognizes that the testing culture in her society depends on the implied associations of deviation from the faction system with the fear of becoming factionless.

Ultimately, however, Tris continues to navigate within the test-based social hierarchy of dystopian Chicago for the better part of Divergent. Despite this, Tris' temporary acknowledgement of the manipulation that is fundamental to the propagation of the ruling ideology makes one thing clear: in dystopian societies adolescents are interpolated into standing social formations under duress. With the fear of the consequences that come with test failure, policy-makers coerce adolescents to remain within the social hierarchies that envelop them and force them to choose between subjection to the ruling ideology and marginalization. I will examine the implications that such coercion has on the agency of test-takers in the following section. 


\title{
"Heroes Get More Options for Their Future": How High-Stakes Testing Provides the Illusion of Agency
}

\author{
Why Test-Takers Fear Failure
}

Manipulated information is only partially responsible for the indoctrination of citizens in the US and in these dystopias. Another way that the ruling class maintains the dominant ideology is through fear. In this section I will analyze how this fear works to further indoctrinate citizens these dystopias into existing test-based social categories under duress. That is, I will argue that the fear tactics inherent in the indoctrinating actions of policy-makers coerce adolescent testtakers into believing that their best chance at success and happiness is to navigate the very structures that reproduce the dominant social hierarchy and the ruling ideology, thus privileging high-stakes testing.

In Discipline and Punish, Michel Foucault speaks to how labor power is dependent on the body being "caught up in a system of subjection" in which need is "a political instrument meticulously prepared, calculated and used" (26). If we read systems of high-stakes testing as systems of subjection, we can see the desire to succeed within these systems as a need that policy-makers propagate in test-takers by creating consequences to coerce adolescents to navigate these systems and "play the game." Moreover, these consequences are necessary incentives to ensure test-takers understand the importance of high-stakes tests. As Henry M. Levin notes in "High-Stakes Testing and Economic Productivity," testing proponents in the US argue that "tests will improve the US labor force and provide employers with useful information for selecting employees" (39). In doing so, policy-makers imbue high-stakes tests with a level of importance that they argue maintains a competitive and productive labor force, so test-takers need to face consequences if they do not test well. 
The idea of consequences as a necessary part of high-stakes testing exists because of the post-apocalyptic nature of each society. Policy-makers often use these heightened stakes to excuse the dire consequences of high-stakes testing. In fact, when Cia's roommate commits suicide in response to the extreme pressure of The Testing, Dr. Barnes, a testing proponent and director, tells Cia that "while this is a tragedy, it is better for the entire Commonwealth population to learn now that she is not capable of dealing with the kinds of pressure she would be forced to deal with in the future" (Charbonneau, The Testing 94). ${ }^{4}$ When read together, these scenes are indicative of both the fear tactics used to support high-stakes testing and the responses used to pacify those who think that the consequences of testing are too high. In other words, Dr. Barnes' words represent a hyperbolized, dystopian version of what many education scholars have noted about the rising stakes of testing systems in the US. As Mark LaCelle-Peterson explains, "stakes in educational attainment are higher for both individuals and society: the postindustrial economy affords no living-wage jobs for those whose school careers are cut short" (27). In putting LaCelle-Peterson in conversation with Levin, scholars see that policy-makers depend on test-takers' fear of the consequences, both individually and more globally, tying poor test-taking to motivating students. Inherent but implicit in both arguments is the idea noted in the slippery slope argument of A Nation at Risk: that test scores are indicative of a society's ability to be globally competitive, so many citizens support this apparent need for consequences because of the cataclysm that will purportedly ensue without them. High-stakes testing systems regularly depend on fear as a motivator.

${ }^{4}$ It should be noted that, in other countries that utilize high-stakes testing, suicide is a much larger epidemic than it currently is in the US. That is to say that the conditions leading to Ryme's suicide and the suicide itself, while an extreme representation according to present testing structures in the US, is not so extreme in a more global context. 
Cia's interaction with Dr. Barnes following Ryme's suicide is representative of the logic Sharon L Nichols describes as being used by testing proponents in the US who argue that "when faced with large incentives and threats of punishment teachers will work harder and be more effective, students will be more motivated, and parents will become more involved" (49). However, given the ideological implications of high-stakes testing noted throughout this chapter, it may well be that this logic is yet another method of manipulation that purports to enforce the betterment of society by implying that "if test performance is tied to important consequences, fear of a low score will motivate lazy, recalcitrant, or otherwise unmotivated students to work harder and learn more" (Madaus et al. 159). While this may be true in theory, policy-makers make such arguments without acknowledging the role that the fear of testing poorly and facing the consequences may have on student. In other words, "high-stakes testing infects our educational system with a culture of fear" (Lucido 5).

This fear is not unfounded. In the US, students are held back, put in remedial classes, and/or given limited academic opportunities if they test poorly. In the Divergent, Legend, and Testing trilogies, unsuccessful test-takers potentially face similar consequences. That this culture of fear is constantly at work manipulating adolescent test-takers is clear, particularly in Roth's Divergent as Tris waits for the results of her aptitude test:

I would have to live on the streets, with the factionless. I can't do that. To live factionless is not just to live in poverty and discomfort; it is to live divorced from society, separated from the most important thing in life: community....

My mother told me once that we can't survive alone, but even if we could, we wouldn't want to. Without a faction, we have no purpose and no reason to live. (20) 
On one hand, Tris has been conditioned to believe that becoming factionless is one of the worst things that can happen as a result of the aptitude test, particularly because of the ostracism and lack of resources that will ensue. On the other hand, the fear of becoming factionless works to imbue the same test with a gravitas that makes it unlikely that any given test-taker will take such testing lightly, especially when they encounter those who have failed to do so and see the terrible conditions in which they live. Tris, for example, encounters the factionless on her way home from testing, lending weight to the fear she felt while waiting for her results:

This is where they factionless live. Because they failed to complete initiation into whatever faction they chose, they live in poverty, doing the work no one else wants to do. They are janitors and construction workers and garbage collectors; they make fabric and operate trains and drive buses. In return for their work they get food and clothing, but, as my mother says, not enough of either. (Roth, Divergent 25)

Dystopian Chicago is far from alone in this marginalization of unsuccessful test-takers.

As noted by Day in Lu's Legend, adolescent test-takers face similar consequences in The Republic as a direct result of their Trial scores: "You squeak by with a score between 1000 and 1249. Congress bars you from high school. You join the port, like my family. You'll probably either drown while working the water turbines or get steamed to death in the power plants" (7). As a result, high-stakes testing evokes a fear of failure in those attempting to navigate these tests in Legend. However, while "motivation by fear is the easiest form of motivation" because it triggers survival instincts, it is an intimidation-based tactic which "may get some knee-jerk results, but the worker will not be able to utilize his or her full potential" (Lucido 116). In other words, fear-based motivation actually inhibits students, particularly due to the psychological ramifications that may occur as a result. The fear associated with failure acts as form of 
discipline that produces "subjected and practiced bodies" (Foucault, Discipline and Punish 138).

These are vulnerable, docile bodies that are subject to manipulation.

"Dejection. Heartbreak. Failure": How Psychological Turmoil from High-Stakes Testing Leaves

\section{$\underline{\text { Students Vulnerable to Manipulation }}$}

In response to the stress of high-stakes testing and the fear of failing such tests, test-takers often have a difficult time coping. In the US, many education scholars have noticed that "students are very quick to paint a negative picture of themselves" (Lucido 107), and some have even argued that "children are under such pressure to pass these tests that they now practice trying to rid their psyches of a monster - the "test monster" (Johnson et al. 96). In interviews, many teachers indicate that this turmoil often manifests physically, with students hysterically crying, refusing to eat due to loss of appetite, and even shutting down out of fear. ${ }^{5}$ Some scholars even cite instances when "anxiety and stress in and around testing produces meteoric rises in headaches and stomachaches, sleep disturbance, increased absences, aggressive behavior, and depression" (Lucido 107).

When fear is not explicitly mentioned in Roth's, Lu's, or Charbonneau's trilogies, the protagonists are similarly experiencing psychological turmoil as a result of their fear of failing. One such passage is in Roth's Divergent as Tris waits for her results: "As the moments pass, I get more nervous. I have to wipe off my hands every few seconds as the sweat collects—or maybe I just do it because it helps me fell calmer. What if they tell me I'm not cut out for any

${ }^{5}$ In Stop High-Stakes Testing, Johnson et al. discuss an example of this sort of response in a ten-year-old boy: "On the final day of the fourth-grade ELA (English Language Arts highstakes test), a student didn't have number 2 pencils with him and he hadn't eaten breakfast - he had forgotten that there was one more day of the test. This poor ten-year-old had been stressed out enough for two days and now he had hit his breaking point. He was hysterically crying" (14). 
faction" (20). In this moment, Tris does not indicate that she is fearful in any straightforward way, but it is clear from her embodied response (the sweating palms), and her acknowledgement that her actions (wiping her palms every few seconds) help her feel calmer that fear tactics are at work here. Moreover, Tris' subsequent introduction of the consequence of failing the aptitude test and becoming factionless implies that her response to the possibility of failure is tied specifically to this consequence.

In Charbonneau's Independent Study, Cia more directly addresses these responses as she takes the University's entrance exam, acknowledging that "fear of failure urges [her] to press on" even as she becomes fatigued (11). While Cia ultimately decides to take a break and refuel, an option not always given or taken by test-takers who are too nervous to do so, her choice has dire psychological impact because she does not finish the exam. In fact, her agitation is so intense that "[her] failure to complete the exam makes it hard for [her] to hold [her] head up as [she] walk[s] out of the room" (13). The fact that Cia is not able to take time to rest during an exceptionally long examination and still finish it indicates that her society does not value student welfare. While the system of high-stakes testing in The United Commonwealth has significantly more brutal consequences for test failure than the US, it should be noted that testing in the US similarly ignores the wellbeing of students so that, as "the welfare and reputation of students is not protected...significant harm is being done to many students' self-worth and desire to learn" (Lucido 107).

When subjected to constant stress and fear through high-stakes testing, test-takers become vulnerable. This is not because of their youth or their intelligence level, but because they are in a prolonged state of panic and exhaustion. When students face similar pressures while undergoing testing in the United States, they may attempt to "stay in the classroom and try to 
deal with the anxiety," but many begin to lose their desire to learn, instead focusing on taking in and then regurgitating information that they are likely to see on a high-stakes test (Lucido 116). In fact, education scholars have noted that, "in a panic, the rationality of the neocortex is compromised ... even though a student's body may be physically present, he/she may have mentally "left the classroom"' (116). In other words, testing promotes a passive regurgitation of information rather than critical thinking.

Policy-makers often "refuse to admit hungry, sick, frightened children cannot compete with well-fed, healthy, safe children on test day," arguing instead that "achievement is low because children and their teachers aren't trying hard enough" (Johnson et al. 2). Furthermore, policy-makers refuse to change their approach regardless of the "findings from the most rigorous studies on high-stakes testing do not provide convincing evidence that high-stakes testing has the intended effect of increasing student learning" (Nichols 57). Policy-makers and testing proponents in these three trilogies take this position as well, offering help such as medical aid only as a way of discovering which students may be too weak to become members of the ruling class even if they do test well. ${ }^{6}$ However, the indoctrination of test-takers into the ruling ideology is so strong and the weaving of fear into the tactics that promote this ideology so seamless and ubiquitous that the adolescent citizens of these dystopian societies are manipulated, into navigating through a corrupt system that perpetuates itself.

${ }^{6}$ In Independent Study, policy-makers indicate that students can and should reach out if their workload becomes too difficult to manage. Cia, however, surmises that this is simply a ploy: "If I hadn't seen Obidiah after redirection, if I hadn't listened to my own recollections of The Testing, I'd feel reassured by her words. I would believe the expression of maternal concern on Professor Holt's face. But I did see, and the words on the recorder are etched in my memory. No matter what the course load, I will not complain. More, I will not fail” (71). 


\section{Discipline, Gratification, and the Lack of Choice in High-Stakes Testing}

In the Divergent, Legend, and Testing trilogies, fear is a disciplinary force that evokes in test-takers a fear of failing and makes them doubt themselves and their abilities. In fact, when Cia graduates from high school and does not initially get chosen for The Testing, she sees this as a failure despite the fact that her graduation is an achievement in and of itself. Instead of acknowledging this achievement, Cia instantly begins to doubt herself: "I have been preparing for this day for years and now it is over. As are my dreams for the future. No matter how hard I worked. I wasn't good enough to be chosen for The Testing" (Charbonneau, The Testing 15). It matters little to Cia that she has graduated. What matters more is that she was not chosen for the one thing that could give her more opportunity than "repairing broken-down tractors for the rest of [her] life," a prospect Cia finds depressing (18). As a result, Cia loses her sense of self, admitting only a few pages after her graduation that she has never felt so unsure of herself. In this way, despite the different stakes in the United Commonwealth, Cia is exhibiting the same doubt and vulnerability that Laura-Lee Kearns notes of students in the US whose perceptions of themselves are altered by high-stakes test scores to the extent that "they question themselves, their abilities" and "experience themselves as inferior to others" (123). It is in this state that fictional test-takers are most easily manipulated and interpolated into the ruling ideology that sees testing as necessity.

Nevertheless, discipline does not operate in isolation. As Foucault notes of discipline, "punishment is only one element of a double system: gratification and punishment" (Discipline and Punish 180). If we understand fear as a disciplinary force based on the punishing consequences dictated by policy-makers, then we can see the opening-up of opportunities for successful test-takers as the other side of Foucault's double system. For example, Day 
acknowledges the benefits of a high Trial score, noting that a perfect score likely leads to "lots of money and power," while a high score gives the test-taker "instant access to six years of high school and then four at the top universities in the Republic.... then congress hires you and you make lots of money" (Lu, Legend 7). It seems clear, then, that beyond the fear that coerces adolescent test-takers in the Republic to attempt to successfully navigate systems of high-stakes testing, benefits remain embedded in this test-based social hierarchy. As a result, in these novels, high-stakes testing functions as a "form of Pavlovian conditioning" in which "rewards and sanctions direct...student behavior" (Madaus et al. 140). Thus, the gratification aspect of this system works to undermine any objections by making test-takers consent to their own subjection. While parents of test-takers in the US have the option to "keep their children home from school on testing days" (R. Thomas 198) despite some of the consequences that such a choice might entail, parents and adolescents in Roth's, Lu's, and Charbonneau's trilogies appear to have no legal right to abstain from their respective testing systems. In fact, attempting to evade testing may result in automatic failure, punishment, or even execution. This is clearest in Charbonneau's trilogy when Zandri, an artist who has no interest in being a part of The Testing, asks whether she can refuse the "honor." The Testing official that has come to inform Zandri, Cia, and others of their selection replies simply that she doesn't have a choice because "the law states that every United Commonwealth citizen chosen must present him or herself for The Testing by the appointed date or face punishment" (Charbonneau, The Testing 22). He further explains that the United Commonwealth considers it a form of treason if an adolescent does not present his/herself, and that treason is punishable by death. Even in dystopian Chicago, where refusal is possible and, like failure, results in the test-taker becoming factionless, the coercion brought on by the fear of what it means to embody this marginalized position and the possibility of 
gratification should one attempt to successfully navigate the system of high-stakes testing often situates this option as the best possible choice.

Thus, high-stakes testing is a categorizing strategy used by those in power to determine which test-takers could potentially become members of the ruling class, the masses, or the marginalized. At the same time, fear of failure, possibility of gratification, and indoctrination into the ruling ideology come together to position high-stakes testing as both the best method for maintaining the status quo and also for establishing individual success and happiness. This position is maintained because it provides opportunities that would not be available to those who do not undergo testing. Although failing or testing poorly erases or reduces these opportunities, the very possibility of greater access to resources, education, and choice helps to convince adolescent test-takers that their best option is to take their chances with high-stakes testing. As noted by assessment scholar Asao Inoue, these test-takers ultimately "consent to their own domination by the ruling classes" (109). Moreover, they do so in order to convince themselves that they have some control over their lives, even as this sense of control is an illusion. In doing so, test-takers play directly to the desires of the ruling class. The reality, however, is as Cia notes in Charbonneau's Independent Study: "the one thing [test-takers] have in common is [their] realization that [they] control nothing" (17).

\section{The Semblance of Agency}

The question of agency often comes up in YA literature, especially in dystopian literature. As explained by Naomi Jacobs, "theorists usually define agency as including both the capacity to choose for oneself and the capacity to act upon one's choices," but, as Jacobs later notes, "both capacities are compromised in dystopia because the spheres of thought and of action are so severely constrained" (92). Moreover, as observed by Paolo Freire in Pedagogy of the 
Oppressed, "one of the most characteristic and ubiquitous features of the world as experienced by oppressed people is the double bind-situations in which options are reduced to a very few" (2). Thus, it is not surprising that the citizens of the dystopian societies in the Divergent, Legend, and Testing trilogies are similarly oppressed in that they are offered few choices in a situation in which any choice is better than none. In this way, then, what the test-takers in these primary texts have is not agency, but agency within the parameters set by those in power. But this is not unique to the dystopian conditions of these texts. In fact, Horace Lucido argues that with high-stakes tests in the US, "the focus is on suppressing independent thinking in an educationally confined environment" which "unduly denies student choices" (88). High-stakes testing is so normalized, however, that students do not realize the level to which they are oppressed.

Due to a combination of the indoctrination I have examined throughout this chapter, the fear evoked by failure, and the possible gratification available through testing, Tris, June, and Cia believe, as Jacobs notes of other dystopian citizens, that "they are freely choosing and freely acting from a position of integrity" (93). However, they are merely following the prescriptions of the ruling class, a phenomenon common in the protagonists of dystopian novels. Moreover, that these protagonists consider themselves agentic is "a mark of the extent to which the subject exists in a state of subjection" (93). In other words, so heavily interpellated are these adolescents that they cannot know just how oppressed they truly are. In this way, these trilogies show that, rather than having agency, these protagonists are given a semblance of agency that encourages them to remain within the systems of testing that hinder them. That is, rather than having actual choices, these adolescents are forced "to choose among the many bad options presented to [them]" (Basu et al. 47). Any agency these protagonists have is an illusion. As Tobias notes of the factions in Roth's Allegiant: "They gave us the illusion of choice without actually giving us a 
choice" (463-64). This is an illusion that many vulnerable and indoctrinated test-takers believe, and they thus choose to remain within high-stakes testing systems.

Ultimately, then, the educational Ideological State Apparatus, its method of reproducing itself (high-stakes testing), the tactics that support this method, and the overarching ruling ideological these all support have one aim: "to convey to adolescents that they are better served by accepting than rejecting the social institutions in which they must live" (Trites 27). This may also be true of high-stakes testing systems in the US since assessment, a kind of high-stakes testing, "moves students, teachers, parents, and administrators to consent to things in schools that benefit primarily a dominant group, somehow masking the contradictory outcomes of what they are consenting" (Inoue 109). However, the higher stakes in these dystopian narratives position test-takers as people "who must nonetheless learn to play the game if [they] are to survive" (Alexander and Black 230). Adolescent test-takers navigate high-stakes testing because "heroes get more options for their future" (Charbonneau, Graduation Day 106). In other words, while a lack of awareness certainly plays a role in any given test-takers' decision to go through testing in the Divergent, Legend, and Testing trilogies, the ideological control of the educational ISA coupled along with the physical intimidation of the RSA coerce adolescents to consent to their own subjugation in order to heighten their privileges. Thus, test-takers are embedded into the standing social hierarchy propagated by high-stakes testing under duress while the power and role of policy-makers is steadily reinforced. 


\section{That's What the Government is Doing, "Conditioning People to Be Happy Under its}

\section{Thumb": High-Stakes Testing as a Method of Control Through Ideological Indoctrination}

In Lu's Champion, Day encounters the Chancellor of the Colonies. The Chancellor is not interested in the liberation of those that were marginalized by the Trial in the Republic. Instead, he plans to modify but continue the ideological manipulation of the Republic: "You have to be careful with [people]—you have to find a way to make them think that you are catering to their every whim. The masses can't function on their own. They need help. They don't know what's good for them" (309). While the Chancellor does not specify whether his system of subjection will depart from the Trial, he clearly intends to continue offering some form of reward as a way of maintaining control over the citizenry by making them think that it is in their best interest to comply. Also clear in this interaction is the Chancellor's single goal: control. Similarly, systems of high-stakes testing shift the power to policy-makers, allowing them to control their subjects and perpetuate all the methods, tactics, and manipulations noted throughout this chapter.

When speaking of control, Trites relies on Foucault to explain that, in systems of subjection, "all individuals hold a certain amount of power that they voluntarily relinquish to exist under the rule of a governing body" (Discipline and Punish 4). This is also true of the protagonists of Roth's, Lu's, and Charbonneau's test-based dystopias, particularly when characters become less able to make their own decisions, enabling those in power to continue controlling them. This is a condition of various systems of high-stakes testing. In fact, many education scholars note that "continually being subjected to a regimen of regulation and limits suppresses the human exercise of free will" (Lucido 83). In this way, not only are choices limited, but also the consistent lack of real, unprescribed choice offered to adolescent test-takers hinders their decision-making abilities. As Freire notes of the kind of prescriptive choice that is 
offered though high-stakes testing, "every prescription represents the imposition of one individual's choice upon another, transforming the consciousness of the person prescribed to" (47). While not explicitly referring to Freire, Lucido argues that, in situations similar to what Freire has observed, "students do not learn how to properly manage choices and options, because the focus is on being obedient to the dogmatic program each school has instituted to raise test scores" (88).

While these theorists speak to systems of high-stakes testing in the US, the protagonists of the Divergent, Legend, and Testing trilogies face similar issues. As observed by Cia in Independent Study, test-takers are rarely given the opportunity to exercise their free will within the educational ISA. In fact, when Cia and others take the University entrance exam, she reflects on her father's career, remarking that she "hadn't realized the decision had been made for him" and wondering "if he had been the one doing the choosing, what would his choice have been?" (22). Moreover, Cia and her classmates are told that "while each of [them] has a preferred choice," they should trust those in charge of the Exam to "slot [them] into the career path that best suits the needs of the country" (8). In other words, the protagonists of the Divergent, Legend, and Testing trilogies are not only denied agency, but they are encouraged to believe that this lack of agency is in their best interest.

As a result of this and other similar moments, those in power steadily and consistently condition test-takers to become passive recipients of adult choice to such an extent that they are uncomfortable making their own decisions. For example, when Tris receives a Divergent test result, meaning she does not fit just one of the given approved factions, she is distraught. She realizes that this result means she can choose any faction she has an aptitude for. In other words, "she is disappointed because she doesn't want to choose a faction herself; Instead, she wants the 
choice to have been made clearly for her by the aptitude test, so she can finally know who she is and where she belongs" (Basu et al., 24). Thus, after years of grooming, adolescent test-takers become passive recipients of adult choice because they have so rarely been agents of their own lives out of fear or indoctrination. Moreover, by subjugating test-takers in this way, policymakers can further reinforce the control they possess and promote through the ruling ideology.

\section{Conclusion: The Implications of Ideological Control}

Ideological indoctrination is difficult to break from because it requires a dissociation from truths that one has long believed to be self-evident. As noted by Madaus and Horn with regard to high-stakes testing, for example, many people refuse to "accept even the simplest and most obvious truth if it be such as would oblige them to admit the falsity of conclusions which they have proudly taught to others, and which they have woven, thread by thread, into the fabric of their lives" (55). In the case of these primary texts, adolescent test-takers adapt to the repression of high-stakes testing as a direct result of the reasons examined in this chapter, choosing to navigate this system in spite of its repressive qualities. Madaus and Horn speak to the strength of ideological conditioning on test-takers and there are various moments in these dystopias that do the same. For example, in Allegiant, Tris notes that Evelyn, a woman who takes over dystopian Chicago after Jeanine's death, "tried to control people by controlling weapons, but Jeanine was more ambitious-- she knew that when you control information, or manipulate it, you don't need force to keep people under your thumb. They stay there willingly" (346). In other words, Tris has realized that if people in power can control the way the masses think, then they can retain their position of power with little to no resistance. Moreover, in Lu's Prodigy, the leader of the Patriots, Razor, explains that the goal of this rebel organization, "is not only to kill Anden, but to turn the country completely against him, so that his regime will be doomed even if 
our plan fails" (46). While not explicitly evoking ideology and its role in social control, the Patriots' plan implies that killing someone in power is not enough, not when many people may, due to indoctrination, support that person and his or her policies. In fact, it is this very phenomenon that speaks to the primary issue with high-stakes testing. As a methodology and through its gatekeeping categorization, high-stakes testing maintains the status quo, reproducing the ruling class, the masses, the marginalized, and the structures that enable this reproduction.

As explained by David Seed in "Cyberpunk and Dystopia: Pat Cadigan's Networks," "the more the dystopian text includes a dimension of debate, by characters and within the narrative structure itself, about the values and directions of its future society, the more justified we would be in reading the narrative as a critical dystopia" (69). That is, a critical dystopia, unlike a more traditional dystopia, has characters who challenge the dystopian tendencies of their own societies. In my primary texts, this is true of the protagonists as well as their immediate companions. However, even the protagonists of these texts do not begin each narrative as rebels. In fact, due to the indoctrination to which these characters are subjected, the reader is at first unaware, as the characters are, of the dystopian nature of societal structures, such as high-stakes testing. The implied reader's cognitive estrangement from this world that is similar to theirs is at first forestalled until protagonists begin to question their world. This questioning, however, is in turn forestalled by the indoctrination of the educational ISA in these test-based societies.

As Bradford et al. explain about dystopian societies, the ideological control that citizens may face helps ensure that many of the dystopian tendencies of their societies become "practices that are internalised without question until the characters find themselves in conflict with society and thus needing to rethink social values" (22). In other words, adolescent test-takers in these societies internalize the ruling ideology and remain embedded in the social hierarchy promoted 
by high-stakes testing until something causes them to conflict with these structures. However, given the extent to which test-takers are, as common in dystopian novels and referred to by Raffaella Baccolini and Tom Moylan, "unreflectively immersed in the society," such conflict is not always enough to enable these characters to take action (5). In fact, and as I will argue in Chapter Four of this thesis, the protagonists of test-based dystopias often require a long-term process of dissociation from their society's norms to even have the possibility of acting against these norms. However, breaking the indoctrination examined in this chapter or, at the very least, acknowledging this indoctrination, is a necessary first step for characters to critique their nation's high-stakes testing ideology. 


\section{CHAPTER II: “WRONG ANSWERS WILL BE PENALIZED”: HOW THE REPRESSIVE}

\section{STATE APPARATUSES FURTHER PROMOTE CATEGORIZATION}

\section{THROUGH HIGH-STAKES TESTING}

\section{Introduction}

In chapter one, I argued that the systems of high-stakes testing in the Divergent, Legend, and Testing trilogies operate to cyclically propagate the dominant ideology of the ruling class within the educational ISA. I further argued that policy-makers in support of high-stakes testing systems in these texts manipulate test-takers and citizens in their respective societies through propaganda, data manipulation, and evoking fear in test-takers, tactics that education scholars have argued are similarly used by policy-makers in the US to promote high-stakes testing but which are taken to dystopian extremes in my primary texts. Departing from education scholarship that primarily examines the methods of ideological control examined in the previous chapter, the dystopian societies of the Divergent, Legend, and Testing trilogies illustrate how, when ideological control fails, the status quo may still be maintained through the repression and marginalization of those who fail to take their place in the reproduction of the ruling ideology.

In this chapter, I will argue that the testing systems in the Divergent, Legend, and Testing trilogies have violent and repressive means of ensuring their own reproduction. While these means depart considerably from the ways in which high-stakes testing is enforced in the US, because characters who fail or test poorly are ostracized, tortured, and/or killed, parts of the logic utilized by policy-makers in these primary texts to support these deadly consequences of testing have underpinnings of a logic somewhat similar to that which is employed by high-stakes testing proponents in the various testing systems of the United States. It is my hope that this chapter will further elucidate the ways in which high-stakes testing operates as a method of control through 
the interaction of the educational ISA and various Repressive State Apparatuses (RSA).

Moreover, I hope to demonstrate that these novels position marginalized rebels as people who are bound to fail, which is a problematic position given that those more comfortably embedded in the social hierarchy are unlikely to rebel and instigate change.

In The Testing, the protagonist, Cia, and others make it through the first round of The Testing and are subsequently addressed by Dr. Barnes before the start of the next round:

"Leaving a problem unsolved is better than giving an incorrect answer. Wrong answers will be penalized" (Charbonneau 105). Two readings are possible here. The first is the most obvious: that Dr. Barnes is referring to the various consequences that accompany an incorrect response in the second round of The Testing. ${ }^{7}$ The second, more metaphorical reading of this quotation, however, is that Dr. Barnes’ warning echoes the larger social structure of the United Commonwealth, and similarly those of Dystopian Chicago in Divergent and the Republic in Legend, wherein citizens take on their assigned roles in the reproduction of the ruling ideology or face marginalization, disempowerment, or elimination. In other words, choosing a path other than that which is laid out for any given test-taker based on their categorizing test score is a "wrong answer," and choosing such a path is unacceptable.

I will examine how the tactics discussed in chapter one, particularly policy makers' propagation of the fear of testing poorly due to the consequences that accompany such "failure," are, in some ways, dependent on the model identified by Louis Althusser's RSA. In fact, as Althusser notes of Ideological State Apparatuses, the educational ISA "largely secure[s] the reproduction specifically of the relations of production, behind a 'shield' provided by the

${ }^{7}$ I will address these consequences in more detail throughout this chapter, but they include poisoning and having a metal rod inserted into one's eye. 
Repressive State Apparatus" (15). In other words, while the ideological control identified in my first chapter is key to maintaining the status quo and reproducing the ruling ideology and the means of reproducing said ideology, the RSA can help maintain this control, particularly in dystopian narratives wherein repressive acts such as beatings or imprisonment are significantly more common. In this chapter, I will clarify how the hyperbolic RSA of the Divergent, Legend, and Testing trilogies work to fortify the ideological control of the educational ISA and vice versa, focusing specifically on how these trilogies call attention to the potential problems that may arise from this interplay by demonstrating the violence committed against those who choose the "wrong answers" in these societies.

The Interplay of the Educational ISA and Repressive State Apparatuses (RSA) In "Ideology and Ideological State Apparatuses," Althusser argues that the various Ideological State Apparatuses are necessarily connected to the Repressive State Apparatuses, with each contributing to the propagation of the ruling ideology. Althusser explains that the "ruling class holds state power ... and therefore has at its disposal the Repressive State Apparatus ... this same ruling class is active in the Ideological State Apparatuses" (13). To begin with, then, the educational ISA and the RSA are interconnected in the sense that they are both under the jurisdiction of the ruling class, thus implying that they support the reproduction of the ruling ideology. Working to enable the educational ISA and others like it, the repressive state apparatus contains "the Government, the Administration, the Army, the Police, the Courts, the Prisons, etc." (11) and functions "as a force of repressive execution and intervention" in the interest of the ruling class (8). In other words, while the ideological manipulation of the educational ISA keeps adolescent test-takers embedded in the test-based social hierarchies of each dystopian society through coercive measures, the RSA bolsters this ideological control by 
providing the material basis for the fear tactics noted in chapter one. Since "every State Apparatus, whether Repressive or Ideological, 'functions' both by violence and by ideology," the educational ISA and the RSA are interdependent, each working to bolster the success of the other in different ways (12).

The primary difference is that the RSA is more heavily focused on the body. In Discipline and Punish, Michel Foucault observes that "systems of punishment are to be situated in a certain 'political economy' of the body: even if they do not make use of violent of bloody punishment, even when they use 'lenient methods' involving confinement or correction, it is always the body that is at issue" (25). The RSA, then, with capillaries such as the government, prison system, army, and police is ultimately a system of punishment in that it operates to maintain order as established by the ruling class through punishments such as imprisonment. In my primary texts, however, the role of the RSA as a system of punishment is clearer due to the dystopian forms that these punishments take such as torture and death. Given that even some more mild forms of punishment, such deprivation of resources, impact the body, the RSA can be classified as a conditioning system of sorts that provides the material threat inherent in the fear tactics used by the ISA.

The RSA helps to position students as malleable, capable of being shaped according to the needs to the ruling class operating within the educational ISA and RSA. In the words of testing scholar Wayne Au, high-stakes testing positions test-takers as raw materials that can be bent and "produced like commodities according to specified standards and objectives" (Taylorism 27), thus implying that "systems of high-stakes, standardized testing are therefore aimed at discipline as part and parcel with control" (35). As a methodology, then, high-stakes testing helps facilitate the aims of the ruling class through categorization, the educational ISA 
helping to indoctrinate students into the social formation that perpetuates the ruling ideology, while the RSA subjugates any and all adolescent test-takers who do not willingly take on the roles assigned to them by their test scores. Ultimately, the goal of the RSA in these dystopian texts is control through the maintenance of the status quo. Thus, as noted in chapter one, the RSA functions like the educational ISA in that it functions, as argued by Roberta Trites "to convey to adolescents that they are better served by accepting than rejecting the social institutions in which they must live" (27). These trilogies show that the RSA achieves this through the violent, repressive acts that prevent any divergence from the status quo.

\section{Potential Gratification Versus Discipline: The Logic of Using Punishment as Motivation in Systems of High-stakes Testing}

In The Paradoxes of High-stakes Testing, George Madaus, Michael Russell, and Jennifer Higgins argue that there are three assumptions underlying high-stakes. ${ }^{8}$ The first is that "the greater the reward offered for success or the punishment for failure, the harder students ... will try" (16). In other words, policy-makers in charge of testing systems in the US believe that the dual system of discipline and gratification can provide a source of motivation that helps ensure students remain embedded in test-based social hierarchies. However, the logic of this assumption is flawed, and its flaws are made clear in the second assumption underlying high-stakes testing: "all students will respond to the rewards and punishments in essentially the same way" (16). Given the diversity of the student population in schools across the US (in terms of race, socioeconomic status, emotional sensitivity, mental health, etc.), this assumption is both generalizing and damaging. The third assumption of high-stakes testing, which will inform my

${ }^{8}$ I will focus on the first assumption here. I will reference the second later on in this chapter and both the third in chapter three. 
third chapter, is that "student ... effort is maximized when rewards are distributed on a competitive basis" (16). Despite the obvious interplay between these three assumptions, I'd like to first address the implications of the first assumption on the systems of high-stakes testing in the Divergent, Legend, and Testing trilogies.

\section{$\underline{\text { Utilitarianism in the Dystopian Context }}$}

To begin with, the first assumption denotes how high-stakes testing functions as a sort of Pavlovian conditioning, using two opposite ends of a binary structure (reward and punishment) to ensure that test-takers remain within testing systems because they are putatively in students' best interest. As discussed in chapter one, this is especially true within my primary texts. Due to the dystopian nature of these texts, the punishments inflicted upon test-takers in Chicago, the Republic, and the United Commonwealth are much more notorious and thus the stakes of the various high-stakes tests in these novels are much higher than those of high-stakes tests in the US. That these stakes are high is clear from our first introduction to the aptitude test in Roth's Divergent: "I stare into my own eyes for a moment. Today is the day of the aptitude test that will show me which of the five factions I belong in. And tomorrow, at the Choosing Ceremony, I will decide on a faction; I will decide the rest of my life; I decide to star with my family or abandon them" (2).

The aptitude test has the potential to shape Tris' life. Certainly, this is the case throughout the various testing systems in these novels. However, the plights of the factionless in Dystopian Chicago, genetically damaged individuals in the Bureau, people of low socioeconomic status in Lu's trilogy, and those in smaller colonies of Charbonneau's trilogy have similarities to what adolescents who test poorly in the US may face. In fact, as observed by R. Murray Thomas in 2005, "students who fail those tests and thus lack diplomas find job opportunities and chances 
for higher education very restricted" (254). While much has changed since R. Thomas wrote, this quotation could easily reflect the plight of the factionless who live below the poverty line, ostracized and starving because they fail to adhere to the test-based factions that organize the citizenry of Dystopian Chicago.

The dystopian societies of the Divergent, Legend, and Testing trilogies are all coping with various different post-apocalyptic conditions including environmental catastrophe, the aftereffects of large-scale war, or a mixture of the two. Thus, one of the reasons for the higher stakes of the aptitude test, the Trial, and The Testing respectively, is scarce resources. That this is true across all three YA dystopias is further seen in the uneven allocation of the plague vaccine between the rich and poor sectors of the Republic in Lu's trilogy and in Cia's observations of the limited resources of various United Commonwealth colonies including her own. For example, Cia discerns that "from the way the twins have piled their plates and the unhealthy cast to their skin, I'd guess there still isn't enough food to go around" (Charbonneau, The Testing 86) and that, in the case of larger colonies not as close to water as Five Lakes, "maybe with so many people it's just harder to stretch the resources they have ... because a large part of their adult populations works on creating batteries and electrical supplies instead of developing the land" (70). While both observations imply that resources are, indeed, limited, the latter instance also shows that, in test-based dystopian societies like that of the United Commonwealth, each subsection of society has a purpose in the maintenance of society as a whole. The same can be said of the different test-based categories of the Divergent and Legend trilogies.

Despite these similarities, YA dystopias imagine "a postapocalyptic or postcatastrophe society in which resources are limited and must be tightly controlled," and thus "these are worlds in which the severity of the various sorting measures might make a kind of sense" (Alexander 
and Black 227). Inherent in this description of dystopia, then, is the impact of these postapocalyptic scenarios. In an attempt to reconfigure society, policy-makers in these novels take on a utilitarian stance in which the ends justify the means, allowing policy-makers to sacrifice those who do not, in their view, serve a purpose in the rebuilding of their respective societies. Given that these new, rebuilt societies are predicated on the social stratification provided by high-stakes testing, a lower test score leaves test-takers open to becoming that sacrifice. Thus, policy-makers practice "subjugation, exile, and diaspora," which are, as noted by Clare Bradford, Kerry Mallan, John Stephens, and Robyn McCallum, "attributes of dystopia" (27).

Dystopian conditions in these novels call attention to how a utilitarian stance can be dangerous because policy-makers in each society often use such a stance to excuse their dehumanizing actions. For example, when discussing the high death toll of The Testing, Dr. Barnes reminds Cia that the president of the United Commonwealth "believes that those losses are minor compared to the number of casualties we'll incur if our leadership should falter" (Charbonneau, Graduation Day 264), exemplifying the exact way in which the repressive actions of the RSA can be excused by the leaders of a society in recovery. The ultimate goal is control and maintenance of the status quo.

In Prodigy, Anden reminds June that the Trial was originally "supposed to encourage hard-work and athleticism, to produce more military-quality people" while also providing a method by which the Government could "weed out the weak and the defiant" (218). In other words, the Trial is meant to find the best of the best while punishing those that did not meet the needs of this militaristic society. However, by hierarchizing test-takers into those who do and do not meet the needs of the Republic, policy-makers inherently create an entire class of people who 
are marginalized because they don't fit within the narrow parameters dictated for them.

Moreover, the fact that the same high-stakes test that began as a genuine, albeit flawed, way of categorizing adolescent members of society was gradually "used to control overpopulation" implies that even systems established with good intentions, can be manipulated into something corrupt over time, especially in times of turmoil where the stakes are high (218).

Reading these texts in tandem with education scholarship indicates that high-stakes testing, and its affiliated consequences, are "a system that operates in the process of training and correction" (Foucault 180). Moreover, given that the aptitude test, the Trial, and The Testing are "not designed to identify students' passions and interests" and instead "geared toward identifying how these young people can be sorted into a group where they will be of the most use to society" (Alexander and Black 219), it is clear that any system of high-stakes testing that is so heavily predicated on consequences to motivate the test-takers, works to embed the body in a "system of subjection" so that it may remain a "force of production" (Foucault 26). In other words, exposure to the dystopian depictions of the consequences of high-stakes testing as upheld by the RSA helps foreground how systems of high-stakes testing are largely a form of social control. The extreme disregard for test-takers in deadly dystopian conditions further illustrates that not only is high-stakes testing a method of control, but it is also one that self-perpetuates by policing anyone who fails to adhere to the limited parameters set out by the ruling class. 


\section{“Unless They Saw Something Dangerous in Him": Policing Those Who Threaten to Challenge the Ruling Ideology}

\section{"Because You Did Too Well": The Danger of Being Special}

The first assumption of high-stakes testing, which posits that discipline can productively motivate students, is flawed in various ways. However, its flaws are not initially discernible. In this section I'd like to work backward to argue that, in depicting the persecution of even those that test well in the Divergent, Legend, and Testing trilogies, these dystopian novels help reveal that the ulterior motive of punishment in high-stakes testing is not the improvement of society, but instead the maintenance of it as preferred by those in power. Given this hidden motivation, high-stakes testing, which essentially functions as a publicized monitoring system, can be used to weed out those that the ruling class would deem undesirable, such as those with low test scores or undesirable traits like defiance, and sets them up for marginalization.

Testing theorists Dale D. Johnson, Bonnie Johnson, Stephen J. Farenga, and Daniel Ness argued that, in the US, "high-stakes testing enthusiasts pretend that all is well with school facilities and at home and that achievement is low because children ... aren't trying hard enough" (2). In doing so, Johnson et al. touch upon the first assumption of high-stakes testing while also implying that lack of motivation isn't the problem. Instead, Johnson et al. argue that the testing system itself and the ideology that cyclically promotes it are the issue. Certainly, this appears to be true in the Divergent, Legend, and Testing trilogies given that those in power persecute even Tris, Day, and Cia, individuals who, by all means, test well. Tris, for example, can manipulate the simulations that encompass much of the testing she must undergo during Dauntless initiation. The time Tris spends unconscious is incredibly low as a result, marking her as an exceptional initiate. As Tobias points out, Tris is special because she "got out three times 
faster than the other initiates" and that "whatever [she is], [she's] not a failure" (Roth, Divergent 238). Similarly, Day is an unknown prodigy who got a perfect score on the Trial even though he is listed as having failed in the public record. Moreover, throughout Lu's trilogy Day is regularly described as having physical skills and attributes that are "on par with the top students at Drake" (Lu, Legend 135), indicating that the physical part of his Trial was satisfactory as well.

Additionally, Cia consistently excels in all the high-stakes tests she takes as part of The Testing and at the University. Moreover, repeatedly Cia exceeds the expectations of The Testing officials.

Given this and the self-proclaimed desire of testing officials to find adolescents with skills that could help maintain/rebuild society, one would expect these individuals to be treasured by a society that so clearly wishes to utilize talents such as theirs. Instead, however, Tris, Day, and Cia are all persecuted. For Tris, this becomes clear from the first moment she discovers she is Divergent, meaning that she does not fit into any one faction and instead shows an aptitude for multiple factions: "I deleted your aptitude results from the system immediately and manually logged your result as Abnegation. But make no mistake — if they discover what you are, they will kill you" (Roth, Divergent 258). Tris receives this warning from Tori, a woman whose brother was Divergent and was killed by the Dauntless as a result. Tori's immediacy in deleting Tris' results speaks to the danger of being Divergent in dystopian Chicago despite the advantage it gives Tris in the various simulation-based texts she must take. Likewise, Day is a fugitive, his name on jumbotrons across the Republic in infamy. While Day's fate seems deserved at the beginning of Legend, however, we soon discover that he didn't begin stealing until he was told he failed his Trial, was experimented on, and left for dead. Cia, on the other hand, is regularly given harder assignments/class loads than her peers. She is also consistently surveilled by testing 
officials who, in turn, ask other students to watch her and indicate any defiance with regards to The Testing or the United Commonwealth that perpetuates it.

If, according to their own arguments, the success of society is dependent on utilizing the best and brightest while disregarding those who are not useful to society, then why do policymakers in these dystopian novels persecute the very students who could most help their respective societies? In other words, as June observes of Day's false score and subsequent attempted termination, “This isn't in line with Republic values. Why waste a prodigy in this way?” (Lu, Legend 201). Even June, revered as the Republic darling and accepted prodigy, experienced some dissonance in processing Day's persecution. In this instance, June's understanding of the Republic's altruistic and reciprocal values seem antithetical to Day's punishment, signaling that perhaps the Trial might not accurately differentiate who will be useful within the society. However, while policy-makers' utilitarian stance may function to excuse the extreme consequences of high-stakes testing, it also provides the basis by which those in power can excuse the same deadly acts as aimed at those whom the ruling class sees as a threat. As Cia surmises toward the end of The Testing, "any government that is willing to stand by and watch as candidates commit suicide or ingest poisonous plants because they gave a wrong answer won't shrink from eliminating a man they might see as a threat" (199). To put it differently, policymakers in these YA dystopias, still holding the same utilitarian belief that the ends justify the means, eliminate any perceived threat to their power, enabling the continuous reproduction of the ruling ideology and the means of the reproduction of that ideology. Thus, any individual who fails to fall, through their test results, within a very limited range of abilities treasured by the ruling class, is, as asserted by Naomi Jacobs, "reprogrammed, exiled, or killed, so that the social 
fabric may maintain its impenetrability" (92). This does not exclude those who, like Tris, Day, and Cia, exceed testing expectations.

What this suggests, then, is that despite the reasoning policy-makers often espouse, their true aim is to police all members of their society so as to maintain social control through the hierarchy created by high-stakes testing, a hierarchy threatened by "special" test-takers like Tris, Day, and Cia. Tris, for example, challenges the test-based faction system, in part, by her Divergent status which indicates that the faction system, which does not account for Divergence, is flawed. Beyond that, however, Tris' ability to keep control during simulations implies that Divergents can't "be controlled. And it means that no matter what [the ruling class does], we will always cause trouble for them" (Roth, Divergent 442). Day, on the other hand, is persecuted not because he's "the most dangerous criminal," but because he is the "most wanted. $[\mathrm{He}]$ makes [the Republic] look bad" (Lu, Legend 2). Day's acknowledgment of his own position in society is interesting because it signals that his persecution is, at least in part, due to his postexperimentation antics because he outwardly challenges the Republic, thus questioning its impenetrability quite publicly. However, Day's initial victimization was not in response to his actions as a fugitive. Instead, as June deduces upon discovering Day's prodigy status in Legend, his attempted elimination and subsequent vilification is a result of "Some defiant spark, the same rebellious spirit he has now. Something that made [policy-makers] think it'd be riskier to educate him than to sacrifice his possible contributions to society" (202). Again, this suggests that policymakers care not about the growth of society, per se, but the growth and reproduction of a society in line with the ruling ideology that is in turn supported and maintained by the social stratification of high-stakes testing. 
The logic behind policy-makers' limited parameters is best shown in a conversation between testing official Dr. Barnes and Maylin in Independent Study. After failing the Entrance Exam, Obidiah is relaxed and blissful, indicating that perhaps his failure was planned so that he could leave the University. Unfortunately, Dr. Barnes redirects (kills) Obidiah. When Maylin questions these deadly methods, Dr. Barnes explains that "Revitalization requires unity. Students with Obidiah's potential cannot be allowed to work outside the framework of the Commonwealth. People would start turning to them for leadership instead of following the course our current leaders have set out for us. That kind of disharmony would undermine everything we have done for the last one hundred years" (Charbonneau, Independent Study 29). In other words, it is not enough to test well. Test-takers must also adhere to the desires of the ruling class and fit within a narrow window of success in order to be considered both useful and safe for society. If not, they may fail and die, or they may prove themselves to be too smart or defiant and die anyway. Thus, when Cia asks why testing officials are trying to overwhelm her with her coursework far more intensive than that of her colleagues, Michal responds that it's "because [she] did too well" (156), signifying that testing officials want to weed her out, if possible. In this way, the narrow, often unspoken parameters set by policy-makers and testing officials, which are often interchangeable, police all peoples subjected to high-stakes testing. In demonstrating the ways in which policy-makers may employ utilitarian logic to vilify and then eliminate test-takers who do not fit within their narrow expectations, these dystopian novels imply that the real reason behind using punishment as motivation in high-stake testing is to categorically identify individuals who threaten the status quo. In fact, Susan Louise Stewart argues that, "the adults sacrifice the young - those who are considered to be the future of humanity - in order to teach the young a lesson about the future" (162). The lesson is that falling 
in line is the safest choice. Policy-makers make this clear in their use of the public execution to silence those who challenge testing and its subsequent categorization.

"They Will Make an Example of Me": The Role of the Public Execution in Homogenization

In the words of Foucault, "the public execution is to be understood not only as a judicial, but also a political ritual" (47), one that functions as a modest kind of discipline in policing individuals. It is modest because the public execution allows those sacrificed in the propagation of the ruling ideology to be acknowledged but destroyed, helping to further police others who might have similar disruptive intentions. That this publicized display of the ruling class' power is effective can be seen in Cia's growing understanding of the consequences of The Testing: “Malachi's bloody face flashes in front of me. Ryme's bulging, bloodshot eyes. Annalise's now empty chair. Judging by Dr. Barnes' serious expression and the tone of his voice, there is no doubt what penalty a failing grade will bring" (Charbonneau, The Testing 135). We can see that, in this moment, Cia recalls the different executions she has witnessed during The Testing. It means very little that policy-makers did not directly cause these deaths. In fact, because these deaths occur in a system in which surveillance is the norm, policy-makers are nonetheless implicated because they could have intervened if they wanted to. Policy-makers thus use such deaths in systems of high-stakes testing as political moves to foster fear and obedience. As such, these deaths can still be considered public executions and part of the RSA. Moreover, when Day is under Republic custody and awaiting his death, he notes that the Republic intends, with its public execution, to "make an example of [him]" (Lu, Legend 192). That Day escapes is of no consequence either because, using the manipulative tactics discussed in chapter one, the Republic doctored footage of the death of Day's brother and circulates it to achieve the same ends: control through fear. 
The disciplinary practices of the RSA instill fear into test-takers while the public execution reminds others of the risks of challenging the ruling ideology. As a result of this combination, policy-makers are able to effectively control the citizens of their societies without having to kill every single person who considers deviating from the status quo. Moreover, in combining the ideological control discussed in chapter one with the possibility of physical repression at the hands of the RSA, the ruling class helps ensure a homogenization of the population by eliminating or marginalizing anyone who does not fit into the narrow confines of their expectations. In fact, Steven Lewis and Ian Hardy argue that punishments like the ones ever present in the background of systems of high-stakes testing allow for "the management of individual conduct through the imposition of normalised expectations of behaviour" (248). As a result, policy-makers can dictate the kind of people that are promoted, through high-stakes testing, into the ruling class, while simultaneously marking others as failures and marginalizing or eliminating them.

Thus, the disciplinary actions of the RSA, made more noticeable in their extreme, dystopian representations and once thought to be a method of motivation, are revealed to be a way of maintaining control. Moreover, as Raffaella Baccolini explains, the "function [of dystopia] is to warn readers about the possible outcomes of our present world" (115), that these narratives all include some version of the consequences that exist to discipline test-takers in systems of high-stakes testing in the US speaks to the dystopian tendencies of the latter. Furthermore, that these dystopias, purportedly "located in a negatively deformed future of our own world" (115), have any consequences that coincide with those existing in the US implies that even high-stakes testing in the US is a method of control that uses punishment to homogenize test-takers. Despite significantly more lenient punishments in the US, the Divergent, 
Legend, and Testing trilogies call attention to the indirect disciplinary methods that may result from the reward-punishment model used in systems of high-stakes testing.

\section{The Effect of Discipline: Self-Policing, Defeatist Mentalities, and Unsuccessful Rebellion}

\section{How Surveillance Fosters Self-Policing}

In creating a system that categorizes test-takers into successes and failures, policy-makers inherently prescribe that individual behavior and intelligence should fit into a narrow margin that is accepted within the ruling ideology. In the Divergent, Legend, and Testing trilogies, anyone falling above or below this narrow margin is repressed in the ways described throughout this chapter, but even punishments in systems of high-stakes testing in the US are not exempt from this phenomenon. Thus high-stakes testing, through the use of punishments and like other systems of discipline, "introduces ... the constraint of a conformity that must be achieved" (183). In order to avoid the consequences of high-stakes testing, then, individual test-takers self-police in order to ensure that they do not step outside the bounds of what the ruling class deems acceptable. In this way, those in power don't have to eliminate every single person that has the potential to challenge the ruling ideology that is maintained through the test-based categories. Instead, by enveloping test-takers in web of surveillance, policy-makers ensure that most individuals police themselves.

While state and end-of-year tests have become less common in recent years, thus lessening the panicked mania around high-stakes testing in the US, the Divergent, Legend, and Testing trilogies demonstrate what can happen when test results determine whether test-takers move forward in their education. Moreover, these trilogies represent the impact that high-stakes test scores may have as students receive a score that identifies them as a failure or a success. As a result of the categorization and scoring, these novels demonstrate how students, especially low- 
income and/or low-class students who do not have the same access to testing resources that can improve test scores, feel caught up in "an ever-increasing web of surveillance ... where the highstakes attached to the tests function to discipline and punish" (Au, Meritocracy 52). In other words, students, routinely tested, scored, and categorized, feel watched by those in charge of high-stakes testing, especially since they may be reduced to their score despite classroom contributions. In this way, high-stakes testing as a system works in a way similar to Foucault's Panopticon in that it induces, in test-takers, "a state of conscious and permanent visibility that assures the automatic functioning of power" (201). That is to say that by making students feel as though they are always under the gaze of those in power even when they aren't, high-stakes testing induces some students to self-police. Certainly, the hyperbolic punishment strategies in these dystopian trilogies encourage this behavior and thus these trilogies illustrate the tendency to self-police throughout their narratives

On the other hand, dystopian communities, such as those in the Divergent, Legend, and Testing trilogies, are also "characterized by practices of surveillance which ensure that the movements and thoughts of members are monitored for adherence to the systems of rules by which power is maintained" (Bradford et al. 119). While these practices are significantly more intrusive than those listed with regards to testing systems in the US, policy-makers nonetheless utilize testing and the measurement of student achievement to provide a basis for their surveillance. Moreover, adolescents in these novels must concern themselves with surveillance at the hands of the state through testing and other more direct means, while also acknowledging the degree to which they are watched by their peers for signs of deviance. As noted above, even the consistent potential of being watched efficiently prompts the individuals in these novels to police their behavior so as to avoid acting in ways that would require reprograming in the form of 
punishment. As a result, the two-fold surveillance of the ruling class and their colleagues, along with the narrow margin of success constructed by policy-makers through high-stakes testing, the citizens of dystopian Chicago (and its macrocosm, the Bureau), the Republic, and the United Commonwealth self-police so that their potential digressions may be overlooked.

For example, in Divergent, Tris' mother insinuates that “every faction conditions its members to think and act a certain way," and reminds Tris that "most people do it" because "for most people, it's not hard to learn, to find a pattern of thought that works and stay that way" (442). Moreover, as Tris remarks earlier in the novel, "faction customs dictate even idle behavior and supersede individual preference," and while it's doubtful that every member of every faction wants to act any given way all the time, "they can't defy the norms of their factions any more than [she] can" (9). If we read Tris' mother's word in conjunction with Tris' observations, it becomes clear that the aptitude test places individuals into factions and disciplines them into adhering to the customs of that faction by juxtaposing the limited freedom of being in a faction community with the fear of being a factionless outsider. As a result, members of different factions self-police in order to act as members of each respective faction are meant to. However, even when the social divisions instigated by the categories of high-stakes testing aren't as clear as they are in the faction system of Roth's Divergent, self-policing may still occur.

For instance, in The Testing, Cia waits for the other Testing candidates to protest the deadly consequences of the second round of The Testing: "I wait for the other candidates to protest. To say this is wrong. But I know why they don't. It's the same reason I don't yell out. The reason is Malachi and his too-still body. We all want to live" (113). Having been exposed to the potential consequences of failing and the subsequent utilitarian response of the testing officials to Malachi's death in the course of The Testing, none of the test-takers in Cia's group 
feels comfortable protesting The Testing. As a result, they learn to self-police by remaining silent in this moment and concealing their weaknesses later on. In fact, Cia later stops a friend from seeking medical attention, concerned that doing so will mark him as weak and thus capable of being eliminated from The Testing. Later, the same friend thanks Cia, explaining that "If [she] hadn't stopped [him] from going for medical attention after the second round of tests, [he] wouldn't even be here. None of the candidates who went came back" (Charbonneau, The Testing 221). Thus, Cia saves her friend's life by realizing the necessity of self-policing according to the desires of those in charge of The Testing.

To expand, however, self-policing is a corollary effect of the discipline enacted by the RSA in response to individuals who challenge systems of categorizing like high-stakes testing. As such, it does not necessarily end after a given test-taker has been categorized into his or her social class. In fact, individuals in these novels self-police so consistently that it becomes a sort of learned behavior that continues long after testing is complete, especially since surveillance often continues after the fact as well. For example, when Day defiantly confronts a Republic officer prior to his Trial, his older brother, having already been subjected to the disciplinary acts of the Trial in his low-wage job and his life in the slum sector, reminds Day of the necessity of self-policing: "Listen to me, and listen to me good. All right? You never fight back. Ever. You do what the officers tell you, and you don't argue with them" (Lu, Legend 275). That even Day's brother, having long-passed his Trial, still works to police himself and his family speaks to how discipline and surveillance by the RSA in these novels ensure control even in moments not directly connected to testing.

While the level of self-policing in the US never amounts to these dystopian levels, it should be noted that students, constantly taught that only passing/doing well on high-stakes tests 
will improve their future opportunities, also self-police by orienting their learning around what's on these tests. Certainly, accountability measures that tie teacher salary and school funding to test-scores play a role in this, enacting a kind of school-wide system of surveillance, but the result is nonetheless similar to that of my dystopian texts in that students, teachers, and even school administrators self-police to fulfill the requirements set upon them by policy-makers. Thus, in both cases, though to varying degrees, the disciplinary side of high-stakes testing works to press upon test-takers the necessity of conforming to the ruling ideology. By self-policing, then, test-takers comply to their own subjugation in response to the fear of the consequences carried out by the RSA.

Consequently, those that self-police well enough and successfully navigate systems of high-stakes testing run the risk of perpetuating the system of repression by taking on a position of willful ignorance as a result of their self-policing. In part, this comes as a result of the fear of being noticed as shown by the above example from The Testing. However, as people self-police and incorporate such behaviors into their everyday life, they begin to internalize these responses to discipline and begin to buy into the idea that testing, with all its various furtive methods of maintaining the status quo for the ruling class, is a normal and expected part of life. For this reason, even test-takers who may have had to self-police in order to fit the parameters set forth by those in power, may "feel it's only fair [that] the new students have to suffer through a similar process" (Charbonneau, Independent Study 233). Unfortunately, this position only works to further divide test-takers into successes and failures, ensuring that those who fail are looked down on for their failures and thus further policed by their own defeatist mentalities. 


\section{$\underline{\text { How Test-Based Class Divisions Foster Defeatist Mentalities }}$}

In New World Orders in Contemporary Children's Literature, Bradford et al. examine and explain the complex relationship that dystopian novels have to the present: "Because its settings are inevitably somewhere in the future, post-disaster fiction has consistently depicted the present as history and uses this temporal relationship as a strategy to foreground dystopian tendencies in present societies" (13). That is, by positioning the present as history, dystopias set up an extreme society set in a future with traits that developed from those of the present, albeit in corrupt ways. For example, one historical event seems to have affected how the American economy can be interpreted: following the Great Recession of 2008, more scholars and YA authors began critiquing neoliberal influences on the American economy. In Meritocracy 2.0, Au sheds light on David Harvey's definition of neoliberalism, explaining it as "a combination of political and economic theories and practices" that is based on the belief that "human well-being can be best advanced by the maximization of entrepreneurial freedoms within an institutional framework characterized by private property rights, individual liberty, unencumbered markets, and free trade" (41). In other words, neoliberalism is the belief that "individuals are solely responsible for their lives and that they have (or ought to have) the capacity to be and do what they most desire" (Bradford et al. 105). When applied to test-takers, however, an unintended consequence of this belief may be that one's failure on a given high-stakes test will be perceived as having to do with one's own lack of ability or intelligence, while a more robust conception of the test-taker might consider how other factors could impact an individual's test score.

When policy-makers combine the belief that high-stakes tests are accurate, objective indicators of students' knowledge with the belief that an individual is solely responsible for his/her own life, they start to make others involved in the testing process believe that "low test 
scores and the educational failure of working class, children of color [are] due to their own deficiencies" (Au, Meritocracy 46). Moreover, because "standardized testing constructs which children (and communities) are identified as "failures" by the tests," such high-stakes testing can become a way to cyclically "justify neoliberal conceptions of individualist educational attainment and the denial of structural inequalities" (42). Thus, students who fail or do poorly on high-stakes tests are considered failures and neoliberal conceptions of the individual ensure that this failure is perceived as the fault of the student while policy-makers ignore other factors that impact test sores.

This pervasive belief helps to solidify the divisions created by the test-based categories/tracks into which test-takers are organized. In fact, as education scholar Laura-Lee Kearns has observed in the youth in her study, "failure ... seems to (re)produce an inequitable separation and differentiation between and amongst students; those who pass are privileged and those who fail are named 'illiterate' and are marginalized by a systemic practice that treats all students the same" (123). The differentiation that Kearns notes is then compounded by the prejudice that neoliberal conceptions of the individual give rise to. Students who are marked as failures face prejudice from others involved in testing who believe that their failure is solely the result of a lack of trying or a lack of intelligence. While, as various education scholars indicate, this phenomenon occurs in the US, it is best exemplified by June's internal judgment when she first enters the slum sectors in search of Day in Lu's Legend: "What a bunch of cons, men who had barely passed their Trials. I wonder if I can catch the plague from these people, even though I'm vaccinated. Who knows where they've been" (97). That June has no knowledge of any of these citizens matters little. In fact, the only thing she does know is that the citizens of the slum sectors have not done well on the Trial. Based only on this knowledge, June calls these people 
"cons" and assumes that they are diseased, indicating that, at the beginning of Legend, June also has some contempt for those who don't test well.

As a result, low-scoring test-takers in the Divergent, Legend, and Testing are marked as other and often demeaned. However, many who view low-scoring test-takers this way can be either earnestly or willfully ignorant of the various socio-economic factors that could impact test scores (such as hunger, lack of additional resources, lack of school funding, etc.) and thus each protagonists' future. In these trilogies, these factors can mean the difference between life and death, and therefore ignoring such factors due to hyperbolized conceptions of individual work support the divisions created through high-stakes testing. These divisions help systems of highstakes testing cyclically reproduce themselves and the ruling ideology of the educational ISA by "further burden[ing] those already experiencing the greatest disadvantage within the education system" and teaching them and others that such failings are their own fault (Lewis and Hardy 246). While Lewis and Hardy speak to accountability legislation in the 2000s, the Divergent, Legend, and Testing trilogies demonstrate how a hyperbolized conception of the individual, coupled with ideological indoctrination, can disadvantage those who are already disadvantaged, while not addressing the factors that create this divide in the first place.

YA dystopian novels follow the impact of this phenomenon to its hyperbolic conclusion in which low-scoring/failed test-takers, already marked as lesser, are dehumanized and sacrificed for the good of society in postapocalyptic times. For example, in Roth's Allegiant, the leader of the Bureau, David, tells Tris that Tris' father once witnessed the dehumanizing effects of the marginalization of the factionless:

he saw her performing an experiment on a factionless man in exchange for somethingfood, or clothing, something like that. Anyway, she was testing the fear-inducing serum 
that was later incorporated into Dauntless initiation.... And Norton, then the representative of Erudite, was there, letting it go on far longer than it should have. The factionless man was never quite right again. (215)

Witnessing such torture convinces Tris' father to leave Erudite and join Abnegation, but it also demonstrates the damaging effects that the disciplinary actions of the RSA can have when coupled with neoliberal ideology. By creating a narrow margin of success that is safeguarded by the punishments enacted by the RSA, high-stakes testing works to marginalize those that the ruling class deems unnecessary or threatening. By building on neoliberal beliefs, high-stakes testing works to convince even those who test poorly that they deserve the consequences they face as a result. In the extreme societies of the Divergent, Legend, and Testing trilogies, however, the effect of these aspects of high-stakes testing are made clear in each protagonist's growing awareness of these effects and the way that they manipulate individuals for the benefit of those in power.

George Madaus and Marguerrite Clarke have noted that "to become motivated students must first see that striving for the rewards attached to examination performance is not only important in their lives but also realistic. In practice, however, some students immediately dismiss the examination because they feel they lack the ability to do what is necessary to pass" (97). Certainly, this response is partially ideologically-driven. However, the continuous interplay between the ISA and RSA in the Divergent, Legend, and Testing trilogies implies that some of the ideological shaping that citizens in these novels subject themselves to may be in response to the threat of physical punishment. For test-takers that have developed defeatist mentalities, then, viewing success as realistic is much more difficult, particularly when others expect less of you. As a result, many students stop trying in earnest as a coping mechanism. Some students, "fearing 
they will fail, rush through a test, marking items almost at random so the score they earn is not an accurate reflection of their actual knowledge" (R. Thomas 247). In response to high-stakes testing, some students adopt defeatist mentalities to cope with their fear of failure, reasoning that if they don't try, don't study, or don't show up, they may still fail, but then at least the failure is not reflective of their abilities. Moreover, when offered make-up opportunities, students with defeatist mentalities "intensely apprehensive about suffering serious consequences from failing tests" (256), and "the longer they have been out of school, the less likely they will attempt a make-up exams" (252). Thus, while some students will try to push through anxieties and defeatist mentalities, many students lose their will to learn, "paint a negative picture of themselves and fulfill self-fulfilling prophecy" (Lucido 107).

We can see this in the Divergent, Legend, and Testing trilogies. For example, as a citizen of Five Lakes colony in The Testing, Cia develops a sort of defeatist mentality because no one from her colony has been selected for The Testing in ten years: "It has been ten years since the last student from Five Lakes was chosen. I'm good at school, but there are those who are better. Much better. What chance do I have?” (3). Unbeknownst to Cia, her father and others who've undergone The Testing and begun to remember their horrible experiences have sabotaged the selection process for the last ten years. ${ }^{9}$ Covertly, this group is desperately attempting to defy the RSA, knowing they are likely to fail and knowing they will be destroyed if the RSA understands their actions. Despite their efforts, Cia is still called to The Testing. Nevertheless, Cia continues

${ }^{9}$ At the end of The Testing process, candidates go through an exit interview of sorts before they are administered a drug that erases their memories of The Testing. After many years, however, some memories may return in the form of dreams. Cia's father thus enlists others who remember to interfere with the selection process so that other adolescents will not be subjected to what he was exposed to during The Testing. 
to doubt her ability before her selection and continues to illustrate a defeatist mentality until she is chosen. Moreover, immediately after not being initially selected, Cia begins to consider her options, eventually remembering that she can appeal to work in Tosu City. Even when she does, however, she quickly falls back on this developing mentality and dismisses the possibility, stating that "after the disappointment of today, [she's] not sure [she's] ready to face another" (Charbonneau, The Testing 18).

Generally speaking, then, in fostering defeatist mentalities through somewhat limited conceptions of the individual, policy-makers ensure that many who fail, or test poorly, become "complicit in his/her own discipline and reform, internalising the norms to which he/she is exposed and thus reconstituting his/her own subjectivity" (Lewis and Hardy 248). We see this in Cia, certainly, as her response to rejection demonstrates how teaching those who test poorly that their failure is uniquely their own may help policy-makers create circumstances by which testtakers further self-police via defeatist attitudes. The fostering of this defeatist mentality also helps guarantee that those marginalized by high-stakes testing do not rebel against the system in significant ways.

Of course, the actions of Cia's father and others in attempting (but failing) to sabotage the selection process are examples of how some citizens may use the limits of the State and its prejudices that spawn from an individualistic mentality to their advantage. Throughout The Testing trilogy, and particularly after the first novel when readers encounter Tosu City students who were able to skip The Testing and take the University entrance exam regardless, readers learn that many Tosu City students look down on the colony students. When the competition heats up among students, many Tosu City students indicate their prejudices in the ways they address the colony students: "we don't need a colony brat's help to pass. We're the ones who 
deserve to be here. We should be the ones working with the President" (Charbonneau, Independent Study 270). As testing official Michal explains to Cia and others, "as a colony student, you already have a strike against you. They expect you to be weak. They expect you to be less than they are. Show them they are wrong," thus implying that this prejudice is pervasive enough to be recognizable (48). Moreover, when analyzing maps as part of her internship, Cia recognizes several mistakes on the map of Five Lakes and remarks that she "could reason them away. Five Lakes is the smallest colony. The most distant. The least communicated with by the leaders here in Tosu," (249). Thus, Cia's father and other have tried to sabotage the selection process by using the policy-makers' belief that Testing-worthy students probably do not exist in Five Lakes. Thus, while Cia's father attempts to game the system, he does not rebel in a way that seeks or even aims dismantle said system. Instead, he uses the side-effects of the high-stakes testing system to try and protect test-takers from his colony, though it is never clear whether he accomplishes this intentionally or just by chance. In the case of his own daughter, he ultimately fails to protect her from the RSA as she is takes part in The Testing.

While smaller acts of rebellion such as those that Cia's father enacts may go unnoticed, bigger deviations from the norm are often quashed, encouraging the development of defeatist mentalities, such as those Cia exhibits. In this way, the RSA's attempts at discipline reinforce the test-based social hierarchy promoted by the educational ISA. However, just as characters like Cia internalize the "failure" classification, self-police, and develop defeatist mentalities, testtakers in her world become fearful of the freedom that may come from rebellion because rebellion would require them to reject the guidelines of the oppressor that they have so thoroughly incorporated into their individual identities. Notably, when rebellions by those marginalized do occur in the Divergent, Legend, and Testing trilogies, these rebellions usually 
fail because they are carried out by people who have so fully internalized the methods of the oppressors that they inadvertently use those same methods in their attempts to overthrow the State.

\section{"From One Tyrant to Another": Failed Rebellion by Those Marginalized}

In the Divergent trilogy, the factionless were scattered and aimless for years, unable to act against their subjugation. A factionless man addresses this point in Insurgent: "you thought they - we - were all split up.... Well, they were, for a while. Too hungry to do much of anything except look for food. But then the Stiffs started giving them food, clothes, tools, everything. And they got stronger and waited" (95). The factionless, ostracized for years, begin to gain strength when the Abnegation start to provide them with the resources they need to survive, resources denied to them as a punishment for not adhering to the test-based faction system. After their survival is ensured, however, the factionless attempt to take over dystopian Chicago under their leader, Evelyn. They fail, primarily because, in attempting to free themselves from the repression they've faced at the hands of those in power, they use the methods of their oppressors.

In Pedagogy of the Oppressed, Freire acknowledged this phenomenon:

during the initial stage of the struggle, the oppressed, instead of striving for liberation, tend themselves to become oppressors, or "sub-oppressors." The very structure of their thought has been conditioned by the contradictions of the concrete, existential situation by which they were shaped. Their ideal is to be men; but for them, to be men is to be oppressors. This is their model of humanity. (79)

The factionless, now able to think beyond survival, want to change the system that disenfranchised them in the first place. However, the only tools of oppression they know are those that were used against them. As a result, when the factionless attempt a hostile take-over 
under Evelyn's leadership, their methods of taking and maintaining control involve deceit and the threat of physical violence. In fact, when the factionless take-over becomes apparent, Tris remarks that "Evelyn has [them] all trapped in the city, controlled by armed factionless patrolling the streets. She knows that whoever holds the guns holds the power" (Roth, Allegiant 13); it's all for a city "where factions are wrenched away from people against their will" (38). Tris later remarks that Evelyn "wanted us to have more than five choices. Now we have none" (38). In other words, while Evelyn and the factionless may have had noble intentions, their take-over still denied agency to the citizens of dystopian society under the guise of liberation. Furthermore, having manipulated all the Dauntless to turn over their weapons during the joint take-over of Erudite headquarters, Evelyn ensures that the only population that remained armed were the factionless, so they can maintain control after the fact through the intimation of physical force. Ultimately, the factionless are unable to maintain control as various fights and riots break out in response to the dismantling of the faction system. Evelyn's methods are so abrasive that Tris compares her to Jeanine, concluding that her society has simply gone "from one tyrant to another" (13).

In the Legend and Testing trilogies, margin-lead rebellions also fail, though for different reasons. In Lu's Prodigy, for example, a rebellion lead by the Patriots turns out to be a plot orchestrated by a double agent to ensure that, "the public would think that the Patriots took over the government, when it's really only the Republic all over again" (309). Similarly, the rebellion that arises in Charbonneau's Graduation Day is also led by a double agent who aims to use the rebellion to identify those that pose a threat to the United Commonwealth before eliminating them. What is significant about these similar rebellions, however, is what they seem to say about the people living on the margins of these societies. As Zeen notes in Graduation Day, "logic 
isn't leading this rebellion ... emotion is" (67), and June, who prevents the Patriot rebellion, similarly questions Day's support of it due to his high level of emotion. In both cases, emotions run high and the rebellion fails, which implies that when marginalized peoples rebel, their heightened emotion due to years of abuse and repression might cause a sort of lashing out that ensures the rebels gain control of the state. However, without a change in the ruling ideology, much of the population, having bought in to said ideology, will not be supportive of the change of power, and society may in fact revert to the status quo described in the openings of these dystopian narratives.

\section{Conclusion}

Citizens who never question the ruling ideology or are successful in navigating their respective systems of high-stakes testing may, in the course of the dystopian narratives of these texts, become more aware of the manipulations and repressive methods utilized by policymakers but may still choose not to act. These citizens may be willfully ignorant of these conditions, as mentioned in chapter one and earlier in this chapter, but they may also be unwilling to act out of fear or out of privilege. That is to say that those who successfully navigate high-stakes testing receive the privileges of the ruling class. However, because these privileges would be revoked if these individuals presented any sort of challenge to those in power or the ruling ideology that their manipulated system espouses, those who successfully navigate systems of high-stakes testing may choose not to act even if they are aware of the oppressive nature of their society.

In combining the inaction of privileged individuals with the failed rebellions of marginalized individuals, then, these YA dystopian narratives suggest that change must somehow come from a combination of both positionalities. Change might require an individual 
or a group that understands and acknowledges the plight of the marginalized while simultaneously having enough privilege and impetus to alter the ruling ideology. The problem, however, is that just as Evelyn and the factionless fail because they know only what they have been taught by their oppressors, any individual who successfully navigates the extreme highstakes testing systems in these societies runs the risk of becoming entrenched in the ruling ideology. As a result, these people may, in accepting all the aspects of the ruling ideology, lack empathy for those in marginalized positions and therefore lack the motivation to evoke change from within.

These novels posit that for change to occur an individual or group must have an awareness of the repressive conditions of his/her society, s/he must maintain a position of privilege, and s/he must be motivated to act from a position of privilege to aid those that are marginalized. Unfortunately, the competition inherent in normative systems of high-stakes testing impedes the first requirement, pitting test-takers against one another so that they forget that the real enemy is, in fact, the ruling class and, specifically, the cyclically reproduced system they maintain. 


\section{CHAPTER III: “THE ODDS FAVOR MY FAILURE”: HOW COMPETITION,}

MANIPULATED STRUCTURES, AND CONFIRMATION BIAS ENSURE

THE REPRODUCTION OF A RULING CLASS IN SUPPORT OF HIGH-STAKES TESTING

\section{Normative Scores and the Competitive Atmosphere They Foster: An Introduction}

In chapter two, I argued that the Repressive State Apparatuses (RSA), working to defend the ideology promoted by the educational Ideological State Apparatus (ISA) and its high-stakes testing-based methodology, physically repress those that do not readily accept the ruling ideology or their place in its reproduction. I also argued that the tactics of the RSA have indirect effects that further promote high-stakes testing by encouraging those marginalized to self-police. In this way, the work leading up to this chapter has been framed by the first two assumptions of high-stakes testing that were examined in The Paradoxes of High-Stakes Testing by George Madaus, Michael Russel, and Jennifer Higgins. ${ }^{10}$ Going forward, I hope to frame this chapter using the third assumption.

To reiterate, the third assumption underlying high-stakes testing states that "student ... effort is maximized when rewards are distributed on a competitive basis" (Madaus et al.16). Certainly, systems of high-stakes testing often function according to this assumption by implementing normative scoring methods. Normative test scores "compare performance of an individual student to the performance of a group of students, referred to as a norm-group" (48), and "a normative standard is based on the relative performance of a group of students who

${ }^{10}$ The first assumption states that "the greater the reward offered for success or the punishment for failure, the harder students ... will try" while the second states that "all students will response to the rewards and punishments in essentially the same way" (Madaus et al. 16). 
comprise the norm group" (124). Horace Lucido further explains that the "way grading curves are created, scores are announced or posted" and the way some students are praised over other can "encourage students to compete with one another... [and] reinforces the view that others on this planet, fellow students included, are to be competed with rather than cooperated with" (166). In other words, norm-referenced test-scores, on which many high-stakes testing systems are based, necessarily place test-takers in competition with one another by measuring them up against each other, often in public ways.

As a result of these normative scoring methods, Jonathan Alexander and Rebecca Black argue that "testing emphasizes the battle of individuals for access to limited resources and opportunities" (213). Naturally, in the hyperbolic high-stakes of the Divergent, Legend, and Testing trilogies, competition among test-takers is more common and deadlier. In Divergent, for example, Dauntless initiates are normatively judged against one-another. Moreover, Dauntless leaders in charge of initiation warn Tris and the others that they will be making cuts at the end of each round, thus encouraging a fairly competitive atmosphere among initiates. This results in strained relationships and violent acts amongst peers who are now deemed competitors, culminating with Peter, who was in second after the first round, stabbing frontrunner Edward in the eye while he sleeps (Roth, Divergent 203). In the second round, Tris rises to the top of the initiate ranking and her friend $\mathrm{Al}$ betrays her by working with other initiates to throw her in the chasm, hoping to cause her death so that he may save himself from becoming factionless. Similarly, The Testing also operates on normative scores while test-takers are cut from the throng or killed after every round.

It is no surprise, then, that a similar competitive atmosphere develops in The Testing with candidates constantly attempting to fluster, poison, or kill their peers. For example, in the team- 
based round of The Testing, Cia must work with a small group to answer five questions. They all attempt the questions together and, based on the responses, decide which person should answer which question. Unbeknownst to Cia and two of her group members, the final member, Roman, purposely answers all the questions wrong and then insists on going first to sabotage the others. Cia discovers Roman's plan and saves at least one of her group members while the other is assumed to have died in Roman's trap. This experience is not unique to this round of The Testing or even to Cia's Testing experience, as her father dealt with the same sort of competition and warned her that "competition might blind some people" (Charbonneau, The Testing 250).

In this chapter, I will use high-stakes testing scholarship to inform the high-stakes testing systems in the Divergent, Legend, and Testing trilogies. I will argue that the third assumption is flawed because it disregards the fact that high-stakes testing structures, such as cut-scores and one-size-fits-all testing, are arbitrarily established by those in power. As such, these structures, along with the competitive nature of high-stakes testing, allow policy-makers to manipulate testing so that only those who exhibit the traits most coveted by the ruling class can succeed and, in turn, reproduce the ruling class. Moreover, I will argue that this manipulation further propagates the class divisions and prejudices cultivated by high-stakes testing, isolating testtakers from one-another while the competitive atmosphere fosters distrust. As a result of these conditions and those examined earlier in this thesis, test-takers are openly hostile to one another while often remaining unaware of the manipulations undertaken to ensure this, blaming their failures on their peers instead. Before I can accomplish any of this, however, I must first argue that, in addition to the assumption that competition is beneficial to systems of high-stakes testing, competition is actively promoted in the Divergent, Legend, and Testing trilogies. 


\section{The Promotion of Competition}

In the United States, competition is inherently promoted through the normative scoring methods used by those in charge of testing and the feeling of surveillance that constant testing evokes in test-takers. ${ }^{11}$ In the Divergent, Legend, and Testing trilogies competition is likewise implicitly promoted by those in power and through the on-going surveillance. It is not the act of being surveilled that is important here, however. Instead, the surveillance that the citizens of dystopian Chicago, the Republic, and the United Commonwealth undergo is important because, despite this surveillance, policy-makers overlook corrupt, competitive acts like those mentioned above. For example, after Peter stabs Edward's eye, Tris' friend Christina asks if they should notify the Dauntless leaders, prompting Tris to respond: "You really think the Dauntless will do anything?.... After they hung you over the chasm? After they made us beat each other unconscious?" (Roth Divergent 204). Roth's novel never specifies that Dauntless initiates are surveilled in their dorms. However, the fact that Dauntless leaders stood by during the fights that Tris recalls in the quotation, and that Dauntless leader Eric is the one to force Christina to hang over the chasm indicates that even in this more mildly surveilled system, competition is implicitly promoted. Similarly, Cia notes that "by singling [them] out" as citizens of Five Lakes "Dr. Barnes has most likely painted targets on our backs" (Charbonneau, The Testing 76). Cia further reasons that this singling out appeared to be intentional. Given this, Dr. Barnes' words can also be read as implicitly promoting, and even encouraging, the sort of competitive acts that Cia's father warned her about.

\footnotetext{
${ }^{11}$ For more information on surveillance, please refer to chapter two.
} 
Beyond policy-makers' implicit promotion of competition, however, policy-makers also explicitly promote competition by offering it as a possibility while still refusing to punish those they know have committed violent acts. For example, in describing the final part of The Testing, Dr. Barnes reminds test-takers that they "may also choose to impair the progress of your fellow candidates in order to ensure that you obtain a passing grade before them" (Charbonneau, The Testing 135). While he indicates that all choices will be considered in one's final evaluation, Dr. Barnes does not clarify how the choice to interfere with another candidate's progress will impact said evaluation. However, given that many test-takers who choose to kill others during the final round of The Testing make it to the University, it seems clear that this sort of behavior is both tolerated and, to some degree, supported by those in power. Thus, as Will surmises just before he betrays Cia and her partner Tomas, the policy-makers in charge of The Testing want to see "how fast [they] get to the end and how many competitors [they'1l] take out along the way" (135).

In this way, high-stakes testing in the Divergent, Legend, and Testing trilogies invites competition through the normative scoring methods it employs while still promoting those that commit hostile, competitive acts. By allowing those who commit these acts to successfully navigate high-stakes testing, policy-makers signify that such competition is normal and encourage test-takers to commit such acts in order to better their chances of success. In effect, then, policy-makers normalize this extreme and corrupt competitive atmosphere in the hopes that test-takers with a 'competitive edge' will cull the herd of anyone lacking this quality, a quality clearly treasured by the policy-makers in theses YA dystopian texts and, to a less extreme degree, by those testing proponents in the US who whole-heartedly believe in that competition increases student effort. However, hostile acts are not the only extremes that policy-makers in the Divergent, Legend, and Testing trilogies support. In fact, policy-makers actively encourage the 
development of behavioral extremes in a way akin to how teaching for the test promotes certain intelligences over others.

\section{“One Bad Thing Goes Away and Another Replaces It": How Manipulated Testing Structures Foster Extremes of Desired Characteristics}

In the US, high-stakes testing systems are comprised of standardized tests that fail to account for the uniqueness of each individual test-taker. Instead, standardized high-stakes tests represent a sort of one-size-fits-all testing method that, in reality, fosters only certain types of intelligences that policy-makers believe are useful in the competitive global market. Moreover, as asserted by Deborah L. Bandalos, Amanda E. Fester, Susan L. Davis, and Karen M. Samuelsen, accountability legislation implemented to improve global competitiveness tethers federal funding to a school's test scores, ensuring that teachers "direct instructional and other resources to the tested material, which will in turn cause students to learn that material" (157). This phenomenon, called teaching to the test, is widely documented by education scholars such as Wayne $\mathrm{Au}$ :

The most prevalent finding in the empirical research in the US is that high-stakes testing narrows the instructional curriculum because, to varying degrees, teachers shape the content norms of their curriculum to match that of the tests.... In this way, high-stakes testing is having the net effecting of standardizing the content of the curriculum in teachers' classroom practices in the US.... In the case of high-stakes testing in the US, as the content of the curriculum moves to match what the tests require, the structure of curricular content knowledge similarly shifts towards the fragmentation demanded by the test. (30) 
In other words, standardized high-stakes tests and accountability measures ensure that the curriculum is dictated by what is on the test, evacuating the power of teachers at the classroom level to policy-makers. R. Murray Thomas notes that most high-stakes tests consist of primarily multiple-choice questions, and teachers, attempting to improve test-scores for school funding, drill "students on the answers to specific test questions which are drawn from past state tests or from sample test items available on the internet," thus encouraging "rote memorization of specific answers rather than promoting a comprehensive understanding of a field of knowledge and its underlying principles" (35). As a result, students who can easily memorize facts, figures, and rules are successful, while others who require a more robust understanding of the subject matter are not. Moreover, this fragmented, memorization-based form of teaching is further limiting because the "time spent in teaching reading or math is doubled or tripled, [while] the remaining time available for other subjects must be reduced" (270). In this way, students who excel in these subjects are more likely to succeed. On the other hand, students with other skillsets in the arts or social sciences may not be so lucky. Thus, high-stakes testing and accountability work to promote certain types of intelligences over others, while the qualities that can't be measured through testing are less and less valued because "the focus on preparing students for tests diminishes the development of other valued talents" (Madaus et al. 148).

Similarly, policy-makers in the Divergent, Legend, and Testing trilogies utilize highstakes testing to produce citizens with certain characteristics because, as explained in The Testing, previous leaders did not "have the correct combination of intelligence, ability to perform under pressure, and strength of leadership to lead us out of confrontations" (144). The favoring of certain characteristics by the ruling class is nowhere clearer than in the faction system of the Divergent trilogy, where test-takers are encouraged, often through the threat of becoming 
factionless, to adhere to the behavioral expectations of their faction. ${ }^{12}$ However, due to the competitive nature of initiation, the initiates who most intensely exhibit the characteristics of their faction typically find more success. In this way, while encouraging characteristics such as logic and intelligence, bravery, honesty, etc., the faction system also promotes extremes of these behaviors.

For example, Tris is devastated by the death of her parents and the fact that she killed her friend Will in self-defense. In response, she throws herself into danger recklessly, prompting her love interest Tobias to respond: "If you throw yourself into danger for no reason again, you will have become nothing more than a Dauntless adrenaline junkie looking for a hit, and I'm not going to help you do it.... I love Tris the Divergent, who ... isn't some faction archetype" (Roth, Insurgent 260-61). That Tobias so readily compares Tris' behavior to that of a "Dauntless adrenaline junkie" implies that the extreme recklessness that Tris masquerades as bravery is fairly commonplace among the Dauntless. Certainly, the fact that only Tobias sees anything wrong with Tris" actions deepens this reading, and his use of the term "faction archetype" demonstrates that the factions play a role in fulfilling stereotypical behaviors.

When Tris arrives at the Bureau in Allegiant, David, the leader of the Bureau, explains the problem with the faction system: “Take away someone's fear, or low intelligence, or dishonesty ... and you take away their compassion. Take away someone's aggression and you take away their motivation or their ability to assert themselves. Take away their selfishness and you take away their sense of self-preservation" (122-23). As he speaks, Tris makes sense of his words:

\footnotetext{
${ }^{12}$ For more information, see "How Surveillance Fosters Self-Policing” in chapter two.
} 
I tick off each quality in my mind as he says it—fear, low intelligence, dishonestly, aggression, selfishness. He is talking about the factions and he's right to say that every faction loses something when it gains a virtue: The Dauntless, brave but cruel; the Erudite, intelligent but vain; the Amity, peaceful but passive; the Candor, honest but inconsiderate; the Abnegation, selfless but stifling. (123)

In other words, when policy-makers encourage the development of certain characteristics, they inherently disregard the possibility that other characteristics will be underdeveloped as a result. This should sound familiar as the same sort of behavior in the favoring of certain intelligences, such as those in reading and math, also leads to a lack of development and opportunities for testtakers in the US who find their passions and skills more in-tune with other, disregarded types of intelligences. Thus, policy-makers in charge of high-stakes testing not only limit the kinds of test-takers that are likely to successfully navigate testing systems, but they also establish a system that produces individuals with the traits they find most valuable for potential members of the ruling class.

The problem is that these extremes are not practical or productive for the individuals in question or, in the long term, for their respective societies. There are many instances in the Divergent, Legend, and Testing trilogies that illustrate this. For example, in Roth's Divergent Tris notes the ineffectual nature of catering to extremes: "I have realized that part of being Dauntless is being willing to make things more difficult for yourself in order to be self-sufficient. There is nothing especially brave about wandering dark streets with no flashlight, but we are not supposed to need help, even from light. We are supposed to be capable of anything” (138). Just as Tris' aforementioned recklessness puts her life in danger, the Dauntless desire to appear brave in order to more fully fit the expectations of their faction has far exceeded the development of 
bravery and has become extreme. Therefore, while stimulating the development of the traits desired by the ruling class, "one bad thing" such as cowardice "goes away and another bad thing [like recklessness] replaces it" (405). Likewise, encouraging competition may take away one's laziness but may instead increase one's aggression and hostility towards others. ${ }^{13}$ In other words, while the equivalent of teaching to the test may have the intended consequences of molding testtakers in ways that the ruling class finds agreeable, it may also erase other qualities that are necessary for leadership, such as the ability to trust others or not act recklessly in a delicate situation.

In The Darker Side of the Sorting Hat, Alexander and Black argue that, in YA dystopias, "the cultivation of particular skills and even mindsets often seem necessitated by the plot and the extremity of the settings through which these characters live" (4). As shown by the Divergent trilogy however, the cultivation of these skills may come with a loss of other traits that, although disregarded by policy-makers, are nonetheless important leadership qualities, implying that perhaps leadership isn't the primary objective. Instead, a very narrow view of leadership, one formed in the cast of members of the ruling class, seems to be the aim here. At the same time, however, test-takers have no option but to foster these traits so as to preserve their own relative safety. As a result, high-states testing systems can be viewed as an example of the banking model of education that Paolo Freire describes in Pedagogy of the Oppressed.

To paraphrase, in the banking model, students are seen as containers/receptacles to be filled by a teacher whose livelihood is dependent on how well s/he accomplishes this (Freire 72). By positioning the success of students as dependent on how well they take on certain

${ }^{13}$ As I discuss in chapter two, this is, by no means, a generalizable claim. In fact, many test-takers respond with defeatist mentalities. 
characteristics or intelligences, policy-makers perpetuate a system in which these test-takers take on whatever traits will most likely lead to their success even if such traits are not productive. As a result, the taking on of these traits and behaviors qualifies the actions of the policy-makers of dystopian Chicago as being modeled after Freire's banking model, especially since test-takers also internalize the ideology of the ruling class in the meantime. Moreover, teaching to the test, which helps cultivate the aforementioned traits and intelligences, furthers the expectation of the banking model that students will simply take on the information —in this case the traits - that will help them successful navigate through their respective system of high-stakes testing. Thus, teaching to the test and the banking model of education, as represented in the Divergent trilogy through the faction system's own version of these testing structures, function to teach test-takers the knowledges and social rules that those in power consider good and useful. Meanwhile, the competitive nature of high-stakes testing system ensures that test-takers feel isolated, thus leaving students to these manipulations.

\section{"People do Strange Things Under Pressure": The Role of Isolation}

In chapter one, I argued that the psychological turmoil that accompanies the fear of failing high-stakes tests can leave test-takers open to the ideological manipulations of the ruling class. However, isolating students also plays a role in leaving them open to manipulation. In dystopian Chicago, the Republic, and the United Commonwealth, children and adolescents undergoing testing may be separated from their families. In the Divergent and Testing trilogies, this separation is permanent regardless of his/her test results. In The Testing, Cia's father explains that having a child chosen for the process is an honor, but that it also means that the child is lost to their family from that day forward (36). In Divergent, however, test-takers are encouraged to see their new factions as their families: "Faction transfers are not really supposed 
to discuss their old factions once they become members. It's supposed to make it easier for them to change their allegiance from family to faction - to embrace the principle 'faction before blood"' (201). Unfortunately, the competitive atmosphere that policy-makers aid in perpetuating makes this impossible. In fact, in Charbonneau's Graduation Day, Professor Holt reminds Cia that her attachment to Tomas "can cause distractions [she doesn't] need" and that "the last thing [they] need is students who have formed personal attachments as a mechanism for dealing with stress" (59). In other words, members of the ruling class isolate test-takers from their families and then encourage further isolation both explicitly—as in this moment—and implicitly by sustaining a competitive atmosphere where hostility is promoted.

Furthermore, this isolation then cyclically reinforces the competitive atmosphere because it causes vulnerable test-takers to lash out against one another. The clearest example of this is Will from The Testing trilogy. Having lost his twin brother in the first round of The Testing, Will loses his sense of self. Cia acknowledges the changes Will undergoes during The Testing in Graduation Day:

I think about the Will I first met. The one who joked with his twin. Who, under the most pressure-filled circumstances, found ways to make the people around him laugh. It was when his brother failed to pass the first test that Will began to change. He felt alone. He was desperate to prove that he could survive without his brother. That the sacrifice of that lifelong anchor was not for nothing. (79)

In other words, Cia believes Will's isolation from his family and specially his twin, Gil, played a role in his decision to betray her and Thomas. Certainly, the end of Charbonneau's trilogy supports Cia's perception when Will, having realized that Cia has the makings of a true leader, helps Cia rather than himself, an act more in-tune with the humorous boy Cia describes. 
Ultimately, the fluctuation of Will's character is indicative of a phenomenon Cia identifies in The Testing: "People do strange things under pressure" (250). Policy-makers capitalize on this in their attempts to enforce a competitive atmosphere. Doing so allows them to sit back while testtakers take each other out, all while the structures of high-stakes testing systems perpetuate the shaping of test-takers in ways that those in power desire. Thus, policy-makers manipulate highstakes testing structures to facilitate the cyclical reproduction of the ruling ideology and those that maintain it.

\section{"Failure Recommended by Staff": The Arbitrary Nature of the High-Stakes Test-Based Categorization}

\section{Cia's Paradoxical Test}

Policy-makers thus manipulate high-stakes testing structures to help ensure the reproduction of the ruling class by promoting those who have the characteristics that those in the ruling class tend to have. This manipulation is unsurprising given that "a social formation which did not reproduce the conditions of production at the same time as it produced would not last a

year" (Althusser 1). Thus, the high-stakes testing systems in the Divergent, Legend, and Testing trilogies are "aimed at constructing and winnowing out certain types of knowledge and people" (Alexander and Black 212) and "focus on the production of youth who, like lab rats, are able to satisfactorily make their way through a maze of often contradictory tasks, while an adult audience watches and judges every movement" (217-18). When policy-makers manipulate test structures to achieve their ends, they produce categories, that help facilitate the production of new members of the ruling class, that share the characteristics that that class values, while also helping to specify which test-takers do not share those characteristics. Those that do not exhibit these characteristics in the Divergent, Legend, and Testing trilogies may be disregarded if they 
are considered relatively harmless, actively repressed if they are considered defiant in some way, or promoted if they take on these characteristics and use them to navigate through their respective testing systems.

In the US, for example, cut-scores are set to establish a baseline for proficiency. A cutscore is an "arbitrarily assigned score ... intended to separate the haves from the have-nots" (Lucido 106). When a student falls below a cut-score, they fail, even if they missed the number by one point. Likewise, a student who falls just above a cut-score passes. Thus, this arbitrary number, which fails to account for test error and student-to-student differences, often dictates where students end up from year to year. Moreover, this number changes from year-to-year, further implying that it is arbitrarily set. Teaching to the test also demonstrates the arbitrary nature of the categories of high-stakes testing in the US. As explained by P.L. Thomas, for instance, "teaching to the test has moral implications, and the practice corrupts the credibility of the date drawn for tests. When teachers teach to the tests, in other words, the numbers we gather are rendered corrupt and the entire process, futile" (P.L. Thomas 82 ). Therefore, by manipulating testing structures in order to improve test scores, policy-makers in the Divergent, Legend, and Testing trilogies may prove that test-based categories are, in some ways, arbitrary. Certainly, a cut-score in the US is a reference point that can, in many cases, inform how a student may compare to others who have theoretically received the same level/type of instruction. However, these scores are still limiting in that they do not measure an entire domain of knowledge, instead measuring only specific parts that a given student may or may not be as familiar with. In these dystopian trilogies, however, cut-scores and the categories they foster become more arbitrary because of the high-level of manipulation that these structures undergo by those in charge of Dauntless initiation, the Trial, and The Testing. 
Similarly, in manipulating high-stakes testing structures so that only test-takers who fit the mold of the ruling class succeed, policy-makers in the Divergent, Legend, and Testing trilogies show that the divisions between successes and failures are arbitrary. For instance, the falsifying of Day's score prior to the events of Legend shows that those in charge of the Trial care little about maintaining certain standards. In the Divergent trilogy, the Bureau is the macrocosm within which the microcosm of the faction system resides. In the Bureau, Tris' Divergent status, for which she is persecuted in dystopian Chicago, makes her genetically pure (GP), a privileged subject position. By having Tris' subject position fluctuate between her more marginalized position in the faction system to this privileged position without any change to Tris' test-based categorization, Roth's trilogy demonstrates that the designations of the faction system are arbitrary as well. Nevertheless, Cia's experiences in The Testing and during her time at the University are the clearest representations of how arbitrary the categorizations of highstakes testing may be, particularly when they are manipulated by those in power to achieve their own ends.

In The Testing, the potentially arbitrary nature of The Testing process is hinted at by Cia's father when he states that one "never know[s] who the search committee might choose or why" (5). When going through initiation at the University, Cia and her face a challenge that is meant to be impossible. The goal of this challenge is for students to admit failure because "it takes a lot of courage to choose to do nothing when you aren't certain of the outcome" and "this is an important lesson to impart to all University students and one many students find almost impossible to accept" (Charbonneau, Independent Study 153). In telling University students to accept failure when The Testing equated failure to death, this scene further shows how policymakers can arbitrarily change the requirements for success in high-stakes testing. Most of the 
University students, with their memories of The Testing erased, fail to see this. Cia, however, experiences the effect of these arbitrary requirements first hand.

In Graduation Day, Cia, who has excelled in every round of The Testing and all her university exams, learns that she was never supposed to make it to the University at all. In fact, her "failure [is] recommended by [The Testing] staff" because she "is not questioning enough of others and not committed enough to her agenda to do whatever is necessary for the country's future development" (241). In other words, Cia is recommended for failure because she fails to exhibit the characteristics that those in charge of The Testing wish to reproduce in new members of the ruling class. Surprisingly, Dr. Barnes requests that Cia be tested in a way that shows that, despite her more trusting nature and her aversion to killing, she is able to make the difficult choices required of a leader. Dr. Barnes, President Collindar, and Professor Holt thus begin to change the requirements for Cia's success. At first the differences are small. For example, Cia is given nine classes, far more than the average first-year student, and told she is expected to act as though managing this course load is easy. In time, however, Dr. Barnes presents Cia with an additional test in the form of a paradoxical choice:

But you, my dear, are here to test whether they system really does function as well as we believe. In previous years, despite your grades and your performance in the fourth test, you would never have passed The Testing.... Your natural inclination to trust and your lack of killer instinct would have been apparent.... Those qualities that have rallied friends to your side would have cause you to fail, because those characteristics are viewed as weaknesses by the selection committee. Today, you will prove that The Testing and the reasoning behind it are flawed. The president doesn't believe that students like you have what it takes 
to do what is required when your country demands it. By killing me, you prove that I am right in my convictions and she is wrong. Kill me, and this all comes to an end. (268) In order to prove that she can be a leader, Cia must go against the very instincts that have made her so successful throughout The Testing and perform the sort of act that is promoted by the competitive and hostile atmosphere of the United Commonwealth's high-stakes testing system. Thus, while killing Dr. Barnes would prove that Cia has a killer instinct and could thus be a leader in the constrained way that those in power wish she were, killing him would also make Cia fit into the very mold that juxtaposes the valuable traits she has that others, so far embedded in the social hierarchy of the testing and all the parameters that come with it, lack.

Luckily, Will, trusting the very leadership traits that killing Dr. Barnes would contradict in Cia, kills Dr. Barnes, hoping that Cia "would prove that The Testing was flawed and that by my hand and through his sacrifice it all would be ended" (Charbonneau, Graduation Day 283). The use of the word "sacrifice" is significant. In chapter two, I outlined the role of utilitarianism in the lack of care that policy-makers exhibit towards test-takers; under this utilitarian stance, many test-takers are sacrificed for the purported good of society. In Cia's paradoxical final test, she is asked to take on this same stance. By offering up the end of The Testing as a potential reward, President Collindar, who disagrees with Dr. Barnes about Cia's potential, has set up a test that would require Cia to take on the same ends-justify-the-means stance that gives rise to the very sort of sacrificing she is trying to prevent. Will, who has already shown that one can easily be corrupted by the structures of The Testing, kills Dr. Barnes to prevent the same corruption in Cia. In doing so, he prevents a potential reproduction of the same beliefs in Cia, who does go on to lead. Moreover, Will's actions show that the manipulated structures of highstakes testing in the United Commonwealth cyclically reproduce themselves so vehemently that 
the success of someone like Cia is extremely unlikely, despite the good it could do for society, because policy-makers can always arbitrarily change things for their benefit. Additionally, the arbitrary categories that form as a result propagate class divisions and prejudice based on those divisions while policy-makers willfully ignore the impact that such things may have on testtakers.

\section{$\underline{\text { Factors and Confirmation Bias }}$}

While policy-makers may arbitrarily change testing structures for their own ends, they often don't have to because standardization - the kind promoted by teaching to the test and onesize-fits-all testing — weeds out test-takers who don't have the specific characteristics or intelligences desired by the ruling class. As explained by Dale D. Johnson, Bonnie Johnson, Stephen J. Farenga, and Daniel Ness, "each person is a unique individual with a different level of intelligence, different prior knowledge and experiences, different interests, different types of creativity, and different health conditions. Individuals come from different family sizes and compositions, different community types, and different peer groups. They come from different levels of family income" (11). These are all factors that may impact a person's test score. Meanwhile, test scores are "are considered objective because they supposedly measure all individuals equally and outside of any potential extenuating contextual circumstances" (Au "Teaching Under" 37). The belief in the objectivity of test scores, however, enables policymakers to ignore these factors as they set up and maintain systems of high-stakes testing. The result is the creation of class divisions, and prejudicial responses to these divisions are reproduced.

One of the factors most often ignored by policy-makers in the US is a test-takers socioeconomic status. A test-taker's socio-economic status impacts many aspects of their lives, 
especially on testing day. Students in lower income situations may have emptier stomachs, less access to tutoring resources, and other disadvantages that stack the deck against these test-takers who must take the same test as others in more advantageous conditions. As a result, test-takers with lower socio-economic status often perform more poorly than others. In the Divergent, Legend, and Testing trilogies, lower-income students face similar hurdles in that they have less access to the resources but more extreme obstacles in that, should they neglect to take on the ruling ideology, they may be made to fail even if they didn't, like Day. However, if a test-taker in a lower socio-economic position tests fairly well and demonstrates an internalization of the ideology of his/her own oppressor, they may become an exception.

In the Legend trilogy, this is depicted in the character Thomas. Thomas has worked with June's family for years before taking his Trial. When he tested fairly well, June and her brother used their privilege as citizens of high social standing to help Thomas get a good job (Lu, Prodigy 102). The dependence of Thomas' promotion on June and Metias implies that students of low socio-economic standing have few ways to rise in the Republic's system of high-stakes testing. Beyond that, however, Thomas so readily accepts the ideology of those in power that he becomes an exception to the rule that is then paraded and held up as proof that the system works. This is not unique to the Republic. In fact, "in an effort to stave off charges of prejudicial treatment of a particular group, a politician may coopt members of that group, publicly enlisting them in the politician's cause" (R. Thomas 127). In other words, Thomas and other test-takers who purportedly prove the neoliberal belief that individuals are in charge of their own destiny, regardless of social and cultural factors, are used as examples to confirm that the system works, while the countless others for which it doesn't work are ignored. 
However, Thomas' success is dependent on his internalization of the ruling ideology which he exhibits in a confrontation with Day: "Well, let me tell you a secret. I'm from a poor sector too. But I followed the rules. I worked my way up, I earned my country's respect. The rest of you people blame the state for your bad luck. Bunch of dirty, lazy cons" (Lu, Legend 216-17). It seems clear from his prejudicial response towards Day and others like him that Thomas has fully bought into the neoliberal beliefs I discuss in chapter two to the extent that he doesn't even mentioned the roles that June and Metias have had in his success. Moreover, in future confrontations, Thomas is quick to follow orders even when they involve murder because he is grateful and loyal to the Republic and its ruling class whose ideology he has so clearly adopted. Thus, Thomas provides a sort of confirmation that policy-makers can use to help defend the Trial. However, since countless others are ignored, Thomas and others like him become an example of confirmation bias used by policy-makers to promote their own agendas. ${ }^{14}$

\section{Conclusion: "Know Your Enemy"}

In manipulating testing structures, policy-makers perpetuate the reproduction of the ruling ideology as well as the reproduction of the ruling class, while the arbitrary categories that arise from these manipulated structures facilitate the marginalization of those who do not accept the ruling ideology. In doing so, however, policy-makers also encourage the development of extreme behaviors that ultimately foster a highly competitive and hostile atmosphere. Moreover, the perpetuation of class divisions and prejudices that accompany these divisions further evoke a high level of distrust among test-takers. In this way, test-takers are pitted against one another while remaining unaware of the manipulated structures that help sustain this hostility. So heavily

\footnotetext{
${ }^{14}$ Confirmation bias is the tendency to interpret new evidence as a confirmation of one's beliefs.
} 
manipulated are these structures, so cyclical in their own reproduction, and so ingrained in the fabric of each societies social hierarchy, that they go unquestioned. As a result, these isolated, hostile, indoctrinated, and fearful test-takers channel their aggression on the only enemies they can recognize—fellow test-takers — oblivious to the ways in which "the odds favor [their] failure" (Charbonneau, Graduation Day 4). Thus, as noted of students in Pedagogy of the Oppressed, "chafing under the restrictions of this order, often manifest a type of horizontal violence, striking out at their own comrades for the pettiest reasons" (Freire 62).

In other words, manipulating testing structures allows policy-makers to foster significant hostility among test-takers which in turn helps this manipulation to go unnoticed. In Prodigy, Day implores the people of the Republic to know their enemy, but that is easier said than done (345). However, in their work as critical dystopias, the Divergent, Legend, and Testing trilogies offer a solution to the sort of oppression depicted in their pages.

In chapter four, then, I shall examine the narrative pattern by which the protagonists of these YA dystopias become increasingly aware of the dystopian tendencies of their societies. Moreover, I will show how, in their growing acknowledgment of these manipulations, Tris, June, and Cia go from being fearful bystanders unable to act in rebellion to empathetic actors who work to change systems of high-stakes testing from within. 


\section{CHAPTER IV: FROM BYSTANDER TO ACTOR: SUBJECTIVE AGENCY IN YOUNG}

\section{ADULT DYSTOPIAN NOVELS}

\section{Introduction}

Dystopian texts often borrow tropes and strategies from the science fiction genre. One such borrowed strategy is that of estrangement. Estrangement is a terms that arises from translations of unheimlich or the uncanny, and it is necessary for the critical work of science fiction and the genres that draw from it. As Tom Moylan notes, estrangement positions readers in a "familiar society now seen freshly and critically ... [and helps them] negotiate an 'anthropological strangeness"” (Moylan, Scraps 4). This is achieved through narrative focalizers like Tris, June, and Cia, and this strangeness generates "a distanced space that can draw willing readers away from the society that produces and envelops them" (30). Thus, estrangement may assist such readers in looking at their own lived experience critically. This process, as explained by Maria Varsam, renews a reader's perception, and, "in the process of making things unfamiliar, of defamiliarizing objects of reality, dystopian fiction invites the reader to observe the dystopian world as the narrator sees it, not merely to sympathize, but also judge," showing the reader the world "not as it is, but as it could be; it shows the world in sharp focus in order to bring out conditions that exist already but which, as a result of our dulled perception, we can no longer see" (206).

More often than not, discussions of estrangement center on the reader as a wanderer who, as Teresa de Lauretis describes, works through the text, continuously "associating, opposing, relating, remembering, or making unexpected discoveries" (8). As a result of this process, dystopian texts "function as critiques by inviting parallels with certain aspects of contemporary culture, encouraging teens to be more thoughtful about politics and society and their place in it" 
(Davis 51). In this way, dystopian texts, and especially those written for young adults, which often feature more hopeful resolutions, are often seen as instruments of change as they encourage the implied reader to take action through this estrangement. While it is unlikely that every reader experiences YA dystopian texts this way, estrangement is nonetheless a prominent feature in narratives such as the Divergent, Legend, and Testing trilogies.

At the same time, however, the renewed perception of the reader is predicated on the narrator/protagonist. Because the Divergent, Legend, and Testing trilogies are all narrated in the first person, these are often the same thing. Quite often, YA dystopian literature focuses on the development of the protagonist's subjectivity, especially since the protagonist's subject position is constrained by the dystopian society the protagonist navigates. As such, it seems reductive to associate estrangement mainly with the readers of these texts and position it as something happening outside the text when, more often than not, protagonists require a similar process of estrangement in order to question their society. In these novels, the protagonist is the focalizer through which the reader experiences and criticizes the events of the plot, and, as such, "the reader must empathize with [them] in order to condemn, as [they] do, those aspects of society that contribute to [their] oppression" (Varsam 205).

Furthermore, the Divergent, Legend, and Testing trilogies are critical dystopias, a subset of dystopian fiction that is self-reflexive and defined by Lyman Tower Sargent as "a non-existent society described in considerable detail and normally located in time and space that the author intended a contemporaneous reader to view as worse than contemporary society" (Sargent 9). Analyzing estrangement in terms of the protagonists in YA dystopian novels, then, can be productive in demonstrating the genre's self-reflexivity. In the work that follows, I posit that the critical dystopias represented in Veronica Roth's Divergent trilogy, Marie Lu's Legend trilogy, 
and Joelle Charbonneau's The Testing trilogy demonstrate a narrative pattern of ongoing dissonance and estrangement by which Tris, June, and Cia move from bystander subject positions to actors with subjective agency, often as a result of dialogic interactions with other characters in marginalized positions.

\section{"I Can't Even Fathom it": Estrangement, Awareness, and Subjectivity}

YA dystopian novels are often focused on questions of subjectivity. In Ideologies of Identity in Adolescent Fiction, Robyn McCallum defines subjectivity as "a sense of personal identity an individual has of her/his self as distinct from other selves, as occupying a position within society, and in relation to other selves"; McCallum also believes it is in flux in adolescence (2). At the same time, however, Naomi Jacobs clarifies that, in highly oppressive dystopian societies, subjectivity is the dystopian regime's primary site of control (9). Certainly, this seems to be true as the analysis in preceding chapters illustrates that the protagonists in these texts are meant to establish themselves within the narrow parameters policy-makers deem acceptable. Certainly, Tris, June, and Cia are introduced as members of society intent on doing just that.

Raffaella Baccolini and Tom Moylan argue that critical dystopias, like more traditional dystopias, begin in medias res, meaning that "the dystopian text usually begins directly in the terrible new world," and, because of this, "estrangement is at first forestalled by the immediacy and normality of the location" (5). Although Moylan and Baccolini are referring to the reader, the same can be said of the protagonist who is "already in the world in question, unreflectively immersed in society" (5). Tris awaits the day of her aptitude test anxiously, a neutral subject of dystopian Chicago, meaning she does not have any strong opinions regarding the faction system and simply navigates it as if it is the only option worth considering; June, on the other hand, is 
fully embedded in the social formation of her society, regularly using derogative markers like "street con" (Lu, Legend 35) to describe those seen as undesirable and professing a hatred of those who, like the patriots, stand against the Republic (90). Similarly, Cia anticipates her chance to become a leader of the United Commonwealth through The Testing, unaware of the horrors that the process entails. Despite their anxiety, Tris, June, and Cia begin their respective trilogies as ideal citizens parroting the ideologies they've been indoctrinated into their entire lives.

All three young women believe that they have agency: "the capacity to choose for one's self and the capacity to act upon one's choices" (Jacobs 92). As argued in chapter one, however, at best they only have agency within the parameters of their repressive societies. In this way, Tris, June, and Cia are the typical protagonists of a YA dystopia, "gripped in a social formation so powerful, a web of control so densely woven, that at worst they do not even know they are not free" (Jacobs 92). They are politically disengaged individuals who have internalized the dominant ideology of the ruling class in their societies. Luckily, this position is open to contestation and change. As noted by Clare Bradford, Kerry Mallan, John Stephens, and Robyn McCallum, these ideologies are "internalized without question until the characters find themselves in conflict with society and thus needing to rethink social values" (21-22). In order to initiate this acknowledgment of ideology long-internalized, however, these protagonists must experience their first bout of estrangement in the form of cognitive dissonance.

Tris is first estranged from her reality when the aptitude fails to tell her, decisively, which faction she should choose. She is marked as other, as "Divergent," because she does not fit into any one faction and her narrative trajectory begins to shift from one of "apparent contentment to an experience of alienation that is followed by growing awareness" of the dystopian nature of Chicago (Moylan 148). Suddenly, what she has been indoctrinated to believe her whole life- 
that the test will place her into whichever faction she was most aligned with - is challenged. Her estrangement, then, is not a result of dislocation, as it often is in non-critical dystopias, but of cognitive dissonance. Moreover, Tris experiences a shift in her subject position as a result of this moment. Tris is now simultaneously privileged and marginalized, though she is not aware of the latter quite yet. She does, however, seem to acknowledge the privilege of her Divergence after she receives her result: "It's my choice now, no matter what the test says" (Roth, Divergent 23). Despite earlier assurances that "the tests don't have to change our choices," Tris is now able to recognize that she was depending on her test result and increasingly questions her society's norms as a result (2).

Regardless of Tris' acknowledgment of people's lack of agency during the Choosing Ceremony - it occurs to her that each 16-year-old only really has 5 predetermined choices — she still adheres to the social formation of her society, the five factions, and chooses one: Dauntless. In fact, throughout the first novel and through much of the second, Tris continues to define her subject position according to the categories set by the high-stakes testing in her society. Even when she claims her Divergence, she is negotiating her subject position according to the boundaries set in her society by defining herself in opposition to them. That is to say that Tris' Divergent status is a classification that is seen as an aberration by those in support of the faction system, but this classification only exists because of the faction system which requires an individual to choose only one faction, one characteristic, to privilege. While Tris' claiming of her Divergence is a significant step away from the bounds of the faction system, she is still effectively defining herself according to that system. Thus, while Tris experiences cognitive dissonance in her recognition of the fallibility of the aptitude test in the case of a Divergent such 
as herself, this dissonance does not immediately cause her to break with the social structure of her society.

June's case is slightly different because she does not begin the narrative of Legend as a neutral participant in the Republic's social formation. In fact, June is privileged throughout most of the trilogy. June self-elects to go into the poor sectors in order to catch Day, and, as she walks through the poor sectors, she acknowledges the terrible conditions of the area and even notes that all poor sectors tend to look this way. She also associates this space with con men and wonders if she could "catch the plague from these people.... who knows where they've been" (Lu, Legend 97), implying that June, the Republic's darling, has securely internalized the prejudices of the ruling class. June must come into contact with something that makes her question her own ideology. June's estrangement from her society begins through a dialogic relationship with her double, Day. A chief side effect of estrangement is a highlighting of the dystopian tendencies of a society. While self-electing to venture into the poor sectors may not have done this for June, entering into a dialogic relationship with someone of a contrasting social position whom she considers to be her intellectual equal, opens up this possibility for June to become estranged from her society and its ruling ideology.

It is clear from the start of Legend that "the formation of subjectivities is... always shaped by social ideologies," but the idea that "an individual's consciousness and sense of identity is formed in dialogue with others" is present as well (McCallum 3). It is also clear from the start of the novel that Day is a double for June. When June is disciplined for climbing up a building, she sets up this relationship for the reader: "rumor has it that Day is once scaled five stories in less than eight seconds"; she reasons that her own undertaking has been a form of self-betterment to prove herself to be as good as Day (Lu, Legend 13). At this point, June's dialog with Day is in 
her head, and even when they meet, much of the dialog is internal as June mentally compares Day with her peers: "It never ceases to amaze me how quickly he can get around the sectors. His agility is on par with the top students at Drake" (Legend 135). These musings—a result of Day's and June's doubling of one another-inspire a sense of kinship in June, and she must remind herself that Day is a criminal for whom she has no sympathy. June is, of course, lying to herself as evinced by her response to Day's mother's murder and its subsequent trivialization as a quicker negotiation method (Lu, Legend 159). Her sympathetic response to Day's situation and her determination to talk to him after his imprisonment mark the beginning of June's cognitive dissonance. After shadowing Day in the poor sector, June begins to notice that Day does not fit what she has been taught to expect of slum sector citizens or criminals. As a result, June has a difficult time negotiating her impression of Day with the impression the ruling ideology fosters of him and others like him. This nascent dialogic relationship between June and Day therefore sparks June's questioning of the ideologies she has grown up with.

Struggling to re-establish some sort of grounding, June continues her dialogic relationship with Day after his capture. At first, it continues to be an internal dialog drawing upon her observations of Day as her double, observations which make her unwilling to believe he could fail his trial with an extremely low score. This internal dialog comes to ultimate fruition when June discovers the truth about Day and experiences cognitive dissonance for the first time: “Day didn’t fail his trial. Not even close. In fact, he got the same score I did: 1500/1500. I am no longer the Republic's only prodigy with a perfect score" (Lu, Legend 187). While June begins to question the ruling ideology long before this moment, thus implying that dissonance was already at work in her development, her realization that Day could have been a prodigy confirms that her impression of her society is rose-colored. This confirmation shifts her behavior because it makes 
her question her society and its system of high-stakes testing. After June acknowledges Day as her double even by the Republic's own standard, she begins to engage with Day in ways that foster her new subject position, one that is not in alignment with the social formation of the dystopian Republic. For example, when a riot breaks out in response to Day's imprisonment, June attempts to prevent the massacre that occurs, engaging in a physical altercation with Thomas. While June is unsuccessful, the vigor with which she attacks Thomas is indicative of her changed position, particularly when compared to her earlier, feebler attempt to prevent Commander Jameson from murdering Day's mother. Like Tris, however, June does not yet act against her society and instead navigates within it.

On the other hand, Cia's first moment of cognitive dissonance comes as a result of an explicit conversation with her father in which he warns her of the cut-throat nature of The Testing. Having always believed in The Testing's importance to revitalization, Cia is thrilled to hear of her selection. However, as her father explains his nightmares, remnants of his erased Testing memories, Cia grows apprehensive. She listens to her father's concerns, but repeatedly argues that he must be mistaken. Given the level of indoctrination she's been subjected to, this is not surprising is, and even as they walk to the magistrate's house on the morning that Cia is to leave for The Testing, Cia states that "a world where you might poison the competition in order to feed your family is inconceivable to me" (Charbonneau, The Testing 42-43). However, were it not for this conversation, the first moment where Cia acknowledges that her beliefs may be incorrect would never have occurred. After arriving at The Testing, Cia and others in her testing group are led into a room that Cia recognizes as the room from her father's nightmares, prompting her to question whether her father's warning is worth heeding: "If this room from my father's subconscious is real, what else is? If my answers today don't make the grade ..." (79). 
In this moment, Cia begins to believe that her father is right and that The Testing, which she has always believed in, could actually be as horrific as her father described. She is thus estranged from her society in the acknowledgment, however brief at first, that The Testing may not be as amazing an opportunity as she has been indoctrinated to believe.

In these moments of dissociation brought about by estrangement, June, Tris, and Cia have begun to do the sort of self-reflexive work characteristic of a critical dystopia. In doing so, they have changed the trajectory of their narratives. Baccolini and Moylan state that the "official, hegemonic order of most dystopias...rests, as Antonio Gramsci put it, on both coercion and consent" (Baccolini and Moylan 5). However, a fully embedded citizen is unaware of the coercion inherent in the dystopian regime. Thus, as Tris, June, and Cia experience this first bout of estrangement, they shift from ideal citizens positioned as statically accepting their realities, to noticing the coercion — through indoctrination — of their society. At the same time, however, they still consent to its control by continuing to navigate within their respective societies without counter-hegemonic action. For example, after seeing the room and realizing her father may have been correct, Cia begins to wonder what might happen if she doesn't make the grade, but she doesn't even allow herself to finish the thought. Instead, she yanks herself "back to the here and now" and attempts to ease her anxieties before this round of The Testing begins (79). Nevertheless, all three protagonists have, as Rocío G. Davis says in "Writing the Erasure of Emotions in Dystopian Young Adult Fiction," begun to unlearn the lessons they have been previously taught” (Davis 60). In other words, while Davis is speaking about different YA dystopian novels, these characters have begun to question the ideology of the ruling class. Despite this nascent awareness, none of these protagonists acts against his or her society and its respective systems of high-stakes testing. June, for one, is clearly still occupying a 
privileged subject position even as she questions the relevancy of such a positioning. Tris, however, occupies a slightly more precarious position. As a Divergent, Tris' previous neutrality about participating in the aptitude test and subsequent initiation testing is almost impossible to maintain because Jeanine and Dauntless leaders persecute her. Tris is aware of this persecution as she notes “if I'm not careful, I could die. I can't even trust the leaders of my faction, my new family" (Roth, Divergent 292). However, Tris' Divergent subject position is also imbued with privilege so long as she hides it form others. Tris can manipulate simulations used to test the incoming Dauntless initiates. As such, she quickly rises through the ranks of her new faction. Given that the best jobs are offered to the highest-ranking initiates, it becomes clear that Tris' place in Divergence is, in some ways, a position of privilege. Comparatively, Cia is privileged in the sense that, in being selected for The Testing, she has opportunities typically denied to other citizens who are not selected. At the same time, however, Cia's subject position is in flux, just as Tris' is, because in order to maintain this privileged position, she must still go through The Testing and the University. However, the threat of losing the opportunities offered by The Testing pushes Cia to continue navigating her system of high-stakes testing just as the threat of becoming factionless encourages Tris to hide her Divergence to maintain her privilege and avoid marginalization. These protagonists, then, occupy privileged subject positions, but none of them choose to act against their hegemonic societies, suggesting that preliminary knowledge/awareness of marginality and the dystopian nature of society is not enough.

Classical dystopias, with their anti-utopian tendencies and subjugation of the protagonists in the end, hinge on despair as a condition of their citizens. On the other hand, the conditions of the protagonists of a critical dystopia involve increased knowledge and awareness. Tris, June, and Cia have begun this process. They have begun to move "from apparent contentment to an 
experience of alienation and resistance" (Baccolini and Moylan 5), but their alienation is incomplete because they still occupy privileged positions. Moreover, they grow steadily aware of the costs of violating the parameters of what their respective societies consider acceptable agency. In other words, they are realizing, as Jacobs notes is common in dystopian narratives, that an individual who violates the social code faces dire consequences.

While June maintains a privileged position throughout most of the Legend trilogy, Tris becomes increasingly marginalized. The Dauntless and Abnegation scatter after Jeanine's takeover and Tris "has no alternative at this point but to embrace her Divergence" (Basu 27), including her marginalized subject position. However, despite her progressively more marginalized position and the various issues she notes with each faction individually, Tris still works to remain within the social formation set by her society and actively fears a world without factions: "No factions? A world in which no one knows who they are or where they fit? I can't even fathom it. I imagine only chaos and isolation" (Roth, Insurgent 110). It is not until she has been actively persecuted for a prolonged period of time and has lost both parents that Tris finally begins to question the hegemony of her world entirely, deeming the faction system stupid to begin with. Her outburst takes her by surprise: "I have never said anything like that before. I have never even thought it. But I'm surprised to find that I believe it" (Roth, Insurgent 472). Despite this belief, Tris refuses to revolt with the factionless because she does not trust their leader. Ultimately, this revolt fails because the new leader of Chicago is just as manipulative and totalitarian as Jeanine had been. The results of this insurrection, as shown in chapter two, imply that to act from a marginalized position—as the factionless do — will lead to little more than destruction and overcorrection to the point of re-creating similar hegemonic conditions and stripping others of agency. 
Cia outwardly maintains a position of privilege by making it through The Testing and the entrance exam for the University. Like Tris, Cia continues to accept the conditions of this position mainly due to her fear of what might happen to her and her family should she refuse to accept them. However, as noted in chapter three, Cia must regularly succeed despite policymakers' manipulation of testing structures so that she and others like her fail. While Cia is semiaware of these manipulations, as she is aware of the difference in course load but not much else, and so she does not act against those in charge of The Testing or the University because she fears the deadly consequences she is steadily becoming more aware of. Furthermore, Cia discovers that the one rebellion she has heard of was orchestrated by the policy-makers in charge of The Testing, and that they've "even encouraged it to eliminate those who have become too hard to control" (Charbonneau, Independent Study 306). With this knowledge, Cia chooses not to take part in this rebellion just as Tris refuses to take part in the factionless rebellion, because to do so would be unproductive. Not acting against the society that wishes to marginalize them, however, is similarly unproductive.

June, Tris, and Cia are thus estranged, but unable or unwilling to act. The totalitarian nature of their societies prevents them from acting against the systems of high-stakes testing due to the consequences that such action may evoke. However, they are also unwilling to act so as not to lose the potential privileges they currently have despite their knowledge of the regime's oppression. June, in her dialogic relationship with Day, is sympathetic to his position. She is not, however, empathetic. She, like Tris before her faction falls apart and forces her to claim her Divergence and like Cia throughout much of The Testing trilogy, is looking to "negotiate [her] role in dystopia rather than seeking to overthrow it," a response Emily Lauer notes as common in dystopian narratives (44). In this way, these protagonists first take on bystander roles despite 
their awareness of the dystopian nature of their societies. It is also clear that rebellion from a marginalized position will come to very little in terms of change.

The duality of awareness/discontentment and inability/unwillingness to act at work with Tris, June, and Cia is evocative of the main tension present in Roth's, Lu's, and Charbonneau's texts: the tension between the subject of society and the agentic individual. As noted by multiple scholars, dystopian YA texts typically "blend the traditional developmental narrative with a heightened concern with issues regarding the individual against society" (Davis 48). Many YA texts "typically valorize the capacity to act independently of social restraint and, in doing so, assume humanistic concepts of agency" (McCallum 257). Dystopian YA texts, then, predicated on concepts of the individual and humanist notions of agency, invite a tension "between individual subject position and the ideology of society" (Bradford et al. 19). As protagonists become aware of the dystopian nature of their societies, this tension builds. Thus far, Tris, June, and Cia are more subjects than agents. They are "subject to, or capable of being acted on or influenced by forces other than oneself, such as situations, environment, and other characters," but they are unable or unwilling to act and produce change effectively and thus cannot be described as "having agency" (Hartley-Kroeger 277). In essence, June, Tris, and Cia have only achieved one aspect of developing subjectivity and have yet to be willed into significant action. In order to become agents that evoke change in their societies, however, they need to become further estranged from them so that remaining a bystander is no longer an option.

\section{Marginalization, Privilege, Empathy, and the Move from Bystander to Actor}

Throughout much of Divergent and Insurgent, Tris questions the faction system in the same way as David, the leader of the Bureau outside of Chicago, who discusses the results of past genetic manipulation and notes that "he's right to say that every faction loses something 
when it gains a virtue' (Roth, Allegiant 123). In fact, when David explains the genetic manipulation experiment, Tris is surprised at the reactions of those around her because she feels as if she is hearing about the same philosophy that spawned the factions. She even goes so far as to say that "on some level [she] even agrees with it" (123). This moment suggests that, despite her marginalization and awareness of the dystopian tendencies of Chicago, Tris is not yet estranged enough from her society to act in order to change it. When she enters the Bureau, another bout of estrangement occurs, this time as Tris recognizes the arbitrary nature of the categorization of the faction system.

Tris arrives at the Bureau thinking its social structure will be refreshingly less limiting than that of dystopian Chicago. However, it soon becomes clear "that the same social system that exists in the cities also exists in the compound; it's just a little harder to see" (Roth, Allegiant 250). As a result, the Bureau functions as a macrocosm of dystopian Chicago that facilitates Tris' awareness of the arbitrary categorization that structures her life in the city and propels her to act. McCallum explains that to "displace a character out of his/her familiar surroundings can destabilize his/her sense of identity" (McCallum 100). Within the Bureau, Tris' subject position changes once again from a persecuted Divergent to someone who is considered genetically pure (GP), causing her to question the necessity for the Divergent classification, along with other faction classifications, in the first place. In this new space, Tris has access to information, people, and opportunities that the other dislocated characters, those who are genetically damaged (GD), don't. Having gone from persecuted to privileged, Tris is skeptical of her new subject position and finally begins to see the test-based social hierarchy of Chicago for what it is: arbitrary. The Bureau, with its own indoctrination in place regarding the genetically damaged, is similar enough in ideology to Tris' Chicago, where she lived in a marginalized subject position, to make 
her question the categories she has so desperately clung to, including her Divergence. Now, once again embodying a different subject position, one of privilege, Tris wonders if she needs these categories anymore or whether she can just be "defined by the choices we make and the love and loyalty that binds us" (Roth, Allegiant 134).

In her interaction with the people of the Bureau, both genetically pure (GP) and damaged (GD), some of whom include the people previously categorized differently in Chicago, Tris begins to engage in the sort of dialogic defamiliarization June has undergone with Day. Tris' interaction with Tobias, whom she has known as a fellow Divergent, when he discovers he is a GD that is the most telling of her estrangement. Tris, having already switched subject positions many times, is already questioning the hegemony of dystopian Chicago when Tobias, the person with whom she most closely associated, is defined in opposition to her as GD. She muses on how the "Divergent" moniker has become meaningless to her now, that "these people still think it means something - they still think it means [she's] healed in a way Tobias is not," but she refuses to believe that (Roth, Allegiant 179). This interaction makes Tris question the divide between pure and damaged and subsequently between the factions, factionless, and Divergent and whether something can be done about it.

Additionally, Cia also begins to perceive the arbitrary nature of high-stakes testing in the United Commonwealth, ultimately acknowledging how the limited parameters dictated by policy-makers in the United Commonwealth measure achievement or lack thereof in arbitrary ways:

All my life, I have believed that hard work and effort will be rewarded. Not just with grades but with results... For the first time, I am forced to contemplate the possibility that the harder I work, the less I will achieve. That I should work to be average instead of 
endeavoring to excel. But I'm not convinced that doing so would not draw even more attention, since I have spent the last several months striving for the top marks in my class. Anything less might make my professors question my dedication to the University or make them wonder if I am aware of their scrutiny. (Charbonneau, Independent Study $161-62)$

Knowing that her own potential marginalization or privileging is dependent on policy-makers' arbitrary decisions based on manipulated structures, Cia is further estranged from her society. Thus, while Cia is first estranged from her society by the cognitive dissonance that emerges as she discovers that her father's nightmares are real, she is further estranged in her discovery that the categorization promoted by The Testing and the University is arbitrary rather than absolute, as the ruling ideology has led her to believe.

Similarly, June's continued dialog with Day makes her hyper-aware of the dystopian tendencies of her society. Like Tris and Cia, she ultimately acknowledges that the class divisions established by the Trial are arbitrary because they are based on a manipulated system. Within the system, however, June is safe; she is privileged; she will not be marginalized as Day is. However, when June discovers the truth about her brother's (Metias) murder at the hands of the government, she comes face-to-face with how tenuous her privileged position really is. Although her dialogic interactions with Day began this work, it is this moment that calls her to action. June realizes that even someone as privileged as she is could be marginalized, taken advantage of, or killed for questioning the Republic as her brother did, and her realization prompts her to act and prevent Day's death.

At this point, Tris, June, and Cia are completely estranged from their societies, but it must be noted that these protagonists all achieve their awakenings in positions of privilege. 
Within these positions, these protagonists remain empowered. Though they are aware of the potential for marginalization, they are situated so as to be able to use their privilege to do something towards the changing of society. As a result, their agency, as observed by dystopian scholar Phillip E. Wegner, kickstarts "history in a moment when it seems to many to be terminally stalled" (Wegner 169). In other words, these protagonists have the chance to move society from its current, dystopian stasis. June has, of course, never truly been marginalized, but has achieved an understanding of the consequences of marginalization through the experiences of Day and Metias. Tris and Cia, on the other hand, have first-hand knowledge of the marginalized subject position but do not fully associate it with the hegemony of their societies until being exposed to other marginalized peoples in the Bureau, in Tris' case, and being forced to make a paradoxical decision in Cia's.

With these past experiences shaping their awareness, these protagonists become empathetic to those who are marginalized because they have come close enough to those positions themselves to be prompted into action. In their awareness and empathetic response to the plight of those marginalized, both protagonists begin to reject their previously passive positions. They realize, as Tris puts it in Allegiant, that these governments continue to function "by conditioning people to be happy under its thumb" (346). They are no longer the ideal citizen, "encouraged to appreciate the life they have and fear anything that would disrupt the society" (Davis 61). Instead, they are encouraged, by their awareness of and empathy for marginalized peoples and empowered by their privileged positions, to act. In other words, June, Tris, and Cia begin their process of estrangement through cognitive dissonance which leaves them open to further estrangement as they discover the arbitrary nature of their respective social hierarchies 
and experience, either through dialogic interactions or active persecution, what it is like to be marginalized.

\section{Rebel from Inside the System: The Role of Overlapping Positionalities}

In Roth's, Lu's, and Charbonneau's trilogies, the use of multiple focalizers “enables the representation of a plurality of narrative voices, social and cultural discourses, and the construction of a range of perceptual, attitudinal and ideological viewpoints associated with the subject positions occupied by characters" (McCallum 35). This is achieved, in part, through the dual perspectives in Allegiant and throughout the Legend trilogy that "overtly structure a novel as a dialogue between two social, cultural, gendered or historical positions" (56). It is also achieved through the dialogic interactions between characters of different subject positions that permit, as Fiona Hartley-Kroeger asserts building off of McCallum, "a variety of an exchange between textual voices and ideas (277). Such a structure provides significant insight into Tobias and Day, characters estranged from their societies from the beginning.

Tobias's and Day's discontentment with society, as evinced from the start of both trilogies, makes them crucial to the readers' estrangement of a dystopian society that seems problematically close to their own. However, as guideposts, these characters express an awareness of the dystopian conditions of their respective societies much too soon. If the work of a critical dystopia is to mimic, through the journey of a protagonist, the reader's own movement from contentment to criticism and perhaps subsequent action, then Tobias and Day are not equipped for the work of demonstrating the process becoming estranged from the ideologies the reader is unable to acknowledge as problematic in his or her own society. On the other hand, Tris', June's, and Cia's progression of estrangement is gradual, done in bits and pieces until, finally, they are willed to act. As such, Tris, June, and Cia provide, as scholars Elizabeth Bullen 
and Elizabeth Parsons identify in other YA dystopian texts, "role models implied readers will identify with, taking them on an ideologically controlled narrative journey" (136). These protagonists, in their progressive awareness of the dystopian aspects of their societies, demonstrate a realistic progression that a young adult reader might hope to follow. Tris, June, and Cia thus come as close as possible to "stand[ing] outside culture and ideology" while still navigating within it successfully for the most part ... providing a map by which a reader can view their society critically which still functioning within it" (138).

Furthermore, having been exposed to the consequences of marginalization — whether by temporarily inhabiting that subject position or by coming to understand it through dialogic interactions — while also ultimately maintaining privileged subject positions, Tris, June, and Cia are poised to make realistic change. On one hand, Tris, June, and Cia possess the empathy and understanding that David, the leader of the Bureau, Anden, the new elector primo of the Republic, and other University students, lack. On the other, they have the know-how and privilege to enact gradual, realistic change that Tobias, Day, and those in the United Commonwealth's colonies are unable to.

David, having believed in and having worked to correct genetic damage most of his life, believes the Chicago experiment is worth continuing, despite the sacrifice of human life. He notes that having power often means having "the ability to make choices for the greater good" (Roth, Allegiant 326), but as Tris asserts in their final encounter, "it's not sacrifice if it's someone else's life you are giving away, it's just evil” (473). David seems to lack the understanding that Tris' marginalization and dialogic interactions afford her, that sacrifice "should be done from love, not a misplaced disgust for another person's genetics. That is should be done from necessity, not without exhausting all other options" (473). Tobias, on the other 
hand, has been marginalized continuously to the point that he, like the factionless, rebels in a way that is explosive and aimed at quick change, having been manipulated by another GD individual to take part. He is vulnerable and is taken advantage of.

Tris, no longer in a marginalized position, is able to act, but does so with caution. She is not, as Tobias is, desperate for change. This is in part because her privileged position makes immediate change unnecessary, but also in part because her interactions with other GP individuals has shown her that the Bureau operates under its own ideologies into which individuals are indoctrinated. Having undergone a process of awakening herself, Tris can assess the situation from both sides to determine a course of action; she doesn't "have to buy into the first plan [she] hears" (Roth, Allegiant 273). She can instead consider the options and make difficult choices, like the choice to erase the indoctrinated memories of the GPs, in order to make gradual change predicated on awareness of dystopian tendencies rather than prejudices induced by those tendencies.

In Lu's trilogy, Anden, like David, is unable to fully consider the marginalized subject position from his own privileged positioning, though perhaps less menacingly so. Having been raised to take over as Elector Primo after his father's death, Anden is a politician who knows how to make tough decisions. As a result of this position, however, Anden often fails to see the position of those marginalized by the Republic's tyranny. In many ways, he recognizes his deficiency and acknowledges that "he doesn't have the people's support... [that] he needs someone to win over the people for him" (Lu, Prodigy 148). In practice, however, he does not account for the privilege of the rich over the poor and often puts the former first, if only because of logistics. For example, when the Republic is under attack, Anden evacuates the rich sectors to enter underground bunkers but cannot do the same with the poor because there aren't bunkers 
underneath those sectors. He also refuses to split the existing bunkers in half, explaining that he can't afford to lose the support of the rich. In sharp contrast, Day gives no thought to logistics regarding the evacuation of the poor; he just wants to see them saved. It is in this moment and others that Day's prolonged subject position as a marginalized individual comes into play. He has a chip on his shoulder, and rightfully so, but it makes him distrustful of most anyone in power, even Anden, who genuinely wants to change things for the better. When June explains her decision to trust Anden, he questions her justifications: "How dare you defend them, how dare you try to reason with yourself over why they are way they are? It's so easy for you to say that, isn't it?... I bet you wouldn't be so quick to logic it all out if you'd spent your life digging up trash to eat in the slums. Would you?" (Lu, Prodigy 265-66, emphasis in the original). This perspective makes Day the face of the people. He understands the injustices dealt to them as a result of his marginalized subject position. However, this quality also makes him unfit to lead the Republic in gradual, realistic change.

In a way similar to Tris, June takes on a mediating role between explosive Day and politically correct Anden. In the above-mentioned showdown regarding the evacuation of the poor, it is June who offers the solution noting that "it's a flawed plan, but the poor will also see that we are making a concerted effort to protect them" (Lu, Champion 111). Her solution does the work of Day and Anden simultaneously. Her exposure and subsequent empathy for the marginalized subject position Day occupied and her political experience resulting from her past and current privileged position, allow her to make decisions that appease people in both situations. In a later conversation, June notes that Anden will never be Day and Day will never be Anden (177), implying that occupancy of different subject positions in the reason for the 
disagreement between the two men. June, having undergone a significant process of awakening because she was exposed to both positions, may effectively fill the roles of both men.

On the other hand, Cia is repeatedly described as different from other Testing candidates and University students. Five Lakes is also looked down on by citizens of other colonies represented at The Testing and the colonies in general are viewed as lesser by test-takers from Tosu City. Despite the conditions she is exposed to in The Testing, however, Cia maintains her trusting nature, even asking a group-mate of hers to select their final team member during the University's initiation, despite the shock this decision evokes from other, less-trusting University students (Charbonneau, Independent Study 87). In this way, Cia maintains the positive aspects of her marginalization as a citizen of Five Lakes, a colony so distant from Tosu City that its citizens must work together to ensure their own self-reliance. At the same time, however, Cia also grows knowledgeable about the dystopian tendencies of her society and adjusts her behavior to avoid marginalization. During her time in The Testing and at the University, Cia learns to trust more conditionally and even commits murder when her life is threatened, gradually recognizing the traits that policy-makers in charge of The Testing desire and taking on those traits without sacrificing the valuable traits she developed in Five Lakes. Given Cia's persecution through The Testing trilogy and her treatment as a second-class citizen, she is ultimately unable to enact change on her own because her lack of killer instinct prevents her from killing Dr. Barnes. However, her successful navigation through The Testing and the University imply that she also developed some of the know-how that Tris and June demonstrate.

Thus, Cia simultaneously has the know-how that successful test-takers in the United Commonwealth exhibit, but she also maintains the characteristics that have developed from her marginalization. In this way, Cia simultaneously embodies the traits of both the marginalized and 
privileged subject positions, and it is her mediation of these positions that inspires Will to kill Dr. Barnes so that Cia, who he believes is a good leader because she is able to trust and delegate even as she acknowledges the danger in doing so, can become a leader of the United Commonwealth and evoke change. Paradoxically, Cia needs Will, a character who exhibits many of the characteristics promoted by The Testing, to do this work because she was never fully able to develop the killer instinct that Will seems to possess. At the same time, it is this lack of a killer instinct, along with Cia's maintenance of other traits that the United Commonwealth disregards, like trusting others, which prompts Will to kill Dr. Barnes in secret so that Cia can take the credit and become a leader in the United Commonwealth.

Likewise, Tris and June embody the characteristics of both positions. They are able to make the tough decisions required of their privileged subject positions while still retaining a sense of empathy and understanding for those not as privileged as they are. Tris' and June's "power lies, on the one hand, in the personal agency, obtained by being able to make choices about what they desire"- a condition more easily and successfully met by those in a privileged subject position- "and, on the other, in their perception of the Government's strategy for political control" (Davis 60). Beyond that awareness, though, is an understanding that they may be best served by remaining a part of the social hierarchy created by high-stakes testing and that maturation may "require an acceptance of dystopian conditions" (Lauer 37). Tris, June, and Cia utilize this awareness and acceptance by doing what Metias fails to do within his solipsistic privileged subject position and what those marginalized are unable to do given their oppression: they rebel from the inside. Tris uses her position in the bureau to erase the memories of the GPs so that they can be taught to work toward their goal without prejudice toward GDs, June works with Anden to ensure that the Trial is discontinued, and conditions are changed in the slum 
sectors, and Cia becomes a United Commonwealth leader, working towards finding a better way of identifying the best of the best and ensuring the end of involuntary experimentation.

Crucial to Tris', June's, and Cia's success in spearheading change from within the system is their overlapping positionality. Their estrangement from their societies allows them to stand far enough outside ideology that they see the dystopian tendencies of their societies while also still operating within these flawed societies to maintain the agentic potential to change them. Tris, June, and Cia thus occupy multiple subject positions in relation to others and the world around them. These overlapping positionalities are made possible by a process of awareness based on estrangement that results from dialogic interactions and dissonance.

\section{Conclusion}

The narrative pattern of growing awareness, empathy, and movement from political disengagement to action in these books demonstrates how change can occur within corrupt systems of high-stakes testing. Unfortunately, the focus of the Divergent, Legend, and Testing trilogies on the role of individuals is problematic in that it reaffirms a validation of individual achievement since these protagonists are considered special from the start of their respective narratives. It could be argued that, especially in the Legend trilogy, no one achieves anything alone. June needs Day for her awakening and Day must, in-turn, give his support to Anden so that the support of the masses follows. Similarly, Cia requires Will's sacrifice to maintain her privileged position and Tris must sacrifice herself in order to provide the means by which the prejudice towards the GDs can be erased. However, in each trilogy, the actions of the individual are depicted as catalyzing change while the role of the masses is often overlooked, again fostering a sense of that the privileged individual may be key for successful, incremental change. 
The Divergent, Legend, and Testing trilogies, like other critical dystopias, keep the utopian possibility alive both within the book with the characters' actions leading to change. However, both these trilogies seem to do so in an ultimately problematic way. As is typical of critical utopias, these texts explore "new forms of oppositional agency" and "go on to explore ways to change the present system so that... marginalized peoples do not only survive but also try to move toward creating a social reality that is shaped by an impulse to human selfdetermination" (Moylan 189). However, because success in producing change is ultimately predicated on both the understanding and awareness of dystopian tendencies of society through an empathetic response with those in a marginalized position AND a privileged subject position, Roth's and Lu's trilogies suggest that change may only come from those occupying a privileged subject position. This problematic position is reinforced by the fact that rebellion by those marginalized is depicted as doomed to fail, while the actions of privileged individuals allow for change.

Therefore, these trilogies imply that the tension between the individual as subject and the individual as agent is resolved when we stop considering subjective agency as a matter of establishing an essential self against totalitarian dystopian regimes. Rather, I argue through my textual analysis that through the establishment of overlapping positionalities in a dialogic interaction with others and the regime, gradual and realistic change could be produced. More generally, however, the solution these trilogies posit as necessary for the prevention of such dystopian conditions, is that of a privileged, individual savior. In other words, observing Tris', June's, and Cia's "trajectory from a bystander to actor," a trajectory that Bullen and Parsons recognize in other protagonists in YA dystopias, within this dystopian societies allows 
adolescent readers to critically engage with their reality and model their awakening in similar ways (Bullen and Parson 138).

While the solution offered in the prevention of these dystopian tendencies may rely on the very beliefs that played into such tendencies, it certainly accounts for the ways in which present systems of high-takes testing may already be significantly corrupt. By implying that only those with privilege resulting from of their success in high-stakes testing may evoke change, these trilogies may encourage readers to consider how testing structures can be manipulated to ensure that those have such privilege don't feel the need to change the system. By indoctrinating test-takers and making them fear the consequences of testing and by utilizing one-size-fits-all testing and teaching to the test in a competitive atmosphere, policy-makers in these novels stack the deck so that those who receive privilege are often those less likely to change the system. Therefore, the solution offered by these texts may marginalize voices that are still largely outside of the conversation. Moreover, these trilogies make clear the costs of high-stakes testing so that even those who test well are aware of the possibilities of these systems becoming corrupt methods of categorization and control that serve primarily those who are already privileged by cyclically reproducing the ruling ideology, the ruling class that maintains it, those subjugated to it, and those marginalized for their lack of acceptance of these cyclical conditions. 


\section{Works Cited}

Primary Texts

Charbonneau, Joelle. The Testing. Houghton Mifflin, 2013.

---Independent Study. Houghton Mifflin Harcourt, 2014

---Graduation Day. Houghton Mifflin Harcourt, 2014

Lu, Marie. Legend. Speak, 2011.

---Prodigy. Speak, 2013.

---Champion, Speak, 2013.

Roth, Veronica. Divergent. Katherine Tegen Books, 2011.

---Insurgent. Katherine Tegen Books, 2012.

---Allegiant. Katherine Tegen Books, 2013.

Secondary Texts

Alexander, Jonathan and Rebecca Black. "The Darker Side of the Sorting Hat: Representations of Educational Testing in Dystopian Young Adult Fiction.” Children's Literature, vol. 43, 2015, pp. 208-34.

Althusser, Louis. "Ideology and Ideological State Apparatuses.” Marxists.org, https://www.marxists.org/reference/archive/althusser/1970/ideology.htm. Accessed 27 Sept. 2017.

Au, Wayne. "Meritocracy 2.0: High-Stakes, Standardized Testing as a Racial Project of Neoliberal Multiculturalism.” Educational Policy, vol. 30, no. 1, 2016, pp. 39-62.

---. "Teaching Under the New Taylorism: High-Stakes Testing and the Standardization of the $21^{\text {st }}$ Century Curriculum.” J. Curriculum Studies, vol. 43, no. 1, pp. 25-45. 
Baccolini, Raffealla, and Tom Moylan. "Introduction: Dystopia and Histories.” Dark Horizons: Science Fiction and Dystopian Imagination. Edited by Raffaella Baccolini and Tom Moylan. Routledge, 2003, pp. 1-12.

Bandalos, Deborah L., et al. "Validity Arguments for High-Stakes Testing and Accountability Systems." High-Stakes Testing in Education: Science and Practice in k-12 Settings. American Psychological Association, 2011, pp. 155-76.

Basu, Balaka, et al. "Introduction." Contemporary Fiction for Young Adults: Brave New Teenagers. Edited by Balaka Basu, Katherine R. Broad, and Carrie Hintz, Routledge, 2013, pp. 1-13.

Basu, Balaka. "What Faction are you in? The Pleasure of Being Sorted in Veronica Roth's Divergent." Contemporary Fiction for Young Adults: Brave New Teenagers. Edited by Balaka Basu, Katherine R. Broad, and Carrie Hintz, Routledge, 2013, pp. 19-33.

Bradford, Clare, et al. New World Orders in Contemporary Children's Literature: Utopian Transformations. Palgrave Macmillan, 2007.

Bullen, Elizabeth, and Elizabeth Parsons. "Dystopian Visions of Global Capitalism: Philip Reeve's Mortal Engines and M. T. Anderson's Feed." Children's Literature in Education, vol. 38, pp. 127-39.

Davis, Rocio G. "Writing the Erasure of Emotions in Dystopian Young Adult Fiction: Reading Lois Lowry's The Giver and Lauren Oliver's Delirium." Narrative Works, vol. 2, no. 2, pp. $48-63$.

Filer, Ann. "Introduction." Assessment: Social Practice and Social Product. Ed. Ann Filer. Routledge Falmer, 2000, pp. 1-5. 
Foucault, Michel. Discipline and Punish: The Birth of the Prison. 1975. Vintage Books, 1995.

---. Power/Knowledge: Selected Interviews and Other Writings (1972-1977). Ed. C. Gordon. Pantheon Press, 1980.

Fraser, James W., editor. The School in the United States: A Documentary History. $3^{\text {rd }}$ ed., Routledge, 2014.

Hartley-Kroeger, Fiona. "Silent Speech: Narration, Gender, and Intersubjectivity in Two Young Adult Novels." Children's Literature in Education, vol. 42, pp. 276-88.

Harvey, David. "Freedom's just Another Word....” A Brief history of Neoliberalism. Oxford University Press, 2005.

Hillocks Jr., George. The Testing Trap: How State Writing Assessments Control Learning. Teachers College Press, 2002.

Inoue, Asao B. Antiracist Writing Assessment Ecologies: Teaching and Assessing Writing for a Socially Just Future. Parlor Press, 2015.

Jacobs, Naomi. "Posthuman Bodies and Agency in Octavia Butler's Xenogenesis." Dark Horizons: Science Fiction and Dystopian Imagination. Edited by Raffaella Baccolini and Tom Moylan. Routledge, 2003, pp. 91-112.

Johnson, Dale D., et al. Stop High-Stakes Testing: An Appeal to America's Conscience. Rowman \& Littlefield Publishers Inc., 2008.

Kearns, Laura-Lee. "High-Stakes Standardized Testing and Marginalized Youth: An Examination of the Impact on Those Who Fail.” Canadian Journal of Education, vol. 34, no. 2, 2011, pp. 112-30. 
LaCelle-Peterson, Mark. "Choosing Not to Know: How Assessment Policies and Practices Obscure the Education of Language Minority Students.” Assessment: Social Practice and Social Product. Ed. Ann Filer. Routledge Falmer, 2000, pp. 27-42.

Lauer, Emily. "Coming of Age in Dystopia: Reading Genre in Holly Black's Curse Worker Series." Contemporary Fiction for Young Adults: Brave New Teenagers. Edited by Balaka Basu, Katherine R. Broad, and Carrie Hintz, Routledge, 2013, pp. 35-49.

De Lauretis, Teresa. "A Sense of Wa/onder.” The Technological Imagination: Theories and Fictions. Edited by Teresa de Lauretis, Andreas Huyssen, and Kathleen Woodward, Indiana University Press, 1987, pp. 159-74.

Levin, Henry M. "High-Stakes Testing and Economic Productivity." Raising Standards or Raising Barriers?: Inequality and High-Stakes Testing in Public Education. Ed. Mindy

L. Kornhaber and Gary Orfield. Century Foundation, 2001, pp. 39-50.

Lewis, Steven, and Ian Hardy. "Funding, Reputation and Targets: The Discursive Logics of High-Stakes Testing." Cambridge Journal of Education, vol. 45, no. 2, 2015, pp. 245-64.

Lucido, Horace. Educational Genocide. Rowan \& Littlefield Education, 2010.

Madaus, George, and Marguerrite Clarke. "The Adverse Impact of High-Stakes Testing on Minority Students: Evidence from One Hundred Years of Test Data.” Raising Standards or Raising Barriers?: Inequality and High-Stakes Testing in Public Education. Ed. Mindy L. Kornhaber and Gary Orfield. Century Foundation, 2001, pp. 85-106.

Madaus, George, and Cathy Horn. "Testing Technology: The Need for Oversight.” Assessment: Social Practice and Social Product. Ed. Ann Filer. Routledge Falmer, 2000, pp. 47-66. 
Madaus, George, et al. The Paradoxes of High-Stakes Testing: How They Affect Students, their Parents, teachers, Principals, Schools, and Society. Information Age Publishing, Inc., 2009.

McCallum, Robyn. Ideologies of Identity in Adolescent Fiction: The Dialogic Contradiction of Subjectivity. 1999. Routledge, 2013.

Moylan, Tom. Scraps of Untainted Sky: Science Fiction, Utopia, Dystopia. Westview Press, 2000.

Natriello, Gary, and Aaron M. Pallas. "The Development and Impact of High-Stakes Testing." Raising Standards or Raising Barriers?: Inequality and High-Stakes Testing in Public Education. Ed. Mindy L. Kornhaber and Gary Orfield. Century Foundation, 2001, pp. 1938.

Sargent, Lyman Tower. “The Three Faces of Utopianism Revisited.” Utopian Studies 5.1 (1994): $1-37$.

Stewart, Susan Louise. “Chapter Ten: Dystopian Sacrifice. Scapegoats, and Neal Shusterman’s Unwind." Contemporary Fiction for Young Adults: Brave New Teenagers. Edited by Balaka Basu, Katherine R. Broad, and Carrie Hintz, Routledge, 2013, pp. 1-13.

Thomas, P.L. Numbers Games: Measuring and Mandating American Education. Peter Lang, 2004.

Thomas, R. Murray. High-Stakes Testing: Coping with Collateral Damage. Lawrence Erlbaum Associates, Publishers, 2005.

Trites, Roberta Seelinger. Disturbing the Universe: Power and Repression in Young Adult Literature. University of Iowa Press, 2000. 
Varsam, Maria. "Concrete Dystopia: Slavery and its Others." Dark Horizons: Science Fiction and Dystopian Imagination. Edited by Raffaella Baccolini and Tom Moylan. Routledge, 2003, pp. 203-24.

Wise, Steven L. and Smith, Lisa F. “A Model of Examinee Test-Taking Effort.” High-Stakes Testing in Education: Science and Practice in k-12 Settings. American Psychological Association, 2011, pp. 139-154. 